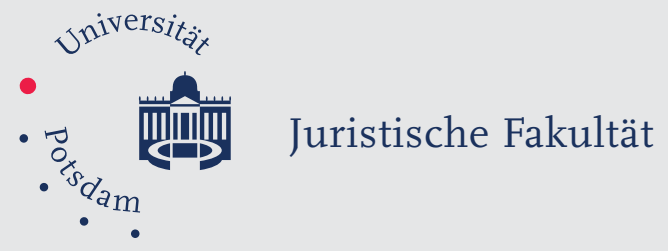

Norman Weiß

\title{
Bedeutung und Funktion von Zivilgesellschaft und Öffentlichkeit im demokratischen Rechtsstaat am Beispiel der Bundesrepublik Deutschland
}

Suggested citation referring to the original publication:

Jahrbuch des Öffentlichen Rechts der Gegenwart : Neue Folge 61 (2013), pp.

15-60

ISBN: 978-3-16-152417-2

ISSN: 0075-2517

Postprint archived at the Institutional Repository of the Potsdam University in:

Postprints der Universität Potsdam

Rechtswissenschaftliche Reihe ; 5

http://nbn-resolving.de/urn:nbn:de:kobv:517-opus4-428643

DOI https://doi.org/10.25932/publishup-42864 



\title{
Bedeutung und Funktion von Zivilgesellschaft und Öfentlichkeit im demokratischen Rechtsstaat am Beispiel der Bundesrepublik Deutschland ${ }^{\star}$
}

von

\author{
Privatdozent Dr. Norman Weiß ${ }^{\star \star}$, Universität Potsdam
}

Heute wird selbstverständlich von einer aktiven Zivilgesellschaft als relevanter Akteurin des politischen Prozesses ausgegangen. Dies gilt für den innerstaatlichen Rahmen ebenso wie für die völkerrechtliche Ebene. Das Engagement zivilgesellschaftlicher Akteure im verfassungsrechtlich eingehegten Rahmen des politischen Prozesses ist mit Fragen verbunden, denen sich dieser Aufsatz nähern wird. Zunächst wird der Begriff der Zivilgesellschaft hergeleitet (I) und danach wird auf die Funktionen der Öffentlichkeit in einem rechtsstaatlich verfaßten republikanischen Gemeinwesen eingegangen (II), bevor zum Schluß aktuelle Themen, die sich in den letzten Jahren entwickelt haben, vorgestellt und als erste Forschungsfragen formuliert werden (III).

* Die Beschäftigung mit dem Thema geht zurück auf meinen Beitrag: Zur Rolle der Zivilgesellschaft für den Schutz der Menschenrechte, in: Eckart Klein/Christoph Menke (Hrsg.) Universalität Schutzmechanismen - Diskriminierungsverbote. 15 Jahre nach der Weltmenschenrechtskonferenz 1993 in Wien, 2008, S. 232-257. Der vorliegende Text ergänzt die seinerzeit präsentierten Überlegungen im Grundsätzlichen. Ich danke Claudia Mahler, Christoph Menke und Justus J. Vasel für kritische Anmerkungen in unterschiedlichen Stadien der Texterstellung. Lutz Römer hat mich bei der Literaturbeschaffung unermüdlich unterstützt. Die Literaturangaben sind nachstehend aus Raumgründen kurz gehalten; Zitate wurden auf das Notwendigste beschränkt.

** Dr. iur. habil., wissenschaftlicher Mitarbeiter im MenschenRechtsZentrum der Universität Potsdam, Privatdozent an der dortigen Juristischen Fakultät. 


\section{Der Begriff der Zivilgesellschaft}

\section{Rasche Karriere eines Begriffs ,ohne Herkunft" oder doch ein Modebegriff mit einer ungewöhnlich langen Karriere?!}

Das „Deutsche Universalwörterbuch“2 aus dem Jahre 1989 verzeichnet die Zivilgesellschaft nicht. ${ }^{3}$ Dieser Befund wiederholt sich mehrfach. ${ }^{4}$ In der deutschsprachigen politik- und sozialwissenschaftlichen Literatur hat die Zivilgesellschaft etwa seit 1989/1990 Konjunktur. ${ }^{5}$

Es handelt sich in diesem Zusammenhang beim Begriff der Zivilgesellschaft um einen Rückimport aus dem Englischen - „,civil society“. Dieser, inhaltlich im Lauf der Zeit durchaus gewandelte Begriff steht zunächst für das, was von Aristoteles ,koinonia politiké" und im Lateinischen ,,societas civilis" genannt worden war. Von hier ausgehend haben die europäischen Sprachen die entsprechenden Übernahmen entwickelt: Eben „civil society", ,société civile“, „società civile“ und im Deutschen etwa bei Immanuel Kant, ${ }^{6}$ Friedrich Hegel, ${ }^{7}$ Karl Marx ${ }^{8}$ Jürgen Habermas ${ }^{9}$ oder

1 Die zweite Variante lehnt sich an an Klaus von Beyme, Zivilgesellschaft - Karriere und Leistung eines Modebegriffs, in: Manfred Hildermeier/Jürgen Kocka/Christoph Conrad (Hrsg.), Europäische Zivilgesellschaft in Ost und West, Begriff, Geschichte, Chancen, 2000, S. 41-55.

2 Duden, Deutsches Universalwörterbuch, 2. Aufl. 1989, dies gilt auch für die 3. Aufl. 1996. Hingegen ist der Begriff in: Duden, Das große Wörterbuch der deutschen Sprache in zehn Bänden, 3. Aufl. 1999, Bd. 10: Vide-Zz, verzeichnet.

${ }^{3}$ Zur Bedeutung von Lexika und Wörterbüchern als historischen Quellen für die Begriffsgeschichte vgl. Reinhart Koselleck/Ulrike Spree/Willibald Steinmetz, Drei bürgerliche Welten? Zur vergleichenden Semantik der bürgerlichen Gesellschaft in Deutschland, England und Frankreich, in: Reinhart Koselleck, Begriffsgeschichten, Studien zur Semantik und Pragmatik der politischen und sozialen Sprache, 2006, S. 402-461 (S. 414).

${ }^{4}$ So kennt Meyers Großes Universallexikon in 15 Bänden (ab 1980 erschienen) den Begriff, Zivilgesellschaft" nicht. Signifikant die Befunde in der Brockhaus Enzyklopädie: Noch die 19. Auflage (ab 1986) enthält im 24. Band (Weli-Zz, 1994) kein Stichwort ,Zivilgesellschaft“. Bereits die 20. Auflage (ab 1996) verzeichnet in ihrem Band 24 (Wek-Zz, 1999) einen etwas mehr als einspaltigen Eintrag (S.605f.) für „Zivilgesellschaft“. Die 2006 erschienene 21. Auflage behandelt "Zivilgesellschaft" in ihrem Band 30 (2006, S. $646 \mathrm{ff}$.) als Schlüsselbegriff, dem sieben Spalten gewidmet werden.

5 Vgl. nur Klaus Naumann, Mythos „Zivilgesellschaft“, Literaturübersicht zu einer unübersichtlichen Kontroverse, in: Vorgänge 1991/6, S. 57-68; Herfried Münkler, Wieviel Tugend braucht die Demokratie? Voraussetzungen der Zivilgesellschaft, in: Neue Gesellschaft/Frankfurter Hefte 38 (1991), S. 612617; Klaus M. Schmals/Hubert Heinelt (Hrsg.), Zivile Gesellschaft, Entwicklung, Defizite, Potentiale, 1997; Frank Adloff, Zivilgesellschaft, Theorie und politische Praxis, 2005.

${ }^{6}$ Immanuel Kant, Kritik der Urteilskraft, Anhang: $\$ 83$ Von dem letzten Zwecke der Natur als eines teleologischen Systems, 2. Aufl. 1793, in: Werke in zwölf Bänden, herausgegeben von Wilhelm Weischedel, 1977, Bd. 10, S. 391.

7 Georg Wilhelm Friedrich Hegel, Grundlinien der Philosophie des Rechts oder Naturrecht und Staatswissenschaft im Grundrisse (1821), (nach der Ausgabe von Eduard Gans, hrsg. von Hermann Klenner) 1981, $\int \$ 33,182 \mathrm{ff}$., 258 und passim.

${ }^{8}$ Karl Marx, Die heilige Familie oder Kritik der kritischen Kritik, Die Judenfrage Nr. III, 1845, in: Karl Marx/Friedrich Engels: Werke. Herausgegeben vom Institut für Marxismus-Leninismus beim ZK der SED, $1956 \mathrm{ff}$., Bd. 2, S. $119 \mathrm{ff}$.

9 Jürgen Habermas, Strukturwandel der Öffentlichkeit, Untersuchungen zu einer Kategorie der bürgerlichen Gesellschaft, 2. Aufl. 1990 (erschien zuerst 1962). 
Ernst-Otto Czempiel ${ }^{10}$ - „,bürgerliche Gesellschaft“ (civis = Bürger). Der hieran orientierte Begriff der „Bürgergesellschaft“ ist in der jüngeren Diskussion vereinzelt geblieben. ${ }^{11}$ Dasjenige, was mit wechselnden Bezeichnungen unter Zivilgesellschaft zu verstehen sei, ist jedenfalls ,ein Konzept mit langer historischer Tradition“" ${ }^{2}$

Eine neue Bedeutung der „Civil Society“, die dann zur Zivilgesellschaft im heutigen Sinne wird, zeichnet sich seit Ende der 1980er Jahre ab. ${ }^{13}$ Die deutsche Begriffsbildung ${ }^{14}$ spiegelt auch antibürgerliche und antimilitärische ${ }^{15}$ Reflexe ihrer Theoretiker, Träger- und Resonanzgruppen. Einerseits arbeitet sich der Begriff Zivilgesellschaft an der bürgerlichen Gesellschaft und der preußisch-deutschen Geschichte ab, ist also ein ,rückblickender Begriff“, andererseits erscheint er als ,,vorausschauender Begriff", als einer jener „Vorgriffe, die eine neue oder andere Zukunft heraufbeschwören". ${ }^{16} \mathrm{Zu}$ diesen Neuerungen gehört nicht zuletzt eine Entlastung des an die Grenzen seiner Steuerungsfähigkeit stoßenden Staates. ${ }^{17}$ Der Wortstamm mag auch

${ }^{10}$ Ernst-Otto Czempiel, Das amerikanische Sicherheitssystem 1945-1949, Studie zur Außenpolitik der bürgerlichen Gesellschaft, 1966.

11 So betrachtete Bert van den Brink, Die politisch-philosophische Debatte über die demokratische Bürgergesellschaft, in: ders./Willem van Reijen (Hrsg.), Bürgergesellschaft, Recht und Demokratie, 1995, S. 7-26 (Anm. 3, S. 24) den Begriff Bürgergesellschaft ,, als geeignetste Übersetzung von ,civil society". Ebenso Chris Hann, Zivilgesellschaft oder Citizenship? Skeptische Überlegung eines Ethnologen, in: Manfred Hildermeier/Jürgen Kocka/Christoph Conrad (Hrsg.), Europäische Zivilgesellschaft in Ost und West, Begriff, Geschichte, Chancen, 2000, S. 85-109 (S. 88f.). Hingegen versteht Gerd Hepp, Wertewandel und Bürgergesellschaft, in: Aus Politik und Zeitgeschichte, B 52-53/1996 vom 20. Dezember 1996, S. 3-12, Bürgergesellschaft als ,pragmatisches Reformprojekt“, als ,,eine Revitalisierung und Erweiterung des Bürgerdialogs" (S. 8). Vgl. auch Helmut Klages, Von der Zuschauerdemokratie zur Bürgergesellschaft?, in: Hermann Hill (Hrsg.), Bürgerbeteiligung, Analysen und Praxisbeispiele, 2010, S. 11-21.

12 So zutreffend Dieter Gosewinkel/Dieter Rucht, „History meets sociology“: Zivilgesellschaft als Prozess, in: Dieter Gosewinkel u.a. (Hrsg.), Zivilgesellschaft - national und transnational (WZB-Jahrbuch 2003), 2004, S. 29-60 (S. 31). Der Beitrag analysiert die jüngeren historischen Arbeiten zum Thema und stellt die vielfältigen Aspekte des Wandels dar, den das Konzept im Lauf der Zeit erfahren hat.

${ }^{13}$ Für die Begriffsentwicklung im angelsächsischen Sprachraum vgl. etwa: John Keane (Hrsg.), Civil Society and the State: New European Perspectives, 1988. Zur Bedeutung in den Transformationsgesellschaften des ehemaligen Ostblocks vgl. infra Fn. 65.

${ }^{14}$ Für eine Begriffsgeschichte dieses ,sehr alten“ Begriffs vgl. Jürgen Kocka, Zivilgesellschaft als historisches Problem und Versprechen, in: Manfred Hildermeier/ders./Christoph Conrad (Hrsg.), Europäische Zivilgesellschaft in Ost und West, Begriff, Geschichte, Chancen, 2000, S. 13-39.

${ }_{15}$ Dabei soll nicht verkannt werden, dass bereits John Locke, The Second Treatise on Government, An Essay concerning the True Original, Extent, and End of Civil Government, in: ders., Two Treatises on Government, 1690, und Charles Louis de Secondat de Montesquieu, De l'Esprit des Loix ou du rapport que les loix doivent avoir avec la constitution de chaque gouvernement, les moeurs, le climat, la religion, le commerce, \&c, 1748, von einer friedlich und gewaltfrei wirkenden bürgerlichen Gesellschaft ausgehen. Zu Recht macht aber Jörg Leonhard, Zivilität und Gewalt: Zivilgesellschaft, Bellizismus und Nation, in: Dieter Gosewinkel/Sven Reichardt (Hrsg.), Ambivalenzen der Zivilgesellschaft, Gegenbegriffe, Gewalt und Macht (WZB Discussion Papers, Nr. SP IV 2004-501), 2004, S. 26-41, auf das Legitimations- und Identifikationspotential des Kriegführens im Nationalstaat vor 1914 aufmerksam. Erst nach 1945 habe sich ein wirklicher Gegensatz von Zivilgesellschaft und Bellizismus herausgebildet (S. $39 \mathrm{ff}$.$) .$

${ }^{16}$ Reinhart Koselleck, Stichwort: Begriffsgeschichte, in: ders., Begriffsgeschichten, Studien zur Semantik und Pragmatik der politischen und sozialen Sprache, 2006, S. 99-102 (S. 100).

${ }^{17}$ Für diese vielfach geteilte Diagnose vgl. Ireneusz Pawel Karolewski, Civil Society and its Discontents, in: Jochen Franzke (Hrsg.), Making Civil Society Work, 2006, S. 7-25 (S. 9 f.). Mit Blick auf die internationale Verflechtung hierzu beispielsweise: Markus Kotzur, Souveränitätsperspektiven - ent- 
als eine deutliche Absage an jene unselige Unterscheidung ${ }^{18}$ zwischen (deutscher) Kultur und (westlicher) Zivilisation verstanden werden, die im sogenannten Augusterlebnis des Jahres 1914 kulminierte $^{19}$.

Wenn also die Begriffsgeschichte keine eindeutigen Schlußfolgerungen zuläßt, mag ein Blick auf den dogmengeschichtlichen Hintergrund ${ }^{20}$ und Kontext der „Zivilgesellschaft" weiterhelfen. Grob vereinfachend lassen sich zwei Begriffsstränge unterscheiden: Zunächst die republikanische Begriffsverwendung der bürgerlichen Gesellschaft in aristotelischer Tradition, die einen Bürgerhumanismus impliziert; ${ }^{21}$ sodann der Ansatz des Liberalismus, ${ }^{22}$ der die Unterscheidung von Staat und Gesellschaft betont und die letztere entpolitisiert. In Hegels Rechtsphilosophie (1821) werden republikanische und liberale Theorietradition miteinander verbunden. ${ }^{23} \mathrm{Mit}$ dem Modell der Korporationen entwickelt Hegel ein Konzept der politisch integrierenden, intermediären freiwilligen Zusammenschlüsse von Menschen. ${ }^{24}$ Er versucht, ,,die liberale Konzeption negativer Freiheit mit der republikanischen Tradition der politischen Gesellschaft unter den Bedingungen der modernen Gesellschaft zusammenzuführen" ${ }^{25}$ Bedacht werden muss allerdings, dass nach Hegel in der bürgerlichen Gesellschaft ,,das Interesse der Einzelnen als solcher de[n] letzte[n] Zweck, zu welchem sie vereinigt sind“, darstellt, wohingegen für den Staat gilt: „Die Vereinigung als solche ist selbst der wahrhafte Inhalt und Zweck, und die Bestimmung der Individuen ist ein allgemeines Leben zu führen." 26

wicklungsgeschichtlich, verfassungsstaatlich, staatenübergreifend betrachtet, in: JöR N. F. 52 (2004), S. 197-218; Helge Rossen-Stadtfeld, Demokratische Staatlichkeit in Europa: ein verblassendes Bild, in: JöR N.F. 53 (2005), S. 45-77. Zur Gegenposition siehe infra Fn. 273.

18 Prominent bei Thomas Mann, Gedanken im Kriege (1914), in: Gesammelte Werke in dreizehn Bänden, 1974, Bd. XIII, S. 527-545, und ders., Betrachtungen eines Unpolitischen (1918), Gesammelte Werke in zwölf Bänden, 1960, Bd. XII, S. 9-589. Vgl. zu diesem Phänomen die breit angelegte Untersuchung von Barbara Beßlich, Wege in den ,Kulturkrieg“, Zivilisationskritik in Deutschland 1890-1914, 2000. Siehe auch Klaus Böhme (Hrsg.), Aufrufe und Reden deutscher Professoren im Ersten Weltkrieg, 1975. Dort, S. 47-49, den „Aufruf an die Kulturwelt“, in dem die später so genannten „Ideen von 1914“ formuliert wurden.

19 Intensive Darstellung bei Volker Ullrich, Die nervöse Großmacht, Aufstieg und Untergang des deutschen Kaiserreichs 1871-1918, 1997, S. $494 \mathrm{ff}$. siehe auch Thomas Nipperdey, Deutsche Geschichte 1866-1918, Bd. II: Machtstaat vor der Demokratie, 1992, S. $778 \mathrm{f}$.

20 Ausführlich Ansgar Klein, Der Diskurs der Zivilgesellschaft, Politische Kontexte und demokratietheoretische Bezüge der neueren Begriffsverwendung (Bürgerschaftliches Engagement und NonprofitSektor, Bd. 4), 2001, S. 270-309.

21 Vgl. die Nachweise bei Herfried Münkler, Die Idee der Tugend, Ein politischer Leitbegriff im vorrevolutionären Europa, in: Archiv für Kulturgeschichte 1991, S. 379-403; ders. Zivilgesellschaft und Bürgertugend, Bedürfen demokratisch verfaßte Gemeinwesen einer sozio-moralischen Fundierung? (Öffentliche Vorlesungen, Heft 23), 1994.

22 Wichtig ist hier Adam Ferguson, An Essay on the History of Civil Society, 1767, der von der schottischen Moralphilosophie, von den Schöpfern der US-amerikanischen Verfassung und von Alexandre de Toqueville rezipiert wurde. Zu Parallelen und Unterschieden vgl. Leonard Krieger, Europäischer und amerikanischer Liberalismus, in: Lother Gall (Hrsg.), Liberalismus, 1976, S. 147-161.

23 Einzelheiten bei Rolf-Peter Horstmann, Hegels Theorie der bürgerlichen Gesellschaft, in: Ludwig Siep (Hrsg.), G. W. F. Hegel, Grundlinien der Philosophie des Rechts (Klassiker Auslegen, Bd. 9), 1997, S. $193-216$.
24 Hegel (Fn. 7), \$250ff.
25 Klein (Fn. 20), S. 295.
${ }^{26}$ Beide Zitate Hegel (Fn. 7), \258. 
Diese Überlegungen bilden den Abschluß einer Entwicklung von der societas civilis cum imperio hin zur societa civilis sine imperio: Anders als in der alten Zeit ist Herrschaft nunmehr allein in der monarchischen Staatsgewalt konzentriert und einem ,nivellierten Untertanenverband“27 gegenübergestellt, was dazu führt, dass zwischen den verschiedenen Elementen der Gesellschaft Freiheit herrscht und diese Freiheit vom Staat zu garantieren ist. In den \$S 1-4 II 13 ALR hat dieses Verständnis am Ende des 18. Jahrhunderts seinen Niederschlag gefunden. ${ }^{28}$ Parallel dazu stellte sich die Frage, ob der Staat selbst vermehrt Freiheitssphären seiner Bürger als Korrektiv für die Machtkonzentration respektieren müsse. ${ }^{29}$ Unter den geschichtlichen Bedingungen der Französischen Revolution und der ihr zugrundeliegenden Aufklärung wurde eine im Wortsinne bürgerliche Rechtsordnung geschaffen, die die Gesellschaft als spezifisch bürgerliche gleichermaßen voraussetzte, konstituierte und beschützte ${ }^{30}$ Eng damit verbunden war die Frage, ob der Gesellschaft auch ein Anteil an der Entscheidungsgewalt des Staates zukommen solle. Da der Staat und die ihn tragenden Teile der Gesellschaft - Adel, Beamte, Militär - daran kein Interesse hatten, führte der Weg zu einer Beteiligung zunächst nur über die Revolution. Folgerichtig wurde die Beteiligung nicht verwirklicht, wo die Revolution ausblieb.

Auch in den deutschen Staaten ist es unter den besonderen Bedingungen der Zeit zwischen 1800 und 1866 zur Herausbildung einer bürgerlichen Gesellschaft gekommen. ${ }^{31}$ Dabei war die Kultur ein wesentlicher Faktor für die weitere Entwicklung, ${ }^{32}$

27 So Erich Angermann, Das ,Auseinandertreten von Staat und Gesellschaft" im Denken des 18. Jahrhunderts, in: Zeitschrift für Politik 1963, S. 89-101 (S.92ff.).

28 Dreyzehnter Titel: Von den Rechten und Pflichten des Staats überhaupt

Allgemeine Grundsätze

§1. Alle Rechte und Pflichten des Staats gegen seine Bürger und Schutzverwandten vereinigen sich in dem Oberhaupte desselben.

\$2. Die vorzügliche Pflicht des Oberhaupts im Staate ist, sowohl die äußere als innere Ruhe und Sicherheit zu erhalten, und einen jeden bey dem Seinigen gegen Gewalt und Störungen zu schützen.

§3. Ihm kommt es zu, für Anstalten zu sorgen, wodurch den Einwohnern Mittel und Gelegenheiten verschafft werden, ihre Fähigkeiten und Kräfte auszubilden, und dieselben zur Beförderung ihres Wohlstandes anzuwenden.

\4. Dem Oberhaupte im Staate gebühren daher alle Vorzüge und Rechte, welche zur Erreichung dieser Endzwecke erforderlich sind.

29 Angermann (Fn. 27), S. 96 ff., argumentiert, die Gesellschaft des nivellierten Untertanenverbandes werde aktiv und suche den mit Absolutheitsanspruch auftretenden Staat aus immer mehr Bereichen des Gemeinschaftslebens zurückzudrängen, der sich seinerseits auch aus bestimmten Bereichen - Religion, freie Bildung der Persönlichkeit und Wirtschaft - zurückgezogen und auf die Kernaufgabe Wahrung von Recht und Sicherheit beschränkt habe. Vgl. auch Reinhart Koselleck, Kritik und Krise, Eine Studie zur Pathogenese der bürgerlichen Welt, 1959/1973, S. $30 \mathrm{ff}$.

${ }^{30}$ Ernst-Wolfgang Böckenförde, Die Bedeutung der Unterscheidung von Staat und Gesellschaft im demokratischen Sozialstaat der Gegenwart, in: ders., Recht, Staat, Freiheit, Studien zur Rechtsphilosophie, Staatstheorie, Verfassungsgeschichte, 1991, S. 209-243 (S. 214 ff.).

31 Siehe Thomas Nipperdey, Deutsche Geschichte 1800-1866, Bürgerwelt und starker Staat, 1983, S. $285 \mathrm{ff}$. zur allgemeinen Entwicklung und S. $721 \mathrm{ff}$. zur Rolle des realitätsorientierten (nachrevolutionären) Liberalismus, der vor allem in der „Neuen Ära“ (nach 1858) erfolgreich war. Lothar Gall, Liberalismus und „bürgerliche Gesellschaft“. Zu Charakter und Entwicklung der liberalen Bewegung in Deutschland, in: ders. (Hrsg.), Liberalismus, 1976, S. 162-186.

${ }^{32}$ Dies wird anschaulich beispielsweise bei Theodore Ziokowski, Berlin, Aufstieg einer Kulturmetropole um 1810, 2002. Zur Bedeutung der „Leserevolution“ zwischen 1800 und 1866 eindringlich Nipperdey (Fn. 31), S. $587 \mathrm{ff}$. 
sie stellte freilich auch ein Ventil dar, als andere Wege verschlossen blieben: Folgerungen, die aus dem Aufstieg des Bürgertums im 18. Jahrhundert zu ziehen gewesen wären, und die nach der notwendigen Mitwirkung des Volkes an den siegreichen Befreiungskriegen eigentlich nicht mehr übergangen werden konnten, nämlich die Beteiligung der Bürger an der. Herrschaft, an Willensbildung und Ausübung von Hoheitsgewalt, wurden durch die nach 1815 durchgeführte Restaurationspolitik ignoriert. ${ }^{33}$ Das Scheitern der Revolution von 1848 tat ein übriges, um einerseits das deutsche Bürgertum zu entpolitisieren und andererseits die „,überschießende Angst“34 vor der sozialen Revolution im kollektiven Bewußtsein der Bürger zu verankern. Die mehrheitliche ${ }^{35}$ Entwicklung des deutschen Bürgers zum Bourgeois anstatt zum Citoyen hat hier ihre Wurzeln; diese Weichenstellung determinierte im Laufe der Zeit auch die vormodernen sozialen Bewegungen, die sich innerhalb der bürgerlichen Gesellschaft herausbildeten und zunächst eine ,neue Ebene des politischen Prozesses “36 eröffneten, dann aber an Prägekraft verloren:

Das, was man im ausgehenden 19. und beginnenden 20. Jahrhundert die bürgerliche Gesellschaft, das bürgerliche Zeitalter genannt hatte, war offenbar [...] eher eine Fessel für die Entfaltung jener ursprünglichen, in Aufklärung und bürgerlichem Aufbruch wurzelnden Werte und Überzeugungen gewesen. ${ }^{37}$

Bedacht werden muss allerdings, dass es die zuvor beschriebene strikte Trennung von Staat und Gesellschaft in der Realität auch zu Zeiten Hegels nicht gab, ${ }^{38}$ dem Wesen des Staates als ,organisierte Wirkeinheit" ${ }^{\text {"39 }}$ nach auch gar nicht geben konnte. Jedenfalls kann mit dem Aufkommen des Sozialstaates, der nicht nur regulierend,

33 Zum zeitgeschichtlichen Hintergrund vgl. Reinhart Koselleck, Die Restauration und ihre Ereigniszusammenhänge 1815-1830, in: Louis Bergeron/François Furet/ders., Das Zeitalter der europäischen Revolutionen 1780-1848, 1969, Nachdruck 2003, S.199-229 (S. 201-217); Heinrich August Winkler, Der lange Weg nach Westen, 1. Bd.: Deutsche Geschichte vom Ende des Alten Reiches bis zum Untergang der Weimarer Republik, 5., durchgesehene Aufl. 2002, S. 53-70. Speziell zum Spektrum des nachrevolutionären Denkens vgl. Theo Stammen/Friedrich Eberle, Einleitung, in: dies. (Hrsg.), Deutschland und die Französische Revolution (Quellen zum politischen Denken der Deutschen im 19. und 20. Jahrhundert, Freiherr vom Stein-Gedächtnisausgabe, Bd. 1), 1988, S. 1-25.

34 Nipperdey (Fn. 31), S. 622. Diese Furcht war im kollektiven Gedächtnis tief verankert: ,,[W] enn sich die Völker selbst befrein,/da kann die Wohlfahrt nicht gedeihn./Weh, wenn sich in dem Schoß der Städte/der Feuerzunder still gehäuft,/das Volk, zerreißend seine Kette,/zur Eigenhilfe schrecklich greift!/Da zerret an der Glocke Strängen/der Aufruhr, daß sie heulend schallt/und, nur geweiht zu Friedensklängen,/die Losung anstimmt zur Gewalt./Freiheit und Gleichheit! Hört man schallen,/der ruh'ge Bürger greift zur Wehr,/die Straßen füllen sich, die Hallen,/und Würgerbanden ziehn umher." (Friedrich Schiller, Das Lied von der Glocke, 1799).

35 Exemplarisch für eine anders verlaufene bürgerliche Familiengeschichte vgl. Lother Gall, Bürgertum in Deutschland, 1989.

36 Zur Tradition außerparlamentarischer Bewegungen vgl. Nipperdey (Fn. 31), S. $617 \mathrm{ff}$, $722 \mathrm{ff}$., 729 ff. (das Zitat auf S. 617). Die Geschichte sozialer Bewegung faßt auch Joachim Raschke, Soziale Bewegungen, Ein historisch-systematischer Grundriß, 1985, S. 22 ff. zusammen.

37 So treffend Gall (Fn. 35), S. 500.

38 Böckenförde (Fn. 30), S. 219; den Staatsbegriff problematisierend Claus-Ekkehard Bärsch, Die Rechtspersönlichkeit des Staates in der deutschen Staatsrechtslehre des 19. und beginnenden 20. Jahrhunderts, Zur Kritik der Substantiierung der Macht und der Homogenität der Gesellschaft, in: Gerhard Göhler/Kurt Lenk/Rainer Schmalz-Bruns (Hrsg.), Die Rationalität politischer Institutionen, Interdisziplinäre Perspektiven, 1990, S. 423-442.

39 Hermann Heller, Staatslehre, 1934, S. 228 ff.; das Argument findet sich bei Böckenförde, aaO. 
sondern auch leitend wirkte, die Verflochtenheit von Staat und Gesellschaft nicht mehr geleugnet werden. ${ }^{40}$ Dies gilt um so stärker für den „Steuerungsstaat“ des 20 . Jahrhunderts ${ }^{41}$ der die Verantwortung für die wirtschaftliche Entwicklung und soziale Wohlfahrt der Gesellschaft als Ganzes übernahm und sich als „Staat der Industriegesellschaft ${ }^{\prime 42}$ weit von einer klassischen Staatsrolle entfernt hatte. ${ }^{43}$ Dass Kooperation das Verhältnis von Staat und Gesellschaft prägt, beschrieb Ernst Forsthoff bereits im Jahre 1950: „Die Verwaltung hat an solchen Arrangements ebenfalls Interesse, da sie, je mehr sie in das Sozialleben ausgreift, auf eine Kooperation mit den Sozialfaktoren angewiesen ist. ${ }^{\text {"44 }}$ Und zu ergänzen ist eine Formulierung von Manfred Hättich: „,Wo Gesellschaft ist, da ist Kooperation. ${ }^{\text {"45 }}$

Es läßt sich eine ,geistesgeschichtliche Kontinuität des ideologischen Musters ${ }^{\text {*46 }}$ bürgerliche Öffentlichkeit beobachten, die in den Staaten Europas den Dualismus Polis-Oikos im 18. Jahrhundert wiederbelebt und die bürgerliche Öffentlichkeit als politischen Raum zwischen der bürgerlichen Gesellschaft und dem Staat konstituiert, in dem die bürgerliche Gesellschaft eine besondere Kontrolle der Staatstätigkeit vornimmt. $^{47}$

${ }^{40}$ Ernst Forsthoff, Lehrbuch des Verwaltungsrechts, I. Band: Allgemeiner Teil, 1950, S. 3: „Diese Schranke zwischen Staat und Gesellschaft ist inzwischen gefallen. Der moderne Staat findet das Sozialleben nicht in einem Zustand präformierter Ordnung vor. Im Gegenteil: Die Herstellung und Aufrechterhaltung einer angemessenen Sozialordnung ist die vordringlichste, seine ganze Kraft in Anspruch nehmende Aufgabe des Staates geworden." Josef Isensee, Subsidiaritätsprinzip und Verfassungsrecht, Eine Studie über das Regulativ des Verhältnisses von Staat und Gesellschaft (Schriften zum Öffentlichen Recht, Bd. 80), 1968, S. 154, betont, dass Staat und Gesellschaft eine dialektische Einheit bilden.

${ }^{41}$ Hierzu Franz-Xaver Kaufmann, Diskurse über Staatsaufgaben, in: Dieter Grimm (Hrsg.), Staatsaufgaben, 1994, S. 15-41 (S. 28 ff.). Aber schon im 19. Jahrhundert zeichnete sich der Interventionsstaat in Deutschland mit der 1879 begonnenen Schutzzollpolitik ab; Umverteilungspolitik der Reichsregierung zeitigte verbandliche Interessenvertretung neuartigen Ausmaßes - näher Nipperdey (Fn. 19), S. 576 ff.; Ullrich (Fn. 19), S. 176 ff. mit dem Hinweis, dass die schwache Stellung von Parteien und Parlament die außerparlamentarische Interessenvertretung begünstigte.

42 Ernst Forsthoff, Der Staat der Industriegesellschaft, Dargestellt am Beispiel der Bundesrepublik Deutschland, 2. Aufl. 1971.

${ }^{43}$ Zur Einordnung als „Gewährleistungsstaat" vgl. die Beiträge in Gunnar Folke Schuppert (Hrsg.), Der Gewährleistungsstaat - Ein Leitbild auf dem Prüfstand, 2005. Der gewährleistende Staat wird entlastet, weil er andere Akteure mit in die Verantwortung einbezieht. Zu den aktuellen Herausforderungen für den Sozialstaat prägnant Hans Günter Hockerts, Vom Problemlöser zum Problemerzeuger?, Der Sozialstaat im 20. Jahrhundert, in: Archiv für Sozialgeschichte 47 (2007), S. 3-29.

${ }_{44}$ Forsthoff (Fn. 40), S. 62. Bitter bilanziert er zwanzig Jahre später, dass die ausgeweitete, von den Bedürfnissen der Gesellschaft diktierte Leistungsverwaltung, ,die Domäne des mittleren und gehobenen Dienstes“ - (Fn. 42), S. 108 - zwar auf Kosten der individuellen Freiheit gehe, der Staatlichkeit aber nichts einbringe - ebenda, S. 109.

45 Manfred Hättich, Demokratie als Herrschaftsordnung (Ordo Politicus, Bd. 7), 1967, S. 89.

46 Habermas (Fn. 9), S. 57.

${ }^{47}$ Habermas (Fn. 9), S. 66 ff.; 86 ff. Vgl. auch Anthony de Jasay, The State, 1998, S. 142: „Liberal doctrine holds that civil society is capable of controlling the state [... ".

Von hoher Bedeutung war im 19. Jahrhundert August Ludwig von Rochau, Grundsätze der Realpolitik, angewendet auf die staatlichen Zustände Deutschlands, 1853, S. 9 ff. und passim. Ausführlich Lucian Hölscher, Öffentlichkeit und Geheimnis, Eine begriffsgeschichtliche Untersuchung zur Entstehung der Öffentlichkeit in der frühen Neuzeit (Sprache und Geschichte, Bd. 4), 1979. Zur Vielgestaltigkeit von Staat und Gesellschaft auf dem Weg in „Modernität und Totalität" nach der französischen Revolution 
In der neugegründeten Bundesrepublik Deutschland setzte sich die während des sogenannten Dritten Reiches begonnene soziostrukturelle Veränderung ${ }^{48}$ des Bürgertums fort; im Zuge des Wirtschaftsaufschwungs bildete sich eine kleinbürgerliche Mittelstandsgesellschaft heraus, für die der Rückzug ins Private kennzeichnend war. ${ }^{49}$ Mit einer zeitlichen Verzögerung ${ }^{50}$ kann die Entwicklung hin

zu einer „Staatsbürgergesellschaft“, im weiteren Verlauf und als Ergebnis einer sich intensivierenden politischen und gesellschaftlichen Liberalisierung jedoch auch zu einer „civil society" im angelsächsischen Sinne [beobachtet werden]. [...] bestimmte gesamtgesellschaftliche und politische Entwicklungen [...] führten zu einer (Wieder-)Entstehung von Bürgerlichkeit, politisch, sozial und kulturell, und nun eben einer gesellschaftlich verallgemeinerten Bürgerlichkeit jenseits der vormaligen Sonderformation Bürgertum. ${ }^{51}$

Dieser in den 1970 Jahren und seither fortgesetzte und vertiefte Prozess zeigt den Erfolg der sogenannten Westernisierung oder Verwestlichung der Bundesrepublik Deutschland. ${ }^{52}$ Ergebnis war der moderne Verfassungsstaat, den Dolf Sternberger als offen und pluralistisch charakterisierte. ${ }^{53}$

Dieser Staat korrespondiert mit einer liberalisierten Gesellschaft, deren Mentalitäten, Wahrnehmungsmuster und Handlungsformen sich signifikant von denjenigen der Zeit vor 1945, aber auch vor 1933 unterscheiden. Diese Liberalisierung ist für die Bundesrepublik Deutschland als Lernprozess charakterisiert worden. ${ }^{54}$

vgl. Wolfgang Reinhard, Geschichte der Staatsgewalt, Eine vergleichende Verfassungsgeschichte Europas von den Anfängen bis zur Gegenwart, 2. Aufl. 2000, S. 406-479.

${ }^{48}$ Anschaulich beispielsweise bei Joachim Fest, Nicht ich, Erinnerungen an eine Kindheit und Jugend, 5. Aufl. 2006, S. 73 ff., 102 ff., der „eine Art bürgerlicher Entwicklungsgeschichte in unbürgerlicher Zeit" (S. 103) schildert.

${ }^{49}$ Hierzu die prägnante Übersicht bei Eckart Conze, Eine bürgerliche Republik? Bürgertum und Bürgerlichkeit in der westdeutschen Nachkriegsgesellschaft, in: Geschichte und Gesellschaft 30 (2004), S. 512-542 m.w.Nw. Früh in diese Richtung bereits Helmut Schelsky, Wandlungen der deutschen Familie in der Gegenwart, Darstellung und Deutung einer empirisch-soziologischen Tatbestandsaufnahme, 2. Aufl. 1954: „nivellierte Mittelstandsgesellschaft“ (S.218), zum Rückzug ins Private S. $122 \mathrm{ff}$. Zu aktuellen Konstellationen Paul Kaiser, Bürgerlichkeit ohne Bürgertum? in: Aus Politik und Zeitgeschichte 9-10/2008, S. 26-32.

${ }^{50}$ Diese Verzögerung kann einem Richtungsstreit zwischen konservativer und liberaler Denkschule zugeschrieben werden. Hierzu Christina von Hodenberg, konkurrierende Konzepte von „Öffentlichkeit" in der Orientierungskrise der 60er Jahre, in: Matthias Frese/Julia Paulus/Karl Teppe (Hrsg.), Demokratisierung und gesellschaftlicher Aufbruch, Die sechziger Jahre als Wendezeit der Bundesrepublik, 2003, S. 205-226 (S. 208ff.).

51 Conze (Fn. 49), S. 535 f. Neuere Ansätze der Bürgertums- und Bürgerlichkeitsforschung wurden im Oktober 2007 auf einer von Cornelia Budde u. a. organisierten Konferenz in Loccum: „Bürgertum und Bürgerlichkeit im 20. Jahrhundert im internationalen Vergleich" präsentiert. Ein Tagungsbericht findet sich unter http://hsozkult.geschichte.hu-berlin.de/tagungsberichte/id=1922 (zuletzt besucht am 29. Februar 2012).

52 Ausführlich hierzu Anselm Doering-Manteuffel, Wie westlich sind die Deutschen? Amerikanisierung und Westernisierung im 20. Jahrhundert, 1999. Außerdem Heinrich August Winkler, Der lange Weg nach Westen, 2. Bd: Deutsche Geschichte vom „Dritten Reich“ bis zur Wiedervereinigung, 5. durchgesehene Aufl. 2002, S. 142 ff., 213, 270, 311 und passim.

${ }^{53}$ Dolf Sternberger, Verfassungspatriotismus, Rede bei der 25-Jahr-Feier der „Akademie für Politische Bildung“ (1982), in: ders., Schriften, Bd. X: Verfassungspatriotismus, 1990, S. 17-31 (S. 29).

${ }^{54}$ Ulrich Herbert, Liberalisierung als LernprozeB. Die Bundesrepublik in der deutschen Geschichte - eine Skizze, in: ders. (Hrsg.), Wandlungsprozesse in Westdeutschland, Belastung, Integration, Liberalisierung 1945-1980 (Moderne Zeit, Neue Forschungen zur Gesellschafts- und Kulturgeschichte des 


\section{Heutiges Verständnis von Zivilgesellschaft}

\section{a) Definitionsversuche}

Festzuhalten ist, dass sich das heutige Konzept von Zivilgesellschaft abgrenzen will von der tendenziell unpolitischen bürgerlichen Gesellschaft. ${ }^{55}$ Für die seit den späten 1980er Jahren übliche Verwendung des Begriffs hat sich keine verbindliche, systematisierende Kriterien verwendende Definition herausgebildet, wie ein Blick in die breitgefächerte Literatur zeigt. ${ }^{56}$ Je nach Herangehensweise werden normative oder formale Kriterien stärker in den Vordergrund gestellt, wobei der Staat einen kontinuierlichen Bezugspunkt darstellt. ${ }^{57}$ Das erste hier angeführte Beispiel greift Elemente der sogenannten "neuen sozialen Bewegungen" auf und nimmt nicht nur formale, sondern auch eine inhaltliche Abgrenzung vor:

Gemeinhin meint Zivilgesellschaft eine Vielfalt gesellschaftlicher Gruppen, Initiativen und Bewegungen, die weitgehend unabhängig von staatlichen, parteipolitischen oder privatwirtschaftlichen Institutionen wirken. Die Zugehörigkeit zu diesen gesellschaftlichen Gruppen ist freiwillig, die Organisationsstruktur demokratisch. Achtung der allgemeinen Menschenrechte, Toleranz gegenüber anderen Meinungen und Wertvorstellungen, Anerkennen der Grundsätze des bürgerlich-demokratischen Gesellschaftsmodells und des demokratischen Rechtsstaats gehören ebenfalls zu den zivilgesellschaftlichen Prinzipien. Auch ein konsequentes Agieren nach dem Legalitätsprinzip und eine aus der Akzeptanz des staatlichen Gewaltmonopols resultierende unbedingte Gewaltlosigkeit in den eigenen Handlungsansätzen bilden den gemeinsamen Nenner, der die Zivilgesellschaft einerseits von rechtsextremen Strukturen abgrenzt, sie andererseits aber auch von revolutionär-antifaschistischen Politikkonzepten unterscheidet. ${ }^{58}$

Damit werden traditionelle Interessenvertretungen wie politische Parteien und Verbände, Kirchen ${ }^{59}$ und kirchliche Hilfswerke, ja auch nationale Menschenrechts-

19. und 20. Jahrhunderts, Bd. I), 2002, S. 7-49. Bilanzierend auch Reinhard Hildebrandt, Staat und Zivilgesellschaft, 2011.

${ }^{55}$ Erlaubt sei der Hinweis auf die Vielfältigkeit soziologischer Gesellschaftsbegriffe, wie sie etwa in den vierzehn Beiträgen in Georg Kneer/Armin Nassehi/Markus Schoer (Hrsg.), Soziologische Gesellschaftsbegriffe, Konzepte moderner Zeitdiagnosen, 1997, zum Ausdruck kommt. Vgl. bereits den Hinweis auf die Vieldeutigkeit des Gesellschaftsbegriffs bei Georg Jellinek, Allgemeine Staatslehre, 3. Aufl., 7. Neudruck 1960 , S. 84-99.

${ }^{56}$ Diesen Befund teilt auch Georg Kneer, Zivilgesellschaft, in: ders./Armin Nassehi/Markus Schoer (Hrsg.) (Fn. 55), S. 229-251 (S. 234 ff.). So versucht etwa Norbert Brieskorn, Zivilgesellschaft - Chancen und Grenzen eines sozialwissenschaftlich-philosophischen Konzepts, in: Julia Inthorn u.a. (Hrsg.), Zivilgesellschaft auf dem Prüfstand, Argumente - Modelle - Anwendungsfelder (Globale Solidarität Schritte zu einer neuen Weltkultur, Bd. 11), 2005, S. 2-19, eine komplexe Charakterisierung anhand von sieben Merkmalen, die dreifach entfaltet wird und somit kaum noch benutzbar erscheint.

57 Vgl. Simone Chambers/Jeffrey Kopstein, Civil Society and the State, in: John S. Dryzek/ Bonnie Honig/Anne Philips (Hrsg.), The Oxford Handbook of Political Theory, 2006, S. 363-381.

${ }_{58}$ Joachim Kolb, Antifa-Bündnisse ohne bürgerliche Loblieder, Möglichkeiten und Grenzen einer zivilgesellschaftlichen Bekämpfung von Rechtsextremismus in Ostdeutschland, in: ak - analyse \& kritik - Zeitung für linke Debatte und Praxis / Nr. 439 vom 8. Juni 2000, S. $26 \mathrm{ff}$.

${ }^{59} \mathrm{Als}$ Beispiel für die aktuelle Diskussion sei nur genannt Ralf $K$. Wüstenberg, Kirchen als Institutionen in Transformationsprozessen? Das sich einigende Deutschland in vergleichender Perspektive, Vortrag auf dem Internationalen Historiker-Kolloquium „Kirchen und Zivilgesellschaft“ des Berliner Kollegs für Vergleichende Geschichte Europas, 20.-22. September 2007. 
institutionen $^{60}$ aus der Zivilgesellschaft ausgeschlossen. Das mag bewegungsideologisch gerechtfertigt sein, erscheint sachlich allerdings unangemessen. ${ }^{61}$ Die meisten der vorgenannten Akteure, die auch als intermediäre Organisationen bezeichnet werden, ${ }^{62}$ dürften sich überdies selbst auch als Teil der Zivilgesellschaft sehen. Allerdings ist pure Interessenvertretung mit der Gemeinwohlkonnotation von Zivilgesellschaft ${ }^{63}$ nicht ohne weiteres in Übereinstimmung zu bringen.

Den institutionellen Kern der Zivilgesellschaft bilden nach Habermas

jene nicht-staatlichen und nicht-ökonomischen Zusammenschlüsse und Assoziationen auf freiwilliger Basis, die die Kommunikationsstrukturen der Öffentlichkeit in der Gesellschaftskomponente der Lebenswelt verankern. Die Zivilgesellschaft setzt sich aus jenen mehr oder weniger spontan entstandenen Vereinigungen, Organisationen und Bewegungen zusammen, welche die Resonanz, die die gesellschaftlichen Problemlagen in den privaten Lebensbereichen finden, aufnehmen, kondensieren und lautverstärkend an die politische Öffentlichkeit weiterleiten. Den Kern der Zivilgesellschaft bildet ein Assoziationswesen, das problemlösende Diskurse zu Fragen allgemeinen Interesses im Rahmen veranstaltender Öffentlichkeiten institutionalisiert. ${ }^{64}$

Mit dieser Definition wird versucht, den Schwierigkeiten der rechtsstaatlichen Regulierung der Machtkreisläufe in komplexen Gesellschaften gerecht zu werden, indem eine wichtige Schnittstelle funktional bestimmt wird. Da allerdings im Rahmen der institutionalisierten Kooperation mit dem Staat die Neigung besteht, kritische oder gesellschaftlich alternative Akteure nicht zuzulassen oder ihnen weniger Gehör einzuräumen, stellt sich die Frage, ob eine solche, tendenziell bestimmte Gruppen ausschließende Zivilgesellschaft den von Habermas geforderten Resonanzboden wirklich in einem umfassenden Sinne bilden kann.

Während der bleiernen Endzeit sowjetischer Hegemonie in den Staaten Mittelund Osteuropas ist es dort sowie in der Sowjetunion selbst zu einer zunehmenden

60 Nationale Menschenrechtsinstitutionen stellen wohl einen Grenzfall dar. Auf staatlichem Gründungsakt beruhend, sollen sie nach den einschlägigen Pariser Prinzipien (Principles relating to the Status of National Institutions (The Paris Principles), GV-Res. 48/134 vom 20. Dezember 1993) bei der Wahrnehmung ihrer (u.a.) Untersuchungs-, Kontroll- und Bildungsaufgaben gleichwohl das gesellschaftliche Interesse an der Beachtung der Menschenrechte wahren und in der Zusammensetzung ihrer Mitarbeiter und Leitungsgremien gesellschaftliche Vielfalt widerspiegeln. Vgl. Valentin Eichele, Die nationale Menschenrechtsinstitution, Eine Einführung, 2006.

61 Auch Habermas (Fn. 9), S. 46 (= Vorwort zur zweiten Auflage), bezieht Kirchen, Berufsverbände und politische Parteien in den Begriff der Zivilgesellschaft ein. Der Unterschied zur bürgerlichen Gesellschaft bestehe darin, dass jene die Sphäre des Ökonomischen mit umfasse, die Zivilgesellschaft sie hingegen ausschließe.

62 Wolfgang Streeck, Vielfalt und Interdependenz, Überlegung zur Rolle intermediärer Organisationen in sich ändernden Umwelten, in: Kölner Zeitschrift für Soziologie und Sozialpsychologie 39 (1987), S. 471-495.

${ }^{63} \mathrm{Zu}$ dieser Ute Hasenöhrl, Zivilgesellschaft, Gemeinwohl und Kollektivgüter (WZB Discussion Paper Nr. SP IV 2005-401), 2005. Hasenöhrl plädiert dafür, den Gemeinwohlbegriff auszuklammern und durch den Bezug auf Kollektivgüter zu ersetzen (S. $30 \mathrm{ff}$.). Dies wiederum läßt dann auch Raum dafür, „bloße" Interessenvertreter als Teil der Zivilgesellschaft zuzulassen. Demgegenüber verbindet Michael J. Sandel, The Problem With Civility, in: ders. Public Philosophy, Essays on Morality in Politics, 2005, S. 54-53, die Gemeinwohlorientierung mit einer starken Verankerung der Demokratie in der Gesellschaft; hierzu infra bei und in Fn. $212 \mathrm{f}$.

${ }^{64}$ Jürgen Habermas, Faktizität und Geltung, Beiträge zur Diskurstheorie des Rechts und des demokratischen Rechtsstaats, 5. Aufl. 1997, S. 443. 
Verwendung des Begriffes Zivilgesellschaft gekommen. ${ }^{65}$ Diese Verwendung hatte einen nach den einzelnen Ländern stark ausdifferenzierten Charakter, der insgesamt die verschiedenen Facetten der Opposition zum System von Apathie über Reform bis hin zur revolutionären Umgestaltung darstellte. ${ }^{66}$ Die Transformationsforschung beschäftigt sich nicht nur mit dem Wandel, den die Zivilgesellschaft in diesen Ländern herbeigeführt hat, sondern auch mit dem Wandel, dem die unter den Bedingungen totalitärer Staatlichkeit herausgebildete Zivilgesellschaft nach dem Systemwechsel selbst unterliegt. ${ }^{67}$

Der Begriff Zivilgesellschaft findet sich heute auch in einer prominenten Übersetzung aus dem Italienischen. Der kommunistische Autor Antonio Gramsci (18911937) beantwortete in seinen ab 1929 entstandenen „Gefängnisheften“ die Frage, warum die sozialistische Revolution im rückständigen Rußland Erfolg hatte, aber im Westen scheiterte, mit einem nachgerade klassisch gewordenen Bild:

Im Osten war der Staat alles, die Zivilgesellschaft war in ihren Anfängen und gallertenhaft; im Westen bestand zwischen Staat und Zivilgesellschaft ein richtiges Verhältnis, und beim Wanken des Staates gewahrte man sogleich eine robuste Struktur der Zivilgesellschaft. Der Staat war nur ein vorgeschobener Schützengraben, hinter welchem sich eine robuste Kette von Festungen und Kasematten befand $[\ldots],{ }^{68}$

Die Verwendung von „Zivilgesellschaft" in dieser Bedeutung mag überraschen. Eine 1980 in der DDR erschienene Auswahl von Schriften Gramscis verwendete denn auch den (klassenkämpferisch verstandenen) Begriff der bürgerlichen Gesellschaft, um die italienische „società civile“ zu übertragen. ${ }^{69}$ Die Herausgeber des in den 1990er Jahren begonnenen „Deutschen Gramsci-Projekts“ erklären ihre Wortwahl damit, ,der Quelle ständiger Verwechslung mit der sozialökonomischen Formation [keine] weitere Nahrung "70 geben zu wollen.

Gramscis Überlegungen zur ,società civile“, eine in marxistischer Tradition stehende Lesart von Hegel, unterscheiden sich in jedem Fall klar von einem liberalen Ansatz. Sie ist gerade nicht freiheitlicher ,oikos“, der von staatlichem Regulierungseinfluß frei oder freizuhalten ist. Sie ist vielmehr ein Raum, in dem die den Staat beherrschende Gruppe auch gesellschaftliche Hegemonie ausübt. ${ }^{71}$ Staat und Zivilge-

65 Ausführlich hierzu Ernest Gellner, Die Bedingungen der Freiheit, Die Zivilgesellschaft und ihre Rivalen, deutsch 2. Aufl. 2001; Michael Walzer, Was heißt zivile Gesellschaft?, in: Bert van den Brink/ Willem van Reijen (Hrsg.), Bürgergesellschaft, Recht und Demokratie, 1995, S. 44-70; Agnes Arndt, Intellektuelle in der Opposition, Diskurse zur Zivilgesellschaft in der Volksrepublik Polen, 2007.

${ }^{66}$ Hierzu Agnes Arndt, Semantisches Mißverständnis, Der Begriff ,Zivilgesellschaft" spielte in Polen keine zentrale Rolle, in: WZB-Mitteilungen, Heft 118, 2007, S. 11-13.

67 Hierzu Aron Buzogány/Rolf Frankenberger (Hrsg.), Osteuropa, Politik, Wirtschaft und Gesellschaft (Weltregionen im Wandel, Bd. 2), 2007.

${ }^{68}$ Antonio Gramsci, Gefängnishefte, Bd. 4, hrsg. von Klaus Bochmann/Wolfgang Fritz Haug, Hefte 6-7, 1992, Heft 7 \& 16 (S. 874).

69 Vgl. Antonio Gramsci, Zu Politik, Geschichte und Kultur, Ausgewählte Schriften, hrsg. von Guido Zamis, 1980, S. 272-273.

70 Klaus Bochmann, Editorische Vorbemerkung, in: Antonio Gramsci, Gefängnishefte, Bd. 4, hrsg. von Klaus Bochmann, 1991, S. 18. Zutreffend können sie sich darauf berufen, dass Gramsci zwischen der „società civile“ und der ,società borghese " unterscheidet.

${ }^{71}$ Hierauf weist zu Recht auch Noberto Bobbio, Gramsci and the Concept of Civil Society, in: Keane (Fn. 13), S. 73-99 (S. 77 ff.), hin. 
sellschaft dienen bei Gramsci wechselseitig dem Schutz der herrschenden Klasse. Revolutionäre Veränderungen zugunsten des Proletariats in den kapitalistischen Staaten der Zwischenkriegszeit, auf die seine Überlegungen zielen, können nicht durch gewaltsame Angriffe auf den Staat, sondern nur durch die langsame Eroberung der „società civile“ erreicht werden. ${ }^{72}$ Das nämlich ist eine Besonderheit der Konzeption Gramscis: Die „società civile“ ist bei ihm zwar ökonomisch und politisch determiniert, aber dennoch dank ihrer Zwischenstellung handlungs- und reaktionsfähig, so dass von ihr aus Veränderungen der staatlichen Macht- und der wirtschaftlichen Produktionsverhältnisse bewirkt werden können.

Ist somit der Funktionszusammenhang der Hegemoniebildung für Gramsci ein entscheidendes Moment der „,società civile“"73 so scheint der Begriff „Zivilgesellschaft", der nach den Ereignissen von 1989/90 auf der Suche nach einem geistigen Ahnherren linker Provenienz mit Gramsci in Verbindung gebracht wurde, für Gramscis Konzept nicht gut gewählt. Jedenfalls verträgt sich Gramscis Ansatz kaum mit der herrschaftskritischen Konnotation, die der Zivilgesellschaft heute gemeinhin beigelegt wird.

Schließlich sei der Hinweis erlaubt, dass sich das Phänomen „Zivilgesellschaft“ nicht auf den innerstaatlichen Raum begrenzen läßt: Es wird diskutiert, ob es eine europäische oder gar eine globale Zivilgesellschaft gibt. ${ }^{74}$

\section{b) Abgrenzungen $z u$ anderen gesellschaftlichen (Teil-)Formationen}

Zivilgesellschaft ist ferner abzugrenzen von Begriffen und Formationen wie „,neue soziale Bewegungen“75, „Nichtregierungsorganisationen “76, „Dritter Sektor/NonProfit-Organisationen/privater Sektor" ${ }^{677}$ und „Bürgerinitiativen“"78. Dies kann hier

72 Die Ausführungen folgen den Darlegungen von Joseph A. Buttigieg, Gramscis Zivilgesellschaft und die civil-society-Debatte, in: Das Argument, Zeitschrift für Philosophie und Sozialwissenschaften 206: Ethik und Staat, 36 (1994) 4/5, S. 529-554.

73 Hier sind freilich verschiedene Lesarten möglich. Peter Alheit, Zivile Kultur, Verlust und Wiederaneignung der Moderne, 1994, S. 291 f., 297f., erkennt hierin die Möglichkeit für einen zivilisierenden Bildungsprozess.

${ }^{74}$ Hierzu nur: John Keane, Global Civil Society?, 2003; David Chandler, Constructing Global Civil Society, Morality and Power in International Relations, 2004; Michèle Knodt/Barbara Finke (Hrsg.), Europäische Zivilgesellschaft, Konzepte, Akteure, Strategien, 2005; Ingo K. Richter/Sabine Berking/Ralf Müller-Schmid (Hrsg.), Building a Transnational Civil Society, Global Issues and Global Actors, 2006; Christiane Frantz, Transnationale Zivilgesellschaft in Europa: Traditionen, Muster, Hindernisse, Chancen, 2009; Elisabeth Conradi, Kosmopolitische Zivilgesellschaft, Inklusion durch gelingendes Handeln, 2011.

75 Zur Bandbreite vgl. Roland Roth/Dieter Rucht (Hrsg.), Neue soziale Bewegungen in der Bundesrepublik Deutschland, 1987; Roland Roth, Demokratie von unten, Neue soziale Bewegungen auf dem Weg zur politischen Institution, 1994.

${ }_{76}$ Vgl. nur Elmar Altvater/Achim Brunnengräber/Markus Haake/Heike Walk (Hrsg.), Vernetzt und Verstrickt, Nicht-Regierungs-Organisationen als gesellschaftliche Produktivkraft, 1997.

77 Umfassend hierzu die Beiträge in Rupert Graf Strachwitz (Hrsg.), Dritter Sektor - Dritte Kraft, Versuch einer Standortbestimmung, 1998; Karl Birkhölzer/Ansgar Klein/Eckhard Priller, Dritter Sektor/ Drittes System: Theorie, Funktionswandel und zivilgesellschaftliche Perspektiven (Bürgergesellschaft und Demokratie, Bd. 20), 2004; Craig N.Murphy, Private Sector, in: Thomas G. Weiss/Sam Daws (Hrsg.), The Oxford Handbook on the United Nations, 2007, S. 264-276. 
aus Raumgründen nicht geleistet werden; letztendlich ist der Begriff der Zivilgesellschaft umfassender.

\section{c) Fazit}

Hier soll nicht der Versuch einer eigenen Definition von Zivilgesellschaft unternommen werden. Vielmehr gilt es jene Elemente zusammenzufassen, die mit Blick auf die weitere Untersuchung von Bedeutung sind und eine kategoriale Lokalisierung ermöglichen. ${ }^{79}$

Zivilgesellschaft ist im nichtstaatlichen Bereich angesiedelt und konstituiert sich in einer Vielzahl von freiwilligen Zusammenschlüssen von Personen. Diese Individuen können sich in ihren jeweiligen Rollen konsekutiv oder gleichzeitig in unterschiedlichen Zusammenschlüssen aktiv engagieren oder solche Zusammenschlüsse als Sympathisanten unterstützen. ${ }^{80}$ Die Zusammenschlüsse können hinsichtlich ihres Organisationsgrades und ihrer Dauerhaftigkeit untereinander stark variieren. ${ }^{81}$ Sie können auf ein Ziel oder Projekt begrenzt sein oder mehrere Ziele verfolgen. Zu ihren Zielen können ebenso die Mitgliederinteressen wie Gemeinwohlinteressen zählen. Nicht selten rücken die Akteure in Aktionsfelder ein, aus denen sich entweder gesellschaftliche Institutionen wie die Familie oder der Staat zurückziehen. „Idealerweise ist die zivile Gesellschaft ein Handlungsraum von Handlungsräumen. " ${ }^{82}$

Die Zivilgesellschaft ist dementsprechend als ein Konglomerat von Akteuren zu bezeichnen, deren Spektrum ,von Attac bis zur Milliardärsstiftung“ ${ }^{83}$ reicht. In vielen Staaten sind ihre Handlungsspielräume eingeengt,${ }^{84}$ nicht selten sind die handelnden Personen bedroht oder akut gefährdet, ${ }^{85}$ insbesondere, wenn sie Funktionen auf

78 Einzelheiten bei Peter John, Bedingungen und Grenzen politischer Partizipation in der Bundesrepublik Deutschland am Beispiel von Bürgerinitiativen, Eine historisch-deskriptive Analyse, 1979 , S. 52 ff.; Gunnar Folke Schuppert, Bürgerinitiativen als Bürgerbeteiligung an staatlichen Entscheidungen, Verfassungstheoretische Aspekte politischer Beteiligung, in: AöR 1977, S. 369-409.

$79 \mathrm{Vgl}$. auch die Übersicht in: Enquete-Kommission „Zukunft des Bürgerschaftlichen Engagements “ Deutscher Bundestag (Hrsg.), Bürgerschaftliches Engagement und Zivilgesellschaft, 2002.

${ }^{80}$ Zur Datenlage in Deutschland vgl. Thomas Gensicke/Sibylle Picot/Sabine Geiss (Hrsg.), Freiwilliges Engagement in Deutschland 1999-2004, Ergebnisse einer repräsentativen Trenderhebung zu Ehrenamt, Freiwilligenarbeit und bürgerschaftlichem Engagement, 2005.

${ }^{81} \mathrm{Vgl}$. Ingo Bode, Organisationsentwicklung in der Zivilgesellschaft, Grenzen und Optionen in einem unerschlossenen Terrain, in: Forschungsjournal Neue Soziale Bewegungen 2/2007, S. 92-101.

82 Walzer (Fn. 65), S. 56, auch 69.

83 Heribert Prantl, Doch, es gibt das Positive, in: Süddeutsche Zeitung vom 30. April/1. Mai 2009, S. 4 .

${ }^{84}$ Siehe die Beiträge in: Heiko Pleines (Hrsg.), Participation of Civil Society in New Modes of Governance, The Case of New EU Member States, Part 2: Questions of Accountability (Forschungsstelle Osteuropa, Bremen: Arbeitspapiere und Materialien, Nr. 74), 2006; Alfred B. Evans (Hrsg.), Russian civil society, A critical assessment, 2006.

85. Indiz hierfür ist die „Erklärung zu den Menschenrechtsverteidigern“, GV-ReS. 53/144 vom 9. Dezember 1998, die den Schutz dieser Personen verbessern will; hierzu Benjamin Beuerle, Zur Umsetzung der „Erklärung zu den Menschenrechtsverteidigern“ fünf Jahre nach ihrer Verabschiedung - eine Bestandsaufnahme, in: MenschenRechtsMagazin 2004, S. 47-52. 
den Gebieten Demokratieförderung, Umgang mit Globalisierungsfolgen und Schutz der Menschenrechte wahrnehmen. ${ }^{86}$

\section{II. Öffentlichkeit und ihre Funktionen im republikanischen Rechtsstaat}

Hier kann nicht auf die - Habilitationsschriften füllende - Diskussion um den Begriff des Rechtsstaats, sein vorgebliches Sich-Überlebt-Haben und die mitunter behauptete inhaltliche Unbestimmtheit eingegangen werden. ${ }^{87}$ Im Anschluß an Katharina Sobota ist in aller Kürze darauf hinzuweisen, dass neben der Bindung an Recht und Gesetz (Art. 20 Abs. 3 GG) und dem Willkürverbot (hergeleitet aus Art. 3 Abs. 1 GG) der Begründungszwang und die Öffentlichkeit des Staatshandelns zu den fundamentalen Bestandteilen des Rechtsstaatsprinzips gehören. ${ }^{88}$ Der Staat, der - wie es in Art. 1 Abs. 1 des Herrenchiemseer Entwurf für das Grundgesetz so treffend formuliert wurde - um der Bürger willen da ist, ${ }^{89}$ kann Heimlichkeit nicht zu seiner Maxime erheben. ${ }^{90}$ Verantwortlichkeit der handelnden Personen und Kontrollierbarkeit ihres Handelns sind unentbehrliche Charakteristika des Rechtsstaats, ${ }^{91}$ die eine Öffentlichkeit erfordern. ${ }^{92}$

Bereits 1848 formulierte Carl Welcker:

Das ganze politische Leben freier Völker bewegt sich in der Oeffentlichkeit, wie man athmet in der Luft. $^{93}$

86 Siehe die Fallstudien aus sechs Ländern auf vier Kontinenten in: Jochen Franzke (Hrsg.), Making Civil Societies Work - Zivilgesellschaft und gesellschaftliche Praxis (Potsdamer Textbücher, Bd. 9), 2006.

87 Vgl. nur Peter Saladin, Verantwortung als Staatsprinzip, Ein neuer Schlüssel zur Lehre vom Rechtsstaat, 1984; Philip Kunig, Das Rechtsstaatsprinzip, Überlegungen zu seiner Bedeutung für das Verfassungsrecht der Bundesrepublik Deutschland, 1986; Ulrich Karpen, Der Rechtsstaat des Grundgesetzes, 1992; Wolf Heintschel von Heinegg, Rechtsstaatlichkeit in Deutschland, in: Rainer Hofmann u.a. (Hrsg.), Rechtsstaatlichkeit in Europa, 1996, S. 107-139; Eberhard Schmidt-Aßmann, Der Rechtsstaat, in: HStR II (3. Aufl. 2004), §26, S. 541-612.

88 Katharina Sobota, Das Prinzip Rechtsstaat, Verfassungs- und verwaltungsrechtliche Aspekte, 1997, S. $471 \mathrm{ff}$.

89 Vgl. JöR N.F. 1, 1951, S. 48.

90 Vgl. zu dieser Frage grundsätzlich Jürgen Bröhmer, Transparenz als Verfassungsprinzip, Grundgesetz und Europäische Union (Ius Publicum, Beiträge zum Öffentlichen Recht, Bd. 106), 2002.

91 Gegen die Marginalisierung des Rechtsstaats bei der Verwaltungsmodernisierung wendet sich nachdrücklich Karl-Peter Sommermann, Verwaltung im Rechtsstaat, in: Klaus König (Hrsg.), Deutsche Verwaltung an der Wende zum 21. Jahrhundert, 2002, S. 87-118.

92 Das heißt natürlich nicht, dass jede amtlicherseits vorliegende Information - etwa die Höhe des zu versteuernden Einkommens von Privatleuten - jedermann zugänglich sein muss. Der Schutz individueller Daten schränkt das Öffentlichkeitsprinzip ebenso ein wie das Interesse an der Funktionsfähigkeit des Staatswesens.

93 Carl Welcker, Öffentlichkeit, in: Carl von Rotteck/ders. (Hrsg.), Das Staatslexikon, Encyklopädie der sämmtlichen Staatswissenschaften für alle Stände, 1848 (Nachdruck 1990), 10. Bd.; S. 246-282 (S. 247). 
Doch wie sieht nun die Öffentlichkeit ${ }^{94}$ aus, die diese Funktionen ausübt? ${ }^{95}$ Ist sie gleichbedeutend mit der im ersten Teil charakterisierten Zivilgesellschaft? Auch hier nur einige Stichworte: Einerseits kann Öffentlichkeit von der privaten Sphäre (dem griechischen ,oikos“) abgegrenzt, andererseits kann sie vom Bereich des Geheimen unterschieden werden. Wird Öffentlichkeit als Publizität staatlichen Handelns begriffen, so verlangt sie gleichzeitig nach dem Publikum, also ,der“ Öffentlichkeit im Sinne einer Personenallgemeinheit. Anders als die typischerweise auf eine gewisse Dauerhaftigkeit angelegten und nach gewissen Ordnungsprinzipien gegliederten zivilgesellschaftlichen Akteure kann das Publikum sich spontan bilden, unstrukturiert zusammensetzen und nur situativ, zeitlich und örtlich begrenzt bestehen. ${ }^{96} \mathrm{Je}$ nach Standort und Funktion des staatlichen Akteurs kommt dem Publikum eine unterschiedliche Rolle zu. ${ }^{97}$ Schließlich ist auch die Öffentlichkeit kein herrschaftsfreier Raum. Der Zugang zum Diskurs und die Auswahl von Themen sind von unterschiedlich begründeten Machtpositionen, zumindest von einer generellen Etabliertheit abhängig. ${ }^{98}$

Der Rechtsstaat des Grundgesetzes ist republikanisch (Art.20 GG); Deutschland ist eine Republik (in Anlehnung an Art. 1 Satz 1 WRV). Zwar hat die Republik vielfältige Bedeutungen - Staatsbegriff, Staatsform, freiheitliches Gemeinwesen, Idealstaat -, doch sind diese in Teilen , in die Begriffe Demokratie und Rechtsstaat übergegangen“"99. Aber der Republik wohnt begrifflich ein starker eigenständiger

94 Zum Begriff ausführlich Hölscher (Fn. 47), S. 81 ff., $118 \mathrm{ff}$. Vgl. auch Alfred Rinken, Das Öffentliche als verfassungstheoretisches Problem, dargestellt am Rechtsstatus der Wohlfahrtsverbände (Schriften zum Öffentlichen Recht, Bd. 152), 1971, S. $23 \mathrm{ff}$., $248 \mathrm{ff} ., 273 \mathrm{ff}$.

${ }^{9}$ Hierzu bereits Habermas (Fn. 9), S. 154 ff., 304 ff.; ausführlich die vom öffentlichen Interesse oder Gemeinwohl ausgehende Untersuchung von Peter Häberle, Öffentliches Interesse als juristisches Problem, Eine Analyse von Gesetzgebung und Rechtsprechung, 1970 (2. Aufl. 2006). Aus neuerer Sicht und kritisch gegenüber Habermas' inhaltslosem Öffentlichkeitsbegriff: Jürgen Gerhards/Friedhelm Neidhardt, Strukturen und Funktionen moderner Öffentlichkeit: Fragestellungen und Ansätze, in: Stefan Müller-Doohm/Klaus Neumann-Braun (Hrsg.), Öffentlichkeit, Kultur, Massenkommunikation, Beiträge zur Medien- und Kommunikationssoziologie, 1991, S.31-89; Karl-Siegbert Rehberg, Die „Öffentlichkeit" der Institutionen, Grundbegriffliche Überlegungen im Rahmen der Theorie und Analyse institutioneller Mechanismen, in: Gerhard Göhler (Hrsg.), Macht der Öffentlichkeit - Öffentlichkeit der Macht, 1995, S. 181-211; Ulrich Sacrinelli, Demokratiewandel im Zeichen medialen Wandels? Politische Beteiligung und politische Kommunikation, in: A. Klein/R. Schmalz-Bruns (Hrsg.), Politische Beteiligung und Bürgerengagement in Deutschland, Möglichkeiten und Grenzen, 1997, S. 314-345.

${ }_{96}$ Darauf macht zu Recht Stefan Marschall, Öffentlichkeit und Volksvertretung, Theorie und Praxis der Public Relations von Parlamenten (Studien zur Kommunikationswissenschaft, Bd. 40), 1999, S. 38f,, aufmerksam. Hierzu bereits Heinhard Steiger, Zur Funktion der Öffentlichkeit parlamentarischer Verhandlungen heute, in: Studium generale 1970, S. 710-733 (S. 723 ff.).

${ }_{77}$ Klassisch zu den verschiedenen Publikumsrollen Niklas Luhmann, Politische Soziologie, 2010, S. 353 ff. Der Text entstand als Vorlesungsmanuskript Ende der 1960er Jahre.

98 So auch Gerhards/Neidhardt (Fn. 95), S. 59. Dementsprechend schildert Ulrich Rödel, Zivilgesellschaft und selbstorganisierte Öffentlichkeiten: in Forschungsjournal Neue Soziale Bewegungen 1994, S.34-45 (S.36f.), die Bemühungen Neuer Sozialer Bewegungen, die Ausgrenzung ihrer Themen aus der institutionalisierten politischen Öffentlichkeit zu überwinden. Die Neugründung periodisch erscheinender Printmedien wird als extensive Erweiterung des öffentlichen Raumes begriffen. Diese Funktion übernimmt heute das Internet.

${ }_{99}$ Hierzu prägnant Josef Isensee, Republik - Sinnpotential eines Begriffs, Begriffsgeschichtliche Stichproben, in: JZ 1981, S. 1-8 (S. 8). Zum Unterschied, den das Grundgesetz zwischen Rechtsstaat und Demokratie macht, siehe Heinrich Amadeus Wolff, Das Verhältnis von Rechtsstaatsprinzip und De- 
Bezug zur Öffentlichkeit im Sinne der Bürgerschaft inne. Seit der Definition Cice$\operatorname{ros}^{100}$

Est igitur res publica res populi, populus autem non omnis hominum coetus quoquo modo congregatus, sed coetus multitudinis iuris consensu et utilitatis communione sociatus

wird diskutiert, welcher Grad von Unmittelbarkeit notwendig ist, um ,den Staat“ zur Sache des Volkes, zur wahren Res populi zu machen. ${ }^{101}$ So wird mit Blick auf die zu wählende Staatsform die These vertreten, es komme nicht notwendigerweise darauf an, dass die Interessen des Volkes vom Volke wahrgenommen werden, sondern darauf, dass sie überhaupt wahrgenommen werden. ${ }^{102} \mathrm{Am}$ besten geeignet sei hierfür eine gemischte Verfassung, die monarchische, aristokratische und demokratische Elemente enthält ${ }^{103}$ und dem Gemeinwohl diene (res ad communem utilitatem) ${ }^{104}$. Damit gewinnt der Gedanke der Partnerschaft Bedeutung, der dazu beiträgt, das Volk zu konstituieren. ${ }^{105}$ Einem solchen Interessenverband gegenüber kann sich der Staat als Gegenstand und Wahrer des Interesses nicht abschotten; er muss - in welcher konkreten Form auch immer - grundsätzlich offen sein. Ist ein Staatswesen demokratisch verfaßt, so liegt diesbezüglich eine klare Grundsatzentscheidung vor. Typischerweise ist die Beteiligung des Volkes aber stark formalisiert, so dass sich die Frage nach den Ansatz- und Wirkungsmöglichkeiten der Öffentlichkeit ebenfalls stellt.

Nachfolgend soll die Bedeutung der Öffentlichkeit für die drei Staatsgewalten skizziert werden.

\section{Legislative und Öffentlichkeit}

\section{a) Das Parlament: Kontrolleur und Kontrollierter}

Das aus allgemeinen, unmittelbaren, freien, gleichen und geheimen Wahlen (Art. 38 Abs. 1 Satz 1 GG) hervorgegangene Parlament ist einerseits selbst „Öffentlichkeit“, da es neben der Gesetzgebungsfunktion (Art. 77 Abs. 1 Satz 1 GG) auch die Aufgabe hat, den von ihm gewählten (Art. 63 GG) und ihm verantwortlichen Kanzler und die Bundesregierung (Art. 43 Abs. 1 GG) zu kontrollieren. Andererseits sind der Bundestag und die Abgeordneten - als „Vertreter des ganzen Volkes“ (Art. 38 Abs. 1 Satz 2 GG) - selbst nach Art. 42 Abs. 1 und 3 GG der Kontrolle durch die

mokratieprinzip, in: Dietrich Murswiek/Ulrich Storost/Heinrich A. Wolff (Hrsg.), Staat - Souveränität - Verfassung, FS für Helmut Quaritsch, 2000, S. 73-93.

100 Marcus Tullius Cicero, De re publica, 51 v.Chr., 1.39-41.

101 Vgl. nur Wilfried Röhrich, Im Umgang mit der Macht: Das Prinzip der Repräsentation, in: Stefan Brink/Heinrich Amadeus Wolff (Hrsg.), Gemeinwohl und Verantwortung, FS für Hans Herbert von Arnim, 2004, S. 639-651 m.w.Nw.

102 So Werner Suerbaum, Vom antiken zum frühmittelalterlichen Staatsbegriff, Über Verwendung und Bedeutung von Res publica, Regnum, Imperium und Status von Cicero bis Jordanis (Orbis Antiquus, Heft 16/17), 1961, S. 13 ff. m.w.Nw. Ihrn folgend Isensee (Fn. 99), S. 3.

103 Cicero (Fn. 100), 1.45, 1.69.

104 Marcus Tullius Cicero, Pro Sestio, 56 v.Chr., 91.

105 Diesen Gedanken entwickelt Elizabeth Asmis, The State as a Partnership: Cicero's Definition of Res Publica in his Work On the State, in: History of Political Thought XXV/4 (2004), S. 569-598. 
Öffentlichkeit ${ }^{106}$ ausgesetzt. Auch Untersuchungsausschüsse des Bundestages erheben die erforderlichen Beweise in öffentlicher Sitzung (Art. 44 Abs. 1 Satz 1 GG). Der Bundesrat verhandelt ebenfalls öffentlich (Art. 52 Abs. 3 Satz 3 GG). Die Öffentlichkeit kann jeweils ausgeschlossen werden.

Diese Vorschriften reflektieren aufklärerisches Gedankengut: Erst die französische Revolution brachte die Öffentlichkeit ins Parlament, wohingegen das britische Parlament und ihm zunächst folgend der amerikanische Kongress die öffentliche Debatte nicht gekannt hatten und auch Berichterstattung nur eingeschränkt stattgefunden hatte. ${ }^{107}$ Für Deutschland brachte die Paulskirchenverfassung von 1848 ( $\left.\$ 111\right)$ den Durchbruch des Öffentlichkeitsprinzips, das sich im Anschluß in der Reichsverfassung von 1871 (Art. 22) und in der Weimarer Reichsverfassung von 1919 (Art. 29) findet.

Eine repräsentative Regierungsform kann auf die Öffentlichkeit parlamentarischer Debatten nicht verzichten: Wenn Herrschaft im Zeichen der Volkssouveränität durch Vertreter ausgeübt wird, so haben die Vertretenen darauf Anspruch, über die Aktivitäten der Repräsentanten und ihre Gründe informiert zu sein. ${ }^{108}$ Das Volk als Souverän kann seine Kontrollrechte nur ausüben, wenn ihm das öffentlich tagende Parlament Zugang und so die Möglichkeit der informierten Diskussion zwischen Repräsentanten und Repräsentierten eröffnet. So können Inhalte geklärt und die Legitimität sowie die Akzeptierbarkeit parlamentarischer Entscheidungen erhöht werden. ${ }^{109}$

Öffentliches Verhandeln von Argument und Gegenargument, öffentliche Debatte und öffentliche Diskussion sind wesentliche Elemente des demokratischen Parlamentarismus. ${ }^{110}$

Außerdem wird die Grundlage gelegt dafür, dass die handelnden Politiker zur Verantwortung gezogen werden können, ${ }^{111}$ aber nicht nur im Sinne nachholender Kontrolle, sondern zunehmend auch im Wege vorhabenbegleitender Rechtfertigung $^{112}$.

„Verhandeln“ im Sinne der vorstehend zitierten Vorschriften des Grundgesetzes erfaßt die Plenarsitzungen und ist dabei weit zu verstehen, erstreckt sich also nicht nur auf die eigentliche Debatte, sondern auf den gesamten Prozess der Entscheidungsfindung. Umstritten ist, ob auch die Ausschüsse dem Öffentlichkeitsprinzip unterliegen. \69 Abs. 1 Satz 1 GeschO-BT sieht die grundsätzliche Nichtöffentlich-

\footnotetext{
106 Aus politikwissenschaftlicher Sicht: Stefan Marschall, Parlamentarische Öffentlichkeit - Eine Feldskizze, in: Heinrich Oberreuter/Uwe Kranenpohl/Martin Sebaldt (Hrsg.), Der Deutsche Bundestag im Wandel, Ergebnisse neuerer Parlamentarismusforschung, 2. Aufl. 2002, S. 168-186.

107 Siehe Steiger (Fn. 96), S. 710 f.

108 Hans Hugo Klein, in: Maunz/Dürig, Komm. z. GG, 39/2001, Art. 42 Rn. 9, 26 ff.

109 Ausführlich zum Vorstehenden: Leo Kißler, Die Öffentlichkeitsfunktion des Deutschen Bundestages, Theorie, Empirie, Reform (Beiträge zur Politischen Wissenschaft, Bd. 25), 1976; Hans-Jürgen Hett, Die Öffentlichkeit der Parlamentsverhandlungen, das Grundrecht der Informationsfreiheit und Informationspflichten der Exekutive, 1987, S. 51 ff.; Joachim Link, Die Parlamentsöffentlichkeit, in: ZParl 23 (1992), S. 673-708.

110 BVerfGE 70, 324 (355).

111 Hierzu Röhrich (Fn. 101), S. $644 \mathrm{ff}$.

112 Zutreffend Steiger (Fn. 96), S. 719, der freilich schon Anfang der 1970er Jahre beklagt, dass dies in der Praxis nicht erreicht werde, S. $720 \mathrm{ff}$.
} 
keit $^{113}$ von Ausschußsitzungen vor. Dies ist verfassungsrechtlich zulässig ${ }^{114}$ und soll den Abgeordneten ein freieres Redeverhalten ermöglichen sowie das Aushandeln von Kompromissen erleichtern. ${ }^{115} \mathrm{Zu}$ bedenken ist aber, dass der Bundestag große Teile seiner Arbeit in die Ausschüsse verlagert, wo die Spezialisten unter den Abgeordneten die Entscheidungen herstellen, deren Ergebnisse im Plenum dann nachvollzogen werden. ${ }^{116}$ Angesichts dessen erscheint es sinnvoll, die Ausschüsse als wesentlichen Ort parlamentarischer Arbeit ebenfalls dem Öffentlichkeitsgebot im Sinne des Publikumszugangs zu unterstellen. ${ }^{117}$ Zwar besteht nach der Geschäftsordnung des Bundestages ( $\$ 69$ Abs. 1 Satz 2 GeschO-BT) die Möglichkeit, die Öffentlichkeit zuzulassen. ${ }^{118}$ Doch hiervon wird wenig Gebrauch gemacht. ${ }^{119}$ Seit 1995 ermöglicht $\$ 69$ a GeschO-BT die sogenannte erweiterte öffentliche Ausschußberatung, an der alle Abgeordneten der fachlich beteiligten Ausschüsse teilnehmen können, womit quasi eine verkleinerte Plenumssituation hergestellt und das Plenum von besonders fachspezifischen Themen entlastet wird. ${ }^{120}$ Hierbei soll zum Abschluß eine öffentliche Aussprache durchgeführt werden, um die Beschlußempfehlung und den Bericht des federführenden Ausschusses zu beschließen.

Das gegen eine generelle Ausschußöffentlichkeit vorgebrachte Effektivitätsargument kann akzeptiert werden, weil Anfang und Ende des parlamentarischen Verfahrens im Plenum öffentlich sind. ${ }^{121}$ Nicht verhehlt werden soll an dieser Stelle auch, dass das Interesse der Medien an der Alltagsarbeit eher gering ist und oftmals gerade für diese markanteren Eckpunkte, die personalisierbar und visualisierbar sind, ausreicht. ${ }^{122}$

Von der Berichterstattung ist die Direktübertragung von Debatten, meist nach vorheriger Regierungserklärung zu unterscheiden. ${ }^{123}$ War dieses Format klassischerweise im öffentlich-rechtlichen Rundfunk und Fernsehen beheimatet und musste

${ }^{113}$ Klein (Fn. 108), Rn. 38: Lediglich kein Zutritt des Publikums, aber Erklärungs- oder Berichtsöffentlichkeit.

114 BVerfGE 1, 144 (152).

115 So Jürgen Jekewitz, Parlamentsausschüsse und Ausschußberichterstattung, Zu Herkunft, Aufgabe und Inhalt einer überkommenen Institutionen, in: Der Staat 25 (1986), S. 399-424 (S. 417 ff.).

${ }^{116}$ Helmuth Schulze-Fielitz, Theorie und Praxis parlamentarischer Gesetzgebung - besonders des 9. Deutschen Bundestages (1980-1983) - (Schriften zum Öffentlichen Recht, Bd. 528), 1988, S.304ff.; Hett (Fn. 109), S. $148 \mathrm{ff}$.

117 So bereits Heinrich Oberreuter, Scheinpublizität oder Transparenz? Zur Öffentlichkeit von Parlamentsausschüssen, in: ZParl 6 (1975), S.77-92. Aktuell: Martin Morlock, in: Horst Dreier (Hrsg.), Grundgesetz-Kommentar, Bd. 2, 2. Aufl. 2006, Art. 42 Rn. 24 m.w.Nw. Für eine fakultative Sitzungsöffentlichkeit plädiert Klein (Fn. 108), Rn. 44 f.

118 Außerdem gibt es nach $\$ 70$ GeschO-BT die Möglichkeit, öffentliche Anhörungssitzungen einzuberufen. Bei diesen sollen gerade auch Experten aus der Zivilgesellschaft zu Wort kommen.

119 Klein (Fn. 108), Rn. 40; ferner Susanne Linn/Frank Sobolewski, So arbeitet der Deutsche Bundestag, Organisation und Arbeitsweise, Die Gesetzgebung des Bundes, 25. Aufl. 2012, S.30. Der Text kann unter https://www.btg-bestellservice.de/pdf/10041000.pdf abgerufen werden (zuletzt besucht am 1. März 2012).

120 Auch dies geschieht eher selten; vgl. Hans-Achim Roll, Geschäftsordnung des Deutschen Bundestages, Kommentar, 2001, \69a, Rn. 1; Schreiner/Linn (Fn. 119), S. 51.

121 So auch Bröhmer (Fn. 90), S. 106 ff. Skeptischer Kißler (Fn. 109), S. $328 \mathrm{ff}$.

122 Dies betont auch Marschall (Fn. 96), S. $70 \mathrm{ff}$.

123 Georg Paul Hefty, Für und wider das Parlamentsfernsehen, in: Frankfurter Allgemeine Zeitung vom 3. Dezember 2007, S. 14. 
dort mit anderen Programminhalten konkurrieren, so verfügt das Parlament mit dem gleichfalls öffentlich-rechtlichen Dokumentationskanal „Phoenix“ seit 1997 über ein Spezialmedium, das gegebenenfalls auch zehn Stunden am Stück überträgt (und dabei achtbare Einschaltquoten erzielt). ${ }^{124}$ Die Direktübertragung erreicht zwar einerseits (weitgehend) ungefiltert das Publikum, prägt aber andererseits die Debatte: ${ }^{125}$ Wer weiß, dass die Kamera läuft, spricht und agiert anders und trägt beispielsweise auch andere, übertragungsgeeignete Kleidung. Es mag auch die Rednerauswahl der Fraktionen beeinflussen, so dass die unbekannteren Fachpolitiker den publikumsbekannten „Allzweckwaffen“ weichen müssen. Gleichzeitig machen sich die Spitzenpolitiker im Parlament rar und suchen lieber die direkte TV-Öffentlichkeit, während der Jahre 1997-2007 vornehmlich bei Sabine Christiansen. ${ }^{126}$

Die Öffentlichkeit, mit der das Parlament es auf diese Weise ,im eigenen Hause“ zu tun bekommt, läßt sich grob in drei Gruppen unterteilen: erstens Schüler, Studenten, Soldaten und sonstige Adressaten politischer Bildungsmaßnahmen, zweitens Besucher aus den Wahlkreisen der Abgeordneten und drittens - die auf einer eigenen Tribüne sitzenden - Pressevertreter. ${ }^{127}$ Alle drei Gruppen sind während der Plenarsitzung in eine passive Zuhörerrolle gezwängt, danach unterscheiden sie sich deutlich: Bei der zweiten Gruppe, den Besuchern aus dem Wahlkreisen, kann ein politisches Interesse vorausgesetzt werden, das zu einer entsprechenden gezielten Kommunikation nicht nur innerhalb der Gruppe, sondern gerade auch mit den „Daheimgebliebenen" führen kann. Demgegenüber ist bei der ersten Gruppe eher mit einer gewissen Apathie zu rechnen, die freilich eine spontane, private Äußerung von (überraschter) Zufriedenheit oder bestätigten Vorurteilen nicht ausschließt. Die Medienvertreter schließlich sind von Berufs wegen verpflichtet, das Erlebte zu kommunizieren, nehmen also eine klar unterscheidbare Sonderrolle ein. Ihre Nachricht muss sich wiederum gegenüber anderen auf dem Markt behaupten. ${ }^{128}$

Das Parlament fungiert somit erstens gegenüber der Regierung als Öffentlichkeit und stellt sich zweitens bei seiner eigenen Arbeit selbst der Öffentlichkeit. Drittens verfügt das Parlament über weitere, wichtige Schnittstellen zur Öffentlichkeit: die eigene Medienarbeit ${ }^{129}$ und die Lobby. Während das Publikum - ob auf der Galerie

${ }^{124}$ Das Parlamentsfernsehen produziert seit 1995 die Bilder selbst; sie können im Berliner Breitbandkabelnetz digital empfangen werden. Einzelheiten Michael F. Feldkamp/Birgit Ströbel, Datenhandbuch zur Geschichte des Deutschen Bundestages 1994-2003 (begründet von Peter Schindler), 2005, S. 794 ff. Für die Zeit davor vgl. Gregor Mayntz, Die Fernsehberichterstattung über den Deutschen Bundestag, Eine Bilanz, in: ZParl 24 (1993), S. 351-366.

${ }_{125}$ Hierzu Armin Burkhardt, Das Parlament und seine Sprache, Studien zu Theorie und Geschichte parlamentarischer Kommunikation, 2003, S. 309 ff. m.w.Nw.

${ }^{126} \mathrm{Vgl}$. Eckart Lohse, Kerben im Mikrofonhals, Der Bundestag geht in die Sommerpause, Macht ja nichts, denn die Politik-Prominenz verbreitet sich ja ohnehin lieber im Fernsehen, in: Frankfurter Allgemeine Sonntagszeitung vom 8. Juli 2007 Nr.27, S. 6; Klaus von Beyme, Der Gesetzgeber, Der Bundestag als Entscheidungszentrum, 1997, S. $250 \mathrm{ff}$.

127 Vgl. Feldkamp/Ströbel (Fn. 124), S. 782 f. Hinzu kommen natürlich Personen, die das Reichstagsgebäude besichtigen.

${ }_{128} \mathrm{Zu}$ den damit verbundenen Fragestellungen etwa Marschall (Fn. 96), S. 47 ff. m.w.Nw.

129 Ausführlich zur „Parlaments-PR“: Marschall (Fn. 96), S. 85 ff., $111 \mathrm{ff}$. Auch wenn der Staat und seine Organe sich am öffentlichen, herrschaftsfreien Diskurs beteiligen, liegt hoheitliches Handeln vor. Hierzu Herbert Bethge, Die staatliche Teilhabe an öffentlicher Kommunikation, in: AfP-Sonderheft 2007, S. 18-21. 
oder medial vermittelt - lediglich zuhören kann, verfügt der Lobbyist über das Mittel der direkten Ansprache und Einflußnahme und interagiert so vor allem mit dem Parlament als Legislativorgan. ${ }^{130}$

\section{b) Das Parlament als Legislativorgan und sein Verhältnis zur Öffentlichkeit}

Heute bestehen vielfältige institutionalisierte Beziehungen, nicht nur zwischen dem Parlament, sondern dem Staat als ganzem und den unterschiedlichsten gesellschaftlichen Akteuren: ${ }^{131}$

Die Gesellschaft des kooperativen Pluralismus und der kooperative Staat leben nicht im Zustand der Distanz, der Nicht-Einmischung und der Nicht-Identifikation zueinander, sondern im Zustand gegenseitiger Durchdringung und Verschränkung.

Auf die von der Korporatismus- und Lobbyismusforschung diskutierten Fragestellungen ${ }^{132}$ kann an dieser Stelle nur hingewiesen werden, beispielsweise Veränderungen bei etablierten Mustern staatlich-verbandlicher Kooperation oder die Ausdifferenzierung der Akteurskonstellationen ${ }^{133}$ und deren Folgen, etwa den zunehmenden Einfluß nur bestimmter Akteure ${ }^{134}$. Der Einfluß mächtiger Normadressaten auf die sie betreffende Normsetzung kann möglicherweise eine Neubewertung des ,allgemeinen" Gesetzes und der Verfassungsstaatlichkeit insgesamt notwendig machen: Jenseits Forsthoffscher Nachrufe auf den klassischen Staat ist der (nach innen) „kooperierende Verfassungsstaat" ${ }^{\prime 135}$ von heute daher vor die Herausforderung gestellt, verfassungsrechtliche Bindungen und europarechtliche Vorgaben unter veränderten

130 Zur Bedeutung der Verbände vgl. Theodor Eschenburg, Herrschaft der Verbände?, 1955; Joseph H. Kaiser, Die Repräsentation organisierter Interessen, 1956 (=unveränderter Nachdruck 1978). Aktuell z. B.: Leo Kißler, Parlament und Gesellschaftliche Interessen, in: Graf von Westphalen (Fn. 109), S. 314346; Martin Sebaldt/Alexander Straßner, Verbände in der Bundesrepublik Deutschland, Eine Einführung, 2004 , S. $140 \mathrm{ff}$.

131 Vgl. bereits Ernst-Hasso Ritter, Der kooperative Staat, Bemerkungen zum Verhältnis von Staat und Wirtschaft, in: AöR 1979, S. 389-413, das nachfolgende Zitat auf S. 409. Umfassend zu dieser Entwicklung die Beiträge in Rüdiger Voigt (Hrsg.), Der kooperative Staat, Krisenbewältigung durch Verhandlung?, 1995.

132 Hierzu Stammer (Fn. 130), S. 9; Thomas von Winter, Vom Korporatismus zum Lobbyismus, Forschungsstand und politische Realität, in: Forschungsjournal Neue Soziale Bewegungen 16/3 (2003), S. 37-44 (S. 40 ff.) m.w.Nw. Für einen breit angelegten Überblick siehe Martin Sebaldt/Alexander Straßner (Hrsg.), Klassiker der Verbändeforschung, 2006.

133 Aus der Perspektive der Elitenforschung mit dem vorsichtigen Hinweis auf Chancen für Angehörige von Nicht-Eliten: Viktoria Kaina, Deutschlands Eliten zwischen Kontinuität und Wandel, Empirische Befunde zu Rekrutierungswegen, Karrierepfaden und Kommunikationsmustern, in: Aus Politik und Zeitgeschichte, B 10/2004, S. 8-15 (S. 14f.).

${ }^{134}$ Arthur Benz, Kooperativer Staat?, Gesellschaftliche Einflußnahme auf staatliche Steuerung, in: A. Klein/R. Schmalz-Bruns (Hrsg.), Politische Beteiligung und Bürgerengagement in Deutschland, Möglichkeiten und Grenzen, 1997, S.88-113 (S.99ff.); Walter Schmitt Glaeser, Die grundrechtliche Freiheit des Bürgers zur Mitwirkung an der Willensbildung, in: Josef Isensee/Paul Kirchhof (Hrsg.), Handbuch des Staatsrechts, Bd. III, 3. Aufl. 2005, §38, Rn. 42 ff. unter Bezugnahme auf Robert A. Dahl, Who governs? Democracy and Power in an American City, 1961.

135 Lothar Michael, Rechtsetzende Gewalt im kooperierenden Verfassungsstaat, Normprägende und normersetzende Absprachen zwischen Staat und Wirtschaft (Schriften zum Öffentlichen Recht, Bd. 901), 2002. 
Bedingungen zu verwirklichen. Holzschnittartige Lösungsvorschläge führen, das macht die Analyse Michaels deutlich, nicht weiter, viel spricht für den Ansatz der kooperativen Verantwortung. ${ }^{136}$ Die in den letzten Jahren verstärkt zu beobachtende Beteiligung von internationalen Anwaltskanzleien an der Gesetzesformulierung bringt zwar zusätzliche Expertise, ist aber eben auch mit dem Risiko des Loyalitätskonfliktes behaftet, wie das Gesetz zur Stabilisierung des Finanzmarktes (2008) zeigt. $^{137}$

Problematisch ist ferner die zunehmende Entmachtung des Parlaments durch (Vor-) Entscheidungen in anderen, überdies nicht oder nicht unmittelbar durch Wahlen legitimierten Gremien ${ }^{138}$ im Rahmen einer extensiv verstandenen, sogenannten deliberativen oder diskursiven Demokratie. ${ }^{139}$ Denn recht eigentlich betrachtet entspricht der vom Grundgesetz konzipierte republikanische Rechtsstaat den diskurstheoretischen Konzeptionen, die Habermas entwickelt, ${ }^{140}$ so dass für ein „emanzipierendes“ oder auch nur aus Bequemlichkeit geschehendes Ausbrechen aus der Verfassungsordnung kein Bedarf besteht.

Sorge muss es allerdings auch bereiten, dass die Parlamentarier nicht nur als gewählte „Vertreter des ganzen Volkes“ anzusehen sind, sondern die Zahl der Vertreter von Partikularinteressen unter ihnen hoch ist: Gewerkschaftsfunktionäre, Verbandsgeschäftsführer, Funktionäre des Bauernverbands, etc. ${ }^{141}$ Die Einrichtung von Institutionen (wie Ombudsstellen), die sich Gemeinwohlinteressen oder den Interessen von ansonsten nicht vertretener oder schwierig zu organisierender Gruppen (Kinder, Embryonen, Steuerzahler) annehmen, könnte hier ein Gegengewicht schaffen ${ }^{142}$ ist aber ihrerseits nicht frei von Folgeproblemen: Besonders problematisch dürfte in

136 Michael (Fn. 135), S. $313 \mathrm{ff}$. und passim.

137 Vgl. nur Thomas Salter, Das Geschäft mit den Gesetzen, in: Die Tageszeitung vom 14. August 2009, abrufbar unter http://www.taz.de/1/politik/deutschland/artikel/1/das-geschaeft-mit-dengesetzen/ (besucht am 1. März 2012).

${ }^{138}$ Hierzu aus neuerer Zeit nur Julia von Blumenthal, Auswanderung aus den Verfassungsinstitutionen: Kommissionen und Konsensrunden, in: Aus Politik und Zeitgeschichte, B 43/2003, S. 9-15; Thomas Puhl, Entparlamentarisierung und Auslagerung statlicher Entscheidungsverantwortung, in: Josef Isensee/Paul Kirchhof (Hrsg.), Handbuch des Staatsrechts, Bd. I, 3. Aufl. 2005, \48. Zur Entmachtung des Parlaments Eckart Klein, Gesetzgebung ohne Parlament?, Vortrag, gehalten vor der Juristischen Gesellschaft zu Berlin am 24. September 2003, 2004.

Diese Entwicklung ist nicht auf das Parlament beschränkt; beispielsweise ist in der Bundesrepublik Deutschland seit längerem das Kabinett als politisches Entscheidungszentrum von Koalitionsausschüssen, uncharmant „Elefantenrunden“ genannt, abgelöst; hierzu Waldemar Schreckenberger, Informelle Verfahren der Entscheidungsvorbereitung zwischen der Bundesregierung und den Mehrheitsfraktionen: Koalitionsgespräche und Koalitionsrunden, in: ZParl 3/1994, S. 329-345.

139 Positiv Habermas (Fn. 64), S. 349 ff.; kritisch Ingeborg Maus, Zur Aufklärung der Demokratietheorie, Rechts- und demokratietheoretische Überlegungen im Anschluß an Kant, 1992, S. 32 ff., 180 ff.; vermittelnd Rainer Schmalz-Bruns, Reflexive Demokratie, Die demokratische Transformation moderner Politik, 1995, S. 102 ff.; Donald D. Searing u. a., Public Discussion in the Deliberative System: Does it Make Better Citizens?, in: British Journal on Political Science 37 (2007), S. 587-618.

140 So auch Bertram Keller, Im Taumel der Freiheit: Demokratie und Repräsentation bei Jürgen Habermas, in: Der Staat 2000, S. 185-207.

${ }^{141}$ Hierzu Eike von Hippel, Machtmißbrauch der Lobby als Herausforderung, in: Stefan Brink/ Heinrich Amadeus Wolff (Hrsg.), Gemeinwohl und Verantwortung, FS für Hans Herbert von Arnim, 2004, S. 79-86 (S. 80); vgl. auch von Beyme (Fn. 126), S. $207 \mathrm{ff}$.

142 Vorschläge bei Eike von Hippel, Rechtspolitik: Ziele, Akteure, Schwerpunkte, 1992, S. 161 f., der das Beispiel Greenpeace aber wohl zu unkritisch sieht. 
praktischer Weise die Frage nach der angemessenen Gewichtung ihres Einflusses sein. Überdies besteht die Gefahr, dass über das Ziel der „wahren“ Gleichberechtigung hinausgeschossen und eine Zersplitterung, ja Refeudalisierung der Gesellschaft bewirkt würde. Die Gleichheit aller Staatsbürger würde abgelöst von einer Gruppenrepräsentanz, bei der sich langfristig wohl Mächtigkeiten durchsetzten und am Ende zu Stimmgewichtungen führten. Dies überwunden zu haben, hat gerade im deutschen Konstitutionalismus lange genug gedauert.

\section{Exekutive und Öffentlichkeit}

Die geheime Verwaltung ${ }^{143}$ als Merkmal der modernen bürokratischen Herrschaft im Sinne Max Webers ${ }^{144}$ wird - neben Armee und Polizei - als Machtmittel gegen die Interessen der bürgerlichen Gesellschaft ${ }^{145}$ oder - anders gewendet - im Sinne des staatlich definierten Gemeinwohls eingesetzt. Der absolute, aber auch noch der konstitutionelle Staat versuchten nicht nur die Gesellschaft sondern auch das Parlament, das noch nicht als Herrschaftsinstrument sondern als Gegenspieler der monarchischen Regierung fungierte, über das Wissen, die Gründe und das Tun der staatlichen Verwaltung im Unklaren zu halten. ${ }^{146}$

\section{a) Entwicklung}

Von dieser gefestigten Ausgangssituation her erscheint der heutige Stand der Verwaltungsöffentlichkeit überraschend groß. Bis in die Anfangsjahre der Bundesrepublik Deutschland war das Amtsgeheimnis kennzeichnend für die Verwaltung. Dabei blieben die Arcana imperii freilich nicht absolut verschlossen, die Entscheidung über Zeitpunkt, Inhalt, Umfang und Empfänger von Informationsweitergabe lag aber frei und unkontrolliert bei der Verwaltung.

Die späten 1960er Jahre brachten in der Bundesrepublik Deutschland eine signifikante Ausweitung leistungs- und sozialstaatlicher Verwaltungsprogramme; ${ }^{147}$ gleich-

${ }^{143}$ Eine frühe Kritik formulierte Karl Freiherr vom Stein, Brief an Gagern vom 24. August 1821, in: Freiherr vom Stein, Briefe und amtliche Schriften, Bd. VI, bearb. von Alfred H. von Wallthor, 1965 , Nr. 368 (S. 381), ,[...] daß wir fernerhin von besoldeten, buchgelehrten, interessenlosen und ohne Eigentum seienden Buralisten regiert werden. Das geht, so lange es geht. [...] sie erheben ihr Gehalt aus der Staatskasse und schreiben, schreiben, schreiben im stillen, mit wohlverschlossenen Türen versehenen Büro, unbekannt, unbemerkt, ungerühmt, und ziehen ihre Kinder wieder zu gleich brauchbaren Schreibmaschinen an."

${ }^{144}$ Max Weber, Wirtschaft und Gesellschaft, Grundriß der verstehenden Soziologie (posthume Erstausgabe 1922), 5. revidierte Aufl. 1972, nachgedruckte Studienausgabe, 1985, S. 572.

145 So die Einschätzung von Habermas (Fn. 9), S. 155; vgl. bereits Welcker (Fn. 93), S. 250, 281 und passim.

146 Ausführlich hierzu Bernd Wunder, Geschichte der Bürokratie, 1986; Michael Stolleis, Geschichte des Öffentlichen Rechts in Deutschland, Zweiter Band: Staatsrechtslehre und Verwaltungswissenschaft 1800-1914, 1992, S. 229 ff., 381 ff.; Lutz Raphael, Recht und Ordnung, Herrschaft durch Verwaltung im 19. Jahrhundert, 2000; Stefan Haas, Die Kultur der Verwaltung, Die Umsetzung der preußischen Reformen 1800-1848, 2005.

${ }_{147} \mathrm{Vgl}$. bereits die Regierungserklärung von Bundeskanzler Kurt-Georg Kiesinger, in: Verhand- 
zeitig wurden gegenüber der Verwaltung Beteiligungs- und Mitentscheidungsforderungen geltend gemacht und Legitimationsmodelle diskutiert. ${ }^{148}$ Das Geheimhaltungsprinzip erklärte sich nicht mehr von selbst, umgekehrt wurde die Informiertheit und Einbindung individueller Betroffener oder einer (räumlich und sachlich begrenzten) Allgemeinheit als Element erfolgreicher Verwaltung erkannt, um gerade auch die intendierten umfangreichen Vorhaben verwirklichen zu können. ${ }^{149}$ Dabei blieb die größere Verwaltungsöffentlichkeit funktionell darauf beschränkt, die Akzeptanz von Verwaltungshandeln zu erhöhen; eine Einbindung in Entscheidungsabläufe oder ein generelles Akteneinsichtsrecht waren auf dieser Entwicklungsstufe weder vorstellbar noch gewünscht. ${ }^{150}$

War eine echte gesellschaftliche Beobachtung und Kontrolle der Verwaltung solcherart noch nicht möglich, so entwickelte sich in der Folgezeit eine begrenzte Aktenöffentlichkeit. Die Verwaltungsverfahrensgesetze des Bundes ( $V_{w V f G}$ ) und der Länder lösten mit diesem Prinzip den überkommenen Grundsatz der Nichtöffentlichkeit ab. $\$ 29$ Abs. 1 VwVfG regelt die Akteneinsicht durch Beteiligte am Verwaltungsverfahren dergestalt, dass grundsätzlich ein ermessensunabhängiger Anspruch auf Akteneinsicht besteht, soweit dies zur Geltendmachung oder Verteidigung ihrer rechtlichen Interessen erforderlich ist. Nach Abs. 2 der Vorschrift schränken Geheimhaltungsinteressen der Verwaltung das Recht auf Akteneinsicht ein; sie unterliegen ihrerseits aber einer Kontrolle durch die Gerichte ${ }^{151}$.

Zweck des Rechts auf Akteneinsicht ist es, dem Betroffenen Klarheit über die von der Verwaltung bereits gesammelten tatsächlichen oder rechtlichen Grundlagen der zu treffenden Entscheidung zu verschaffen, damit er seine im Rechtsstaat unverzichtbaren Mitwirkungsmöglichkeiten auch wirksam wahrnehmen kann. ${ }^{152}$

Die auf diese Weise ermöglichte unmittelbare rezeptive Öffentlichkeit blieb allerdings an ein „rechtliches Interesse“ gebunden. Nach dem Willen des Gesetzgebers sollte den Beteiligten Akteneinsicht gewährt werden nur zur Klärung tatsächlicher Unsicherheit über ein Rechtsverhältnis, zur Regelung rechtlich relevanten Verhal-

lungen des Deutschen Bundestages, 5. Wahlperiode, Stenographische Berichte Bd. 63, S. 3656-3665 (80. Sitzung vom 13. Dezember 1966): „Gesamtprogramm“, „fortschrittliche Gesellschaftspolitik“, „konzertierte Aktion“ und „Globalsteuerung“. Zur „,konzertierten Aktion“ zwischen 1967 und 1977 vgl. Manfred Kern, Konzertierte Aktion als Versuch einer Verhaltensabstimmung zwischen Regierung und Wirtschaftsverbänden (Institut für Wirtschaftspolitik an der Universität zu Köln, Untersuchungen Bd. 24), 1973.

${ }^{148}$ Hierzu den Überblick bei Edwin Czerwick, Demokratisierung der öffentlichen Verwaltung in Deutschland, Von Weimar zur Bundesrepublik, in: Geschichte und Gesellschaft 29 (2002), S. 183-203 (S. $197 \mathrm{ff}$.$) .$

149 Prägnant Helge Rossen-Stadtfeld, Kontrollfunktion der Öffentlichkeit - ihre Möglichkeiten und ihre (rechtlichen) Grenzen, in: Eberhard Schmidt-ABmann/Wolfgang Hoffmann-Riem (Hrsg.), Verwaltungskontrolle, 2001, S. 117-203 (S. 123); ausführlich Bernhard W. Wegener, Arkantradition und Informationsfreiheitsrecht, 2006.

${ }_{150}$ Vgl. etwa Fritz Haueisen, Akteneinsicht im Verwaltungsverfahren, in: NJW 1967, S. 2291-2294; Häberle (Fn. 95), S. 107 f.

151 Hierzu Ursula Ziegler, Die gerichtliche Kontrolle der Geheimhaltungsmittel der Exekutive, in: ZRP 1998, S. 25-28.

152 Vgl. etwa BVerwE 92, 132 (136ff.). Mit Blick auf das schweizerische Recht: Alexander Dubach, Das Recht auf Akteneinsicht, Der verfassungsmässige Anspruch auf Akteneinsicht und seine Querverbindungen zum Datenschutz - unter besonderer Berücksichtigung der elektronischen Datenverarbeitung (Computer und Recht, Bd. 20), 1990, S. 1 ff. 
tens nach der Einsichtnahme und zur Erlangung einer hinlänglich gesicherten Anspruchsgrundlage. ${ }^{153}$ Lediglich berechtigte Interessen - die im Rahmen von $\$ 12$ Abs. 1 GBO eine Grundbucheinsicht rechtfertigen können - sollten ausgeschlossen sein.

\section{b) Heutiger Stand}

Damit ist das Verwaltungsverfahren vom Prinzip der ,beschränkten Aktenöffentlichkeit“" geprägt. Allerdings können weiterreichende Einsichtsrechte durch besondere Rechtsvorschrift begründet werden, um das Informationsinteresse der Öffentlichkeit oder eines größeren Kreises der Bevölkerung zu befriedigen. Dementsprechend können die zuständigen Behörden nach pflichtgemäßem Ermessen in atomrechtlichen, gentechnischen oder immissionsschutzrechtlichen Genehmigungsverfahren Akteneinsicht gewähren (z. B. \6 AtVfV, \4 Abs. 1 Satz 2 GenTAnhV, $\$ 10$ a 9. BImSchV). Auch diese beträchtliche Erweiterung der Publizität knüpft die Kontrolle der Verwaltung noch an ein konkretes Genehmigungsverfahren, Einsichtsrechte enden also mit dem Abschluß des Verfahrens. Das Prinzip der beschränkten Aktenöffentlichkeit wird an dieser Stelle demzufolge noch nicht durchbrochen.

Nicht zu unterschätzen ist auch der internationale Einfluß auf die Fortentwicklung der Verwaltungsöffentlichkeit in der Bundesrepublik Deutschland. Neben einer Empfehlung des Ministerkomitees des Europarats aus dem Jahre $1981^{154}$ ist hier jedoch hauptsächlich der Einfluß des Rechts der Europäischen Gemeinschaften/Europäischen Union zu nennen. Dieser hat sich, der an einzelnen Politikbereichen orientierten Struktur des Gemeinschaftsrechts folgend, mit Blick auf die Verwaltungsöffentlichkeit schrittweise und punktuell bemerkbar gemacht. Am Anfang dieser Entwicklung stand das Umweltschutzrecht (seit 1987 in Art.130r EWGV, heute Art. $191 \mathrm{ff}$. AEUV niedergelegt). In den diesbezüglichen Aktionsprogrammen hatte die Gemeinschaft die wichtige Rolle hervorgehoben, die der Information der Öffentlichkeit bei den Maßnahmen zum Schutz der Umwelt zukommt. Der hieraus entwickelte Grundsatz der umfassenden Umweltinformation hat einerseits zur Begründung von Informationspflichten der Gemeinschaft und der Mitgliedstaaten geführt und andererseits ein Informationszugangsrecht der Bürger etabliert. Zu dessen Verwirklichung im Bereich des Umweltrechts wurde v.a. die Richtlinie über den freien Zugang zu Informationen über die Umwelt ${ }^{155}$ verabschiedet. Diese hat in der Bundesrepublik Deutschland für jedermann ein subjektives Recht auf Zugang zu

153 Entwurf des Verwaltungsverfahrensgesetzes, BT-DrS. 7/910, S. 53.

154 Ministerkomitee, Empfehlung Nr. R (81) 19, vom 25. November 1981, Präambel, Erwägungsgründe 3 und 4, abrufbar unter http://www.access-info.org/documents/Access_Docs/Thinking/ Get_Connected/Recommendation_81_19.pdf (zuletzt besucht am 1. März 2012). Daraus ist die Konvention über den Zugang zu öffentlichen Dokumenten hervorgegangen (vom 18. Juni 2009), die allerdings noch nicht in Kraft getreten ist; Deutschland hat sie bislang noch nicht unterschrieben.

155 Vom 7. Juni 1990, ABl. EG Nr. L 158/1990, S. 56-58. Hierzu Matthias von Schwanenflügel, Das Öffentlichkeitsprinzip des EG-Umweltrechts - Zur Bedeutung der Richtlinie über den freien Zugang zu Umweltinformationen, in: DVBl. 1991, S. 93-101. 
Umweltinformationen begründet, ${ }^{156}$ das nur durch den gebotenen Schutz öffentlicher Belange begrenzt wird (vgl. $\$ 7 \mathrm{f}$. UIG). Ziel der gemeinschaftsrechtlichen Regelungen ist die Erweiterung bestehender und die Öffnung neuer Diskursräume unter Einbeziehung zivilgesellschaftlicher Organisationsformen. ${ }^{157}$ Damit ist eine neue Qualität der Behördenkontrolle durch Offentlichkeit erreicht, die durch das deutsche Recht zunächst allerdings nur in Ansätzen verwirklicht wurde.

Landesverfassungsrechtlich haben Umweltinformationsansprüche Grundrechtsrang verliehen erhalten (etwa in Art. 6 Abs. Verfassung Mecklenburg-Vorpommern oder Art. 21 Abs. 4 Verfassung Brandenburg). Daneben statuiert Art. 21 Abs. 3 S. 2 der brandenburgischen Landesverfassung ein originäres Grundrecht auf Informationszugang für Verbände. Zutreffenderweise wird die Verknüpfung zur politischen Mitgestaltung hergestellt und so der republikanische Bezug der Öffentlichkeit unterstrichen. So sehr das grundsätzlich zu begrüßen ist, so berechtigt sind Hinweise auf damit verbundene Risiken, die sich im Zusammenhang mit Demokratie generell ergeben: Sind die Bürger hinreichen kompetent und überhaupt (nachhaltig) interessiert? Da einerseits aufgeklärter Absolutismus, Aristokratie oder paternalistisch-fürsorgliche Expertenherrschaft keine echten Optionen mehr darstellen, und andererseits Bürger der Art, wie sie Paul Kirchhof beschrieben hat, ${ }^{158}$ nicht ,,vom Himmel fallen“ und überdies das Massenpublikum durchaus anfällig für demagogische Ansprache ist, kann eine Lösung langfristig nur in freiheitlicher, diskriminierungsfreier und befähigender Bildung liegen. ${ }^{159}$ Verantwortung hierfür tragen jedoch keineswegs nur die staatlichen Bildungseinrichtungen, sondern zuvörderst die Eltern (Art. 6 Abs. 2 Satz 1 GG) aber auch Familien insgesamt und gesellschaftliche Gruppen, Vereine, Parteien, Kirchen.

Der sich in diesen landesverfassungsrechtlichen Bestimmungen andeutende Schritt hin zu einer ,,allgemeinen Aktenöffentlichkeit", wie es sie beispielsweise schon länger in Spanien, Schweden, Portugal oder den USA gibt, hat sich in der Bundesrepublik Deutschland erst allmählich durchsetzen können. ${ }^{160}$ Das Gesetz zur Regelung des Zugangs zu Informationen des Bundes (Informationsfreiheitsgesetz - IFG) ${ }^{161}$ vom 5. September 2005 ist am 1. Januar 2006 in Kraft getreten. ${ }^{162}$ Nach seinem $₫ 1$ Abs. 1 Satz 1 hat jedermann einen voraussetzungslosen Rechtsanspruch auf Zugang zu amtlichen Informationen von Bundesbehörden. Ein Interesse rechtlicher, wirtschaftlicher oder sonstiger Art ist nun nicht mehr erforderlich. Nach wie vor besteht aller-

156 Zum Prozess siehe Roland Bieber, Informationsrechte Dritter im Verwaltungsverfahren - Ansätze zu legislativer und dogmatischer Neubewertung -, in: DÖV 1991, S. 857-867.

157 Hierzu und zum folgenden Rossen-Stadtfeld (Fn. 149), S. 137 f.

158 Paul Kirchhof, Der Staat als Organisationsform politischer Herrschaft und rechtlicher Bindung, Kontinuität und Erneuerung des deutschen Verfassungsstaates in Freiheitlichkeit, Weltoffenheit und demokratischer Solidarität, in: DVB1. 1999, S. 637-657 (S. 640 ff.), zu den Bedrohungen: „Orientierungsarmut der Freiheitsberechtigten", S. 650 f.

159 So unter anderem Frankenberg (Fn. 5), S. $201 \mathrm{ff}$.

$160 \mathrm{Vgl}$. etwa das rechtspolitische Plädoyer bei Jean Angelov, Grundlagen und Grenzen eines staatsbürgerlichen Informationszugangsanspruchs, 2000.

161 BGB1. 2005 I S. 2722.

162 Hierzu Michael Kloepfer/Kai von Lewinski, Das Informationsfreiheitsgesetz des Bundes (IFG), in: DVBl. 2005, S. 1277-1288; Dieter Kugelmann, Das Informationsfreiheitsgesetz des Bundes, in: NJW 2005, S. 3609-3613. 
dings das Antragserfordernis ( $\$ 7 \mathrm{IFG}$ ); aber grundsätzlich muss dem Antragsteller Zugang zu den begehrten Informationen gewährt werden, es sei denn, im Einzelfall stehen schützenswerte und höherwertige Interessen Dritter dem Informationszugang entgegen ( $\$ 5$ und 6 IFG). Die Behörde muss dies in jedem Einzelfall prüfen und darlegen.

Allerdings bestehen weitere Ausnahmetatbestände, die das Recht auf Informationszugang einschränken oder ganz verwehren können. Diese zahlreichen, kasuistisch aufgezählten Ausnahmen sollen die Funktionsfähigkeit der Verwaltung gewährleisten sowie das Staatswohl und Staatsinteresse schützen ( $\$ 3$ und 4 IFG) ${ }^{163}$ So darf beispielsweise Zugang zu personenbezogenen Daten nur dann gewährt werden, soweit das Informationsinteresse des Antragstellers das schutzwürdige Interesse des Betroffenen überwiegt oder der Betroffene eingewilligt hat. Bezüglich der Inhalte von Personalakten und Personalverwaltungssystemen besteht kein Informationszugangsanspruch. Informationen über Namen und dienstliche Anschriften von Beschäftigten sollen jedoch grundsätzlich zugänglich gemacht werden. Dasselbe gilt für Informationen zu Gutachtern und Sachverständigen. Zugang zu Betriebs- und Geschäftsgeheimnissen wird nur mit Zustimmung des Unternehmens gewährt.

\section{c) Probleme}

Nicht unerwähnt bleiben soll, dass die Verwaltung immer häufiger die Adressaten ihrer Steuerungsbemühungen nicht nur im Vorfeld der Entscheidung einbezieht, sondern auch mit ihnen über die Modalitäten des Vollzugs verhandelt, also tatsächlich kooperativ agiert. ${ }^{164}$ Dies wird mit Blick auf Rechtsstaatlichkeitsanforderungen und auf Effizienz des Verwaltungshandelns thematisiert, aber auch unter politischlegitimatorischen Gesichtspunkten diskutiert. ${ }^{165}$ Unter Rechtsstaatsgesichtspunkten ist an den Grundsatz der Gesetzmäßigkeit der Verwaltung (Art. 20 Abs. 3 GG) und an den Gleichheitssatz (Art. 3 Abs. 1 GG) zu erinnern. Letztendlich könnte die Gefahr bestehen, dass, wenn der Bürger als Kunde der Verwaltung verstanden wird und auch entsprechend auftritt, die unterschiedliche Argumentations- und Tauschfähigkeit der Kunden selektiv wirken kann. ${ }^{166}$

Während also auf der einen Seite Unterschiede zwischen den Bürgern drohen, die aus deren Kundenposition resultieren, sieht sich die Verwaltung auf der anderen Seite dem Verbandseinfluß ausgesetzt, der in einem solchen Verhandlungsprozess ausge-

163 Für ausführliche Erläuterungen vgl. Serge-Daniel Jastrow/Arne Schlatmann, Informationsfreiheitsgesetz, Kommentar, 2006, \$3, Rn. 15ff,; \$4. Aktuell: Friedrich Schoch, Informationsfreiheitsgesetz, Kommentar, 2. Aufl 2012, \$3 und \$4.

${ }_{164}$ Umfassend Nicolai Dose, Die verhandelnde Verwaltung, Eine empirische Untersuchung über den Vollzug des Immissionsschutzrechts (Schriften zur Rechtspolitologie, Bd. 4), 1997. Dort S. $19 \mathrm{ff}$. zu den verschiedenen Forschungsansätzen. Vgl. außerdem Arthur Benz, Kooperative Verwaltung, Funktionen, Voraussetzungen und Folgen, 1994; Helge Rossen, Vollzug und Verhandlung, Die Modernisierung des Verwaltungsvollzugs, 1999, S. $336 \mathrm{ff}$.

165 Horst Dreier, Hierarchische Verwaltung im demokratischen Staat, Genese, aktuelle Bedeutung und funktionelle Grenzen eines Bauprinzips der Exekutive, 1991, S. 150 ff., $299 \mathrm{ff}$. und passim; Benz (Fn. 164), S. $318 \mathrm{ff}$.

166 Benz (Fn. 134), S. 98. 
übt wird. ${ }^{167}$ Immerhin tritt er offen zu Tage und ermöglicht so den Bürgern Einblicke in Interaktionsprozesse, die es nach dem alten Modell auch gegeben hatte.

Aus politisch-legitimatiorischer Perspektive stehen einerseits asymmetrische Einflußmöglichkeiten der Kooperationspartner und andererseits die legitimationsbeschaffende Funktion solcher Kooperation im Mittelpunkt des Interesses. Dabei wird ausdrücklich gewarnt:

Je mehr sich die öffentliche Verwaltung in ,sozietale Diskurse“ neuer Art verstricken läßt, umso weniger kann sie der demokratisch-rechtsstaatlichen Form des offiziellen Machtkreislaufs genügen. Derselbe Neokorporatismus, der die Gefahren einer gesamtgesellschaftlichen Desintegration bewältigen und damit die von neuem aufbrechenden Legitimationspropbleme eindämmen soll, stört den in eigener Regie ablaufenden Prozeß der Selbstlegitimation. ${ }^{168}$

Die intensivsten Formen der Beteiligung von Bürgern sind sicher einerseits auf der kommunalen Ebene insgesamt und sektoral im Bereich der Bauleit- und Stadtentwicklungsplanung andererseits zu beobachten.

\section{d) Zwischenfazit}

Das Verhältnis von Exekutive und Öffentlichkeit hat trotz der vorstehend skizzierten Entwicklungen einen strukturellen Antagonismus bewahrt. Kooperation und Bürgerbeteiligung sind zwar als wichtige Elemente in die Arbeit der Verwaltung aufgenommen worden und tragen erheblich zur Akzeptanz von Verwaltungsentscheidungen bei. An der Grundkonstellation - Bindung der Behörden an Recht und Gesetz und die daraus resultierende, gegebenenfalls zwangsweise Durchsetzung derselben - hat das gleichwohl nichts geändert. Im dritten Teil soll dies im Lichte der Erfahrungen von „Stuttgart 21“ noch einmal untersucht werden (unten III).

\section{Judikative und Öffentlichkeit}

Die Reichsjustizgesetze, also Gerichtsverfassungsgesetz (GVG), ${ }^{169}$ Strafprozessordnung (StPO), ${ }^{170}$ Zivilprozessordnung, ${ }^{171}$ Konkursordnung ${ }^{172}$ und Rechtsanwaltsordnung ${ }^{173}$ sind gleichzeitig am 1 . Oktober 1879 in Kraft getreten. ${ }^{174}$ Ihre Funktion war es, die politische Einigung Deutschlands im Deutschen Reich von 1871 auf dem

167 Mit Blick auf die Regierung Rudzio (Fn. 131), S. 75 ff.

168 Habermas (Fn. 64), S. 423.

169 Vom 27. Januar 1877, RGB1. 1877 S. 41; Neufassung vom 9. Mai 1975 BGBl. 1975 I S. 1077, zuletzt geändert BGB1. 2003 I S. 3007.

170 Vom 1. Februar 1877, RGBI. 1877 S. 253; BGBl. 1950 I S. 455, Neufassung BGBl. 1987 I S. 1074 , 1319.

171 Vom 30. Januar 1877, RGBl. 1877 S. 83; BGBl. 1950 I S. 455.

172 Vom 10. Februar 1877, RGB1. 1877 S. 351 in der Fassung vom 20. Mai 1898, RGBl. 1898 S. 612. Heute: Insolvenzordnung vom 4. Oktober 1994 (BGBl. 1994 I S. 2866).

${ }_{173}$ Vom 1. Juli 1878, RGBl. 1878 S. 177; Bundesrechtsanwaltsordnung vom 1. August 1959 (BGB1. 1959 I S. 565).

$174 \mathrm{Zu}$ den Reichsjustizgesetzen insgesamt siehe die Beiträge in: Bundesminister der Justiz (Hrsg.), 75 Jahre Reichsjustizgesetze, 1954. 
für den jungen Nationalstaat wichtigen Gebiet der Justiz nachzuvollziehen. ${ }^{175}$ Gleichzeitig legten sie Zeugnis ab für den Stand der Rechtsstaatlichkeit ${ }^{176}$ der damaligen Zeit. Hierzu gehörte die Öffentlichkeit von Gerichtsverhandlungen aller Gerichtszweige ( $\$ 169$ Satz $1 \mathrm{GVG})^{177}$ und die öffentliche Verkündung des Urteilstenors $(\$ 173$ Abs. 1 GVG), die selbst dann ohne weiteres öffentlich zu erfolgen hat, wenn die Öffentlichkeit aufgrund besonderer Gründe ausgeschlossen war.

Sinn dieser Regelungen ist es generell und besonders mit Blick auf die Strafgerichtsbarkeit, dass keine Geheimjustiz erfolgt. ${ }^{178}$ Es handelt sich um eine der ,grundlegenden Einrichtungen des Rechtsstaats" ${ }^{\text {179 }}$ und soll das Vertrauen in die Justiz festigen. Die Öffentlichkeit des gerichtlichen Verfahrens ist von herausragender Bedeutung für die Rechtspflege ${ }^{180}$ deshalb dürfen Ausnahmen vom Öffentlichkeitsgrundsatz nur aus zwingenden Gründen in den vom Gesetz vorgesehenen Fällen gemacht werden. Eine weitere Funktion der Öffentlichkeit des Gerichtsverfahrens ist es, der Möglichkeit vorzubeugen, dass sachfremde Umstände auf das Gericht und so auf das Urteil Einfluss gewinnen. ${ }^{181}$ Hier ist jedoch zu beachten, dass nicht nur zu weitreichende Einschränkungen der Öffentlichkeit, sondern auch deren Überdehnung den Richterspruch mit sachfremden Einflüssen konfrontieren können. Dementsprechend kann selbstverständlich in den Medien über Gerichtsverhandlungen berichtet werden, ${ }^{182}$ allerdings verbietet $\$ 169$ Satz 2 GVG Ton- und Bildaufzeichnungen, um das Massenpublikum als wirkungsmächtigen und eventuell verzerrenden Faktor auszuschließen. Diese Entscheidung des Gesetzgebers ist allerdings nicht unumstritten. ${ }^{183}$ Mit Blick auf das Bundesverfassungsgericht wird dieses Verbot überdies durch $₫ 17$ a BVerfGG durchbrochen, wonach sowohl Teile der mündlichen Verhandlung als auch der öffentlichen Entscheidungsverkündung im Rundfunk übertragen werden dürfen. Das Bundesverfassungsgericht hat in seiner „N-TV-Entscheidung" vom 24. Januar 2001 mehrheitlich bekräftigt, dass die Ton- und Bildberichterstattung aus Gerichtsverhandlungen unzulässig ist, und die Öffentlichkeit als „Saalöffentlichkeit“ definiert. ${ }^{184}$

175 Allgemein Richard Thoma, Das Staatsrecht des Reiches, in: Gerhard Anschütz/ders. (Hrsg.) Handbuch des Staatsrechts, Bd. 1, 1930, unveränderter Nachdruck 1998, S. 69-80 (S. 77).

176 Näher: Otto Hintze, Preußens Entwicklung zum Rechtsstaat, in: ders., Regierung und Verwaltung, Gesammelte Abhandlungen zur Staats-, Rechts- und Sozialgeschichte Preußens, hrsg. von Gerhard Oestreich, 2. Aufl. 1967, S. 97-163; Reinhold Zippelius, Die Entstehung des demokratischen Rechtsstaates aus dem Geiste der Aufklärung, in: JZ 1978, S. 1125-1131.

177 Vgl. zum folgenden insgesamt Otto Rudolf Kissel/Herbert Mayer, Gerichtsverfassungsgesetz, Kommentar, 6. Aufl. 2010, \$169.

178 Grundlegend Anselm von Feuerbach, Betrachtungen über die Öffentlichkeit und Mündlichkeit der Gerechtigkeitspflege, 1821.

179 BGHSt 7, 218 (221); 9, 280 (281)

${ }^{180}$ BVerfGE 70, 324 (358). Siehe grundsätzlich hierzu Eberhard Rothberg, Öffentlichkeit der Rechtspflege, in: Studium Generale 23 (1970), S. 752-768.

181 BGHSt 9, $280(282)$.

182 BVerfGE 103, 44 (61 f.).

${ }^{183} \mathrm{Vgl}$. Klaus Olbertz, Fernsehöffentlichkeit von Gerichtsverfahren unter verfassungsrechtlichen Gesichtspunkten, Zur Frage der Verfassungsmäßigkeit des $\$ 169$ S. 2 GVG, 2002.

${ }^{184}$ BVerfGE 103, 44 (62) = EuGRZ 2001, S. 59-70. Eine kritische Analyse des Urteils bei Tobias Gostomzyk, Die Öffentlichkeitsverantwortung der Gerichte in der Mediengesellschaft (Materialien zur interdisziplinären Medienforschung, Bd. 54), 2006, S. 159 ff. m.w.Nw. 
Ohne dies hier vertiefen zu können, so muss doch die Bedeutung dieses Urteils für die Grundrechtsdogmatik insgesamt unterstrichen werden. Aus Art. 5 Abs. 1 Satz 1 GG folge ein

gegen den Staat gerichtetes Recht auf Zugang, wenn eine im staatlichen Verantwortungsbereich liegende Informationsquelle auf Grund rechtlicher Vorgaben zur öffentlichen Zugänglichkeit bestimmt ist, der Staat den Zugang aber verweigert. ${ }^{185}$

Diese Neuausrichtung einer objektiv-rechtlichen Bindung des Gesetzgebers in ein subjektives Recht war notwendig, um dem Rundfunkveranstalter die Einlegung einer Verfassungsbeschwerde zu eröffnen. Diesen Weg hatte das Bundesverfassungsgericht zuvor stets abgelehnt, ${ }^{186}$ seither aber erneut beschritten. ${ }^{187}$

Weite Teile der familiengerichtlichen Streitigkeiten sind kraft Gesetzes von der Öffentlichkeit ausgenommen ( $\$ 170$ GVG). In Unterbringungssachen kann die Öffentlichkeit ausgeschlossen werden ( $\$ 171$ a GVG); ebenso zum Schutze der Privatsphäre ( $\$ 171$ b GVG) oder zum Schutze anderer wichtiger Rechtsgüter und Interessen ( $(172$ GVG). Eine besonders wichtige Kategorie bildet hierbei heute der Schutz von Prozessbeteiligten, Opfern und Zeugen. ${ }^{188}$

Angesichts der heutigen Bedeutung von Massenmedien läßt sich die Frage nach einer eigenen Öffentlichkeitsarbeit der Justiz nicht mehr verdrängen. ${ }^{189}$ Dabei sollte es weniger um Beiträge zur politischen Meinungsbildung durch hohe und höchste Richter gehen, als vielmehr um eine sachdienliche Information über die Sacharbeit der Gerichte. Öffentlichkeitsarbeit der Justiz hatte das Bundesverwaltungsgericht bereits 1997 als direkt aus der Verfassung abgeleitete Pflicht bezeichnet. ${ }^{190}$ Öffentlichkeitsarbeit kann und sollte gelegentlich Hilfestellung zu einer Versachlichung der Diskussion geben. Umgekehrt vermag eine verstärkte Außenorientierung des Justizapparates das Nachdenken über die eigene Rolle und Tätigkeit im republikanischen Rechtsstaat fördern.

\section{Eine Zwischenbilanz zu Staat und Öffentlichkeit}

\section{a) Zustimmungsfunktion}

Der moderne Staat ist auf die Zusammenarbeit mit der Gesellschaft angewiesen, wenn er erfolgreich Politik machen und regieren will. ${ }^{191}$ „Regieren“ heißt, dass verbindliche Entscheidungen herbeigeführt werden, um in bestimmten Politikfeldern

185 BVerfGE 103, 44 (44, 2. Leitsatz).

186 Etwa in BVerfGE 91, 125 (136 ff.).

187 Vgl. BVerfGE 105, 279 (300f.).

188 Hierzu Walter Odersky, Die Öffentlichkeit der Hauptverhandlung nach dem Opferschutzgesetz, in FS Pfeiffer 1988, S. 325-338; Helmut Seitz, Das Zeugenschutzgesetz, in: JR 1988, S. 309-313.

189 Weiterführend Gostomzyk (Fn. 184), S. $176 \mathrm{ff}$. Siehe ferner Martin W. Huff, Notwendige Öffentlichkeitsarbeit der Justiz, in: NJW 2004, S. 403-407 plus S. 432.

190 BVerwG, in: NJW 1997, S. 2694-2696 mit Besprechung von Martin W. Huff, Die Veröffentlichungspflicht der Gerichte, in: NJW 1997, S. 2651-53.

191 So bereits Hans F. Zacher, Pluralität der Gesellschaft als rechtspolitische Aufgabe, in: Der Staat 1970, S. 161-186 (S. 172). 
konkrete Ziele zu erreichen, indem das Verhalten anderer Beteiligter gesteuert wird. ${ }^{192}$ Dieses Regieren geschieht durch Rechtssetzung ${ }^{193}$ und Rechtsanwendung, also in allen drei Staatsgewalten. Folgt man bei deren Betrachtung einem institutionentheoretischen Ansatz, so kommt man nicht umhin, die Perspektiven von „öffentliche $[\mathrm{m}]$ Recht, Politikwissenschaft und Soziologie eng zu verzahnen“194. Dies soll nachfolgend aus der Perspektive des öffentlichen Rechts versucht werden, wobei ergänzend auf Erkenntnisse der Governanceforschung zurückgegriffen wird. Auch diese folgt einem institutionalistischen Ansatz, soweit sie den akteurszentrierten Steuerungsansatz der „Government-Perspektive“ zu überwinden sucht, ${ }^{195}$ und nimmt das Verhältnis von staatlichen und nichtstaatlichen Akteuren, ${ }^{196}$ also Strukturen in den Blick. Erfaßt werden von der Governanceforschung nicht zuletzt Unternehmen, deren gesellschaftliche Verantwortlichkeit untersucht wird. ${ }^{197}$

Die Steuerung des Verhaltens seiner Bürger erreicht der Staat nicht von selbst; das wirksame Regieren ist nicht voraussetzungsfrei, eine Einbeziehung der gesellschaftlichen Sphäre notwendig. Dies spricht bereits Art. 6 der Französischen Menschenund Bürgerrechtserklärung aus:

La loi est l'expression de la volonté générale. Tous les citoyens ont le droit de concours personellement ou par leurs représentants à sa formation.

Hier wird eine Erkenntnis aufgegriffen, die Immanuel Kant formuliert hat: Da die Gesetzgebung niemandem Unrecht tun dürfe, um ohne Transzendenzbezug legitimiert zu sein, und da niemand sich selbst Unrecht zufüge, könne

192 Statt aller Karl-Rudolf Korte/Manuel Frohlich, Politik und Regieren in Deutschland, Strukturen, Prozesse, Entscheidungen, 2004, S. 15, $175 \mathrm{ff}$.

193 Hierzu die ausführliche Untersuchung von Schulze-Fielitz (Fn. 116), insbesondere S. 184ff., $246 \mathrm{ff}$., $375 \mathrm{ff}$.

194 Hans-Joachim Mengel, Institutionelles Denken im öffentlichen Recht, in: Gerhard Göhler/Kurt Lenk/Rainer Schmalz-Bruns (Hrsg.), Die Rationalität politischer Institutionen, Interdisziplinäre Perspektiven, 1990, S. 403-422 (S. 409). In diese Richtung auch Rehberg (Fn. 95).

195 Hierzu Renate Mayntz, Governance Theory als fortentwickelte Steuerungstheorie?, in: Gunnar Folke Schuppert (Hrsg.), Governance-Forschung, Vergewisserung über Stand und Entwicklungslinien (Schriften zur Governance-Forschung, Bd. 1), 2. Aufl. 2006, S. 11-20, die eher eine Akzentverschiebung als einen Paradigmenwechsel im Gange sieht. Ähnlich bereits Helmut Willke, Kontextsteuerung durch Recht? Zur Steuerungsfunktion des Rechts in polyzentrischer Gesellschaft, in: Manfred Glagow/ders. (Hrsg.), Dezentrale Gesellschaftssteuerung, Probleme der Integration polyzentrischer Gesellschaften, 1987, S. 3-26; Fritz W. Scharpf, Politische Steuerung und Politische Institutionen, in: Politische Vierteljahresschrift 30 (1989), S. 10-21 (S. 14f.).

196 Werner Jann, Der Wandel verwaltungspolitischer Leitbilder: Von Management zu Governance?, in: Klaus König (Hrsg.), Deutsche Verwaltung an der Wende zum 21. Jahrhundert, 2002, S. 279-303; Wulf Damkowski/Claus Precht, Public Management, Neuere Steuerungskonzepte für den öffentlichen Sektor, 1995; sowie die Beiträge in Arthur Benz (Hrsg.), Governance - Regieren in komplexen Regelsystemen, Eine Einführung, 2004. Vgl. aber auch Helmut Willke, Die Steuerungsfunktion des Staates aus systemtheoretischer Sicht, Schritte zur Legitimierung einer wissensbasierten Infrastruktur, in: Dieter Grimm (Hrsg.), Staatsaufgaben, 1994, S. 685-711, der für eine Anleitung zur Selbststeuerung plädiert (S. 706). Kritisch zu Willkes Ansatz Habermas (Fn. 64), S. 405 ff., 416 ff., der demgegenüber die Kommunikations- und Entscheidungsprozesse in einem „Zentrum-Peripherie-Modell " verortet (S. $429 \mathrm{ff}$.).

197 Zur Corporate Social Responsibility vgl. Thomas Clarke/Marie dela Rama (Hrsg.), Corporate Governance and Globalization, Vol. II: Development and Regulation, 2006; Matthias Münstermann, Corporate Social Responsibility: Ausgestaltung und Steuerung von CSR-Aktivitäten, 2007. 
nur der übereinstimmende und vereinigte Wille aller, sofern ein jeder über alle und alle über einen jeden ebendasselbe beschließen, mithin nur der allgemein vereinigte Volkswille gesetzgebend $\operatorname{sein} .^{198}$

Dabei geht es nicht nur um eine formale Mitwirkung, sondern um die inhaltliche Zustimmung der Bürger. ${ }^{199}$ Diese Zustimmung ist nicht selbstverständlich, sie muss durch im Wortsinne mehrheitsfähige Politik erwirkt werden; dabei stehen nicht länger nur die Ziele im Wettstreit miteinander:

Die Wertgemeinschaft, auf der die Bürgerdemokratie beruhte, ist in der Massendemokratie aufgelöst, eben weil die extensiv entfaltete Demokratie auch die unbürgerliche Bevölkerung gleichberechtigt umfaßt und aktiviert. Nicht mehr auf gemeinsamer Wertgrundlage wird nunmehr gestritten, sondern $u m$ die Wertgrundlage. ${ }^{200}$

Ein Blick auf die Auseinandersetzungen um die Volkszählung, ${ }^{201}$ den $₫ 218$ StGB $^{202}$ sowie den NATO-Doppelbeschluß und die nachfolgende Stationierung von Mittelstreckenraketen ${ }^{203}$ zeigt, welche Widerstände es dabei mitunter zu überwinden gilt und welche mentalitätsgeschichtlichen Erklärungen ${ }^{204}$ hierfür in Betracht zu ziehen sind (zu aktuellen Fragen unten III).

Weitere Grundlagen der vom Staat benötigten Zustimmung sind einerseits die Rückbindung politischer Entscheidungen an die öffentliche Meinung, ${ }^{205}$ andererseits die informatorische Einbindung betroffener Gruppen oder sogar die konkrete Be-

198 Immanuel Kant, Metaphysik der Sitten, Rechtslehre $₫ 46$, in: ders., Werke in sechs Bänden, hrsg. von Wilhelm Weischedel, Band IV, 1963, S. 432.

199 Josef Isensee, Die alte Frage nach der Rechtfertigung des Staates, Stationen in einem laufenden ProzeB, in: Petra Kolmer/Harald Korten (Hrsg.), Recht, Staat, Gesellschaft: Facetten der politischen Philosophie, 1999, S. 21-68 (S. 26). Vgl. auch Bas Denters/Oscar Gabriel/Mariano Torcal, Political confidence in representative democracies: socio-cultural vs. political explanations, in: Jan W. van Deth/José Ramon Montero/Anders Westholm (Hrsg.), Citizenship and Involvement in European Democracies, A comparative analysis, 2007, S. 66-87.

200 Trotz des heute irritierend erschrocken klingenden Tones nach wie vor zutreffend Theodor Geiger, Demokratie ohne Dogma, Die Gesellschaft zwischen Pathos und Nüchternheit, 1963, S. 356 (Hervorhebungen im Original).

201 Gesetz über eine Volks-, Berufs-, Wohnungs- und Arbeitsstättenzählung (Volkszählungsgesetz 1983) vom 25. März 1982, BGBl. 1982 I S. 369; BVerfGE 65, 1; Barbara Pfetsch, Volkszählung '83: Ein Beispiel für die Thematisierung eines politischen Issues in den Massenmedien, in: Hans-Dieter Klingemann/Max Kaase (Hrsg.), Wahlen und politischer Prozeß, Analysen aus Anlaß der Bundestagswahl 1983 (Schriften des Zentralinstituts für sozialwissenschaftliche Forschung der Freien Universität Berlin, Bd. 49), S. 201-231.

${ }^{202}$ BVerfGE 46, 160 und 90, 145. Christian Starck, Der verfassungsrechtliche Schutz des ungeborenen menschlichen Lebens, in: JZ 1993, S 816-822.

203 BVerfGE 66, 39 und 68, 1. Theodor Schweisfurth, Die „Zustimmung“ der Bundesregierung zur Stationierung amerikanischer Mittelstreckenraketen in der Bundesrepublik Deutschland, in: AVR 1984, S. 195-219; Stephan Layritz, Der NATO-Doppelbeschluß, Westliche Sicherheitspolitik im Spannungsfeld von Innen-, Bündnis- und Außenpolitik, 1992, S. $91 \mathrm{ff}$.

204 Pointiert Reinhard Schwickert, Soziale Herrschaftsverweigerung in der westdeutschen Gegenwart, Die politischen Folgelasten einer lage-entrückten Staatsräson, in: Der Staat 1986, S. 521-544.

205 Hierzu Niklas Luhmann, Öffentliche Meinung, in: ders., Politische Planung, Aufsätze zur Soziologie von Politik und Verwaltung, 1971, S. 9-34. Bereits Welcker (Fn. 93), S. 253, hatte erklärt, dass sich der Gesamtwille des Volkes in der öffentlichen Meinung spiegele, die „Eins und Dasselbe mit der Freiheit, Gerechtigkeit und Gesundheit des Staats" sei und diesen so zu ,zu einem Gemeinwesen des ganzen Volkes" mache (S. 262). 
rücksichtigung von deren Interessen. Öffentlichkeit wirkt so als „,System, in dem die Agenda des politischen Systems mitdefiniert wird ". 206 Öffentlichkeit ist heterogen und vielgestaltig, sie ist, um John Stuart Mill zu paraphrasieren, ${ }^{207}$ ein Marktplatz vieler Ideen. Dass Öffentlichkeit als Kommunikationssystem dabei Eigengesetzlichkeiten bei der Sammlung, Verarbeitung und Anwendung von Informationen, nicht zuletzt im Rahmen der Meinungsbildung, folgt, kann hier nur erwähnt werden. ${ }^{208}$

Die klassischen und modernen Demokratietheorien ${ }^{209}$ erfassen die Bedeutung und Funktion zivilgesellschaftlicher Akteure naturgemäß unterschiedlich. Dabei steht die Frage im Mittelpunkt, welche Voraussetzungen und Auswirkungen verstärkte und in neuartigen Formen sich vollziehende politische Partizipation für das Gelingen demokratischer Ordnungen hat. ${ }^{210}$ Aus der Sicht der prozessualen Demokratietheorien gehört zu den Voraussetzungen einer auf Verständigung orientierten politischen Beteiligung das Zusammenspiel von zwei Sphären der Öffentlichkeit. Dabei handelt es sich nach Habermas erstens um eine ,verfaßte“ Öffentlichkeit, die auf Meinungsund Willensbildung im Parlament und im Rechtswesen des Verfassungsstaates beruht. Diese wird ergänzt durch eine ,nichtverfaßte" Öffentlichkeit, die vor allem aus autonomen, zivilgesellschaftlichen Zusammenschlüssen besteht; ${ }^{211}$ insbesondere Bürgerinitiativen können bislang unpolitischen Menschen als Anlaufstelle dienen. Prozessuale Demokratietheorien sind allerdings zu stark auf die wachsende Partizipation fokussiert, als dass sie zur gleichzeitigen Optimierung mehrerer Ziele - darunter eben auch effektive politische Steuerung und Entscheidungsfähigkeit angesichts komplexer Problemlagen - beitragen.

Geht man wie neuere Ansätze der Demokratietheorie davon aus, dass es für den Erfolg einer Demokratie nicht nur auf den Stand der wirtschaftlichen Entwicklung ankommt, sondern auch Institutionen und Akteure sowie eine Streuung wirtschaftlicher, bildungsbezogener und gesellschaftlicher Machtressourcen eine wichtige Rolle spielen, ${ }^{212}$ so kann das Verlangen nach mehr Partizipation als Chance und nicht primär als Gefährdung von Demokratie begriffen werden. ${ }^{213}$ Das solcherart als „Sozialkapital" verstandene gemeinschaftliche Handeln und das daraus gegebenenfalls folgende Streben nach größerer politischer Beteiligung ist allerdings keine unwan-

206 Gerhards/Neidhardt (Fn. 95), S. 40.

207 John Stuart Mill, On liberty, 1859. Zitiert nach ders., On Liberty and Utilitarianism, 1992, dort S. $21 \mathrm{ff}$.

208 Hierzu Gerhards/Neidhardt (Fn. 95), S. 44 ff., 69 ff.

209 Für eine ausführliche Zusammenstellung vgl. Manfred G. Schmidt, Demokratietheorien, Eine Einführung, 3. überarbeitete und erweiterte Auflage 2000, unveränderter Nachdruck 2006.

${ }^{210}$ Hierzu speziell mit Blick auf die Bundesrepublik Deutschland Dieter Roth, Partizipative Demokratie, in: Stefan Brink/Heinrich Amadeus Wolff (Hrsg.), Gemeinwohl und Verantwortung, FS für Hans Herbert von Arnim, 2004, S. 761-778. Grundlegend Hans Rattinger, Einführung in die Politische Soziologie, 2009, S. $225 \mathrm{ff}$.

211 Jürgen Habermas, Drei normative Modelle der Demokratie: Zum Begriff deliberativer Politik, in: Herfried Münkler (Hrsg.), Die Chancen der Freiheit, Grundprobleme der Demokratie, 1992, S. 1124.

${ }^{212}$ Vgl. den Überblick zu den verschiedenen Funktionsvoraussetzungen der Demokratie bei Schmidt (Fn. 209), S. $438 \mathrm{ff} ., 450 \mathrm{ff}$.

213 Robert D. Putnam, Making Democracy Work: Civic Traditions in Modern Italy, 1993; siehe auch Kenneth Newton, Support for Democracy. Social Capital, Civil Society and Political Performance (WZB-Discussion Paper Nr. SP IV 2005-402), 2005. 
delbare Größe, wie die Stichworte Parteien- und Politikverdrossenheit belegen. ${ }^{214}$ Aus diesen Verdrossenheiten eine allgemein nachlassende Unterstützung der Demokratie in der Bevölkerung abzuleiten, erscheint aber zu weitgehend, ${ }^{215}$ denn der fortbestehende Beteiligungswille sucht sich andere Kanäle. Auch Hinweise auf eine veränderte Mediennutzung durch die Bürger (Informationsorientierung weniger gegenüber Unterhaltungsorientierung vieler) und durch staatliche Akteure (Standardisierung, Spektakularisierung) erlauben keine eindeutigen Schlußfolgerungen ${ }^{216}$ (zu den aktuellen Fragen unter III).

Zutreffend ist die Erkenntnis, dass ,,[n] ur ein demokratischer Staat [...] eine demokratische zivile Gesellschaft schaffen, nur eine demokratische zivile Gesellschaft [...] einen demokratischen Staat aufrechterhalten [kann] ". ${ }^{217}$ Nicht vergessen werden darf allerdings auch, dass die Demokratie ihrerseits Erwartungen und sogar Ansprüche gegenüber den Bürgern geltend machen kann: zuvörderst die Erwartung auf aktive Beteiligung und auf Interesse an den zur Entscheidung anstehenden Fragen, aber - unter kosmopolitischem Blickwinkel - unter Umständen auch ein grenzüberschreitendes Interesse an Menschen und Problemen. ${ }^{218}$ Das hier ein hochkomplexes Geflecht widerstreitender Interessen besteht, macht die aktuelle Diskussion über die Schuldenkrise im Euroraum deutlich (dazu unter III).

Soziologische Überlegungen zu einer reflexiven Modernisierung gehen davon aus, dass die fortschreitende Modernisierung ${ }^{219}$ - wie sie sich eben auch in der Entwicklung einer starken und ausdifferenzierten Zivilgesellschaft zeigt - die Grundlagen der industriegesellschaftlichen Modernisierung aufhebt und nicht von den bestehenden Institutionen, Organisationen und Teilsystemen eingehegt werden kann. ${ }^{220}$

214 Robert D. Putnam, Tuning In, Tuning Out: The Strange Disappearance of Social Capital in America, in: Political Science \& Politics, 28 (1995) 5, S. $664-683$ (S. 666 ff.); Thomas Jäger/Dieter Hoffmann (Hrsg.), Demokratie in der Krise? Zukunft der Demokratie, 1995; Hans Herbert von Arnim, Politikerverdrossenheit, Wertewandel und politische Institutionen, in: Volker J. Kreyher/Carl Böhret (Hrsg.), Gesellschaft im Übergang, Problemaufrisse und Antizipationen, 1995, S. 31-37.

${ }^{215}$ In diese Richtung argumentiert auch Helmut Klages, Der „schwierige Bürger“, Bedrohung oder Zukunftspersonal? in: Werner Weidenfeld (Hrsg.), Demokratie am Wendepunkt, Die demokratische Frage als Projekt des 21. Jahrhunderts, 1996, S. 233-253; ferner Olaf Winkel, Wertewandel und Politikwandel, Wertewandel als Ursache von Politikverdrossenheit und als Chance ihrer Überwindung, in: Aus Politik und Zeitgeschichte B 52-53/96 vom 20. Dezember 1996, S. 13-25.

216 Wolfgang van den Daele/Friedhelm Neidhardt (Hrsg.), Kommunikation und Entscheidung, Politische Funktionen öffentlicher Meinungsbildung und diskursiver Verfahren, 1996. Putnam (Fn. 214), S. $677 \mathrm{ff}$, verdächtigt allerdings das durch den Fernsehkonsum veränderte Freizeitverhalten, das bürgerschaftliche Engagement insgesamt verringert zu haben.

217 Walzer (Fn. 65), S. 65.

218 Hierzu Michael Saward, Democracy and Citizenship: Expanding Domains, in: John S. Dryzek/ Bonnie Honig/Anne Philips (Hrsg.), The Oxford Handbook of Political Theory, 2006, S. 400-419 (S. 412 ff.).

219 Instruktiv zu Modernisierung, Modernität und Postmoderne: Christian Lutz, Die „Postmoderne" - das Ende des Projekts Moderne?, in: Volker J. Kreyher/Carl Böhret (Hrsg.), Gesellschaft im Übergang, Problemaufrisse und Antizipationen, 1995, S. 79-90; Thomas Nipperdey, Probleme der Modernisierung in Deutschland, in: ders., Nachdenken über die deutsche Geschichte, Essays, 2. Aufl. 1986, S. 44-59.

220 Hierzu Ulrich Beck, Vom Veralten sozialwissenschaftlicher Begriffe, Grundzüge einer Theorie reflexiver Modernisierung, in: Christoph Görg (Hrsg.), Gesellschaft im Übergang, Perspektiven kritischer Soziologie, 1994, S. 21-43 (S. 31 ff.); sowie ausführlich ders. (Fn. 236). 
Es gilt als wichtiges Ziel politischen Handelns, die Öffentlichkeit für sich und seine Ziele zu gewinnen; hierfür braucht man in der Regel zunächst Medienöffentlichkeit. Hierfür werden aktives „,news management“ oder die Inszenierung von sogenannten Pseudoereignissen eingesetzt. Diese Strategie verfolgen aber nicht nur Politiker und staatliche Stellen, sondern auch die verschiedenen zivilgesellschaftlichen Akteure, die Aufmerksamkeit für ihre Belange erreichen und ihren Zielen durch öffentliche Unterstützung Nachdruck verleihen wollen. ${ }^{221}$ Man denke nur an die zahlreichen spektakulären Aktionen von Greenpeace oder das Vorgehen der „Cap Anamur" im Jahre 2005 222 . Gehen diese Akteure erfolgreich aus der Konkurrenz um die gesellschaftliche Zustimmung hervor, so führt dies in ihren Augen zur Delegitimierung staatlicher Entscheidungen. Das Regieren gegen eine mobilisierte (Teil-) Öffentlichkeit und die veröffentlichte Meinung ist freilich möglich, solange an der Wahlurne Erfolge errungen werden, wie die Kanzlerschaft Helmut Kohls (19821998) deutlich macht.

\section{b) Auswirkung auf staatsleitende Prinzipien}

Art. 20 Abs. 2 Satz 1 GG stellt lakonisch fest, dass alle Staatsgewalt vom Volke ausgeht. Satz 2 erläutert, dass einerseits das Volk sie in Wahlen und Abstimmungen ausübt, andererseits besondere Organe der Gesetzgebung, der vollziehenden Gewalt und der Rechtsprechung Staatsgewalt ausüben. Hierin kommt die funktionale Delegation der Staatsgewalt an die vielfältig verästelten Organe zum Ausdruck, die für den modernen Staat unerläßlich ist, aber bereits in der Antike notwendig gewesen war. Art. 20 Abs. 2 GG (i. V.m. Abs. 1) ist zugleich auch Sitz des Demokratie- und Mehrheitsprinzips. Diese Prinzipien gelten für die „Wahlen und Abstimmungen“ des Volkes, aber auch für diejenigen, die im Parlament stattfinden. Mehrheitsentscheidungen setzen Willensbildung voraus, für die unter anderem Information unverzichtbar ist. Information ist, nicht zuletzt durch die Auswahl, Intensität und den Zeitpunkt der Informationsweitergabe, stets auch Beeinflussung. Ob objektive Information überhaupt möglich ist, soll hier dahinstehen. Im politischen Raum ist die Information durch Interessenvertreter, die auf diese Weise Entscheidungen beeinflussen wollen, an der Tagesordnung.

Heute steht jedoch - angesichts der fortschreitenden gesellschaftlichen Differenzierung $^{223}$ hinsichtlich der relevanten Akteure - die überkommene Dominanz verbandsförmiger Interessenvertretung in Frage. ${ }^{224}$ Ein hohes Mitsteuerungspotential ist den in westlichen Demokratien allerdings immer noch zu verzeichnen. Die Auflö-

221 Eine aktuelle quantitative Analyse zur Medienpräsenz bezogen auf Dänemark findet sich bei Anne Skorjar Binderkrantz, Interest groups in the media: Bias and diversity over time, in: European Journal of Policy Research 2012, S. 117-139.

222 Siehe Arnd Pollmann, Nussschale. War die Cap Anamur-Aktion eine PR-Maßnahme?, in: Freitag, 32/2004; abrufbar unter http://www.freitag.de/2004/32/04321102.php (zuletzt besucht am 2. März 2012).

223 Skeptisch schon vor fast vierzig Jahren Zacher (Fn. 191), S. 165: Pluralismus dürfe nicht zu Fragmentierung führen.

224 So von Winter (Fn. 132), S. 39 f. Zu den Diskussionslinien der letzten sechzig Jahre vgl. Rudolph Bauer, Zivilgesellschaftliche Gestaltung der Bundesrepublik: Möglichkeiten oder Grenzen? Skeptische 
sung des einstmals beherrschenden „Elitenkartells“225 ist einerseits auf die rückläufigen Mitgliederzahlen der Verbände und den dadurch bedingten geminderten Vertretungsanspruch sowie die geringere Mächtigkeit und andererseits auf das Aufkommen der neuen sozialen Bewegungen, Bürgerinitiativen und Nichtregierungsorganisationen (NRO) zurückzuführen. ${ }^{226}$ Damit einher geht eine neue Form der Einflußnahme durch die Öffentlichkeit: Bürgerinitiativen und NRO gründen ihren Einfluß anders als beispielsweise Gewerkschaften nicht auf das Potential ihrer Leistungsverweigerung, sondern auf die Macht von organisiertem Protest und medienwirksamen Auftritten, wie etwa das Beispiel Greenpeace zeigt. Soziale Bewegungen und NRO beleben aber auch jene Formen von Präsenzöffentlichkeit neu, die im medialen Zeitalter marginalisiert zu werden drohen. Ihnen kann auf diese Weise eine besondere Authentizität zukommen; diese darf allerdings nicht mit einer - gar demokratischen - Legitimation gleichgesetzt werden. Die vermeintlich bessere Moral darf das Mehrheitsprinzip nicht unterlaufen. ${ }^{227}$ Dass es zwischen Marktplatz und Wahllokal zu Periodenverschiebungen kommen kann, ist im Interesse einer über den Tag hinaus funktionierenden Staatstätigkeit zu akzeptieren. ${ }^{228}$ Schon länger wird Politikern der Vorwurf gemacht, sie dächten nur bis zum nächsten Wahltermin. Besteht also einerseits kein Bedarf an einer noch kurzfristiger orientierten Politik, so bedeutet auf demokratische Mehrheiten gestütztes Regieren andererseits, dass solcherart legitimierte und mandatierte Politikziele auch gegen lautstark agierende Interessengruppen durchgesetzt werden können. ${ }^{229}$ Im Lichte der Proteste gegen Abriss und Neubau des Stuttgarter Hauptbahnhofs scheint diese Feststellung neubewertet werden zu müssen (dazu unten III).

Wenn die Öffentlichkeit als Kontrollinstrument eingesetzt wird, ist aus der Perspektive staatlicher (Entscheidungs-) Verfahren stets nach den Auswirkungen auf das sorgsam austarierte Gewaltenteilungsgefüge zu fragen. Die Öffentlichkeit ist den beteiligten Staatsorganen - etabliert und organisiert - nicht vergleichbar, ihre Wirkung beruht ja gerade auch auf ihrer Spontaneität und Unorganisiertheit. Das Inter-

Anmerkungen aus Sicht der Nonprofit-Forschung, in: Klaus M. Schmals/Hubert Heinelt (Hrsg.), Zivile Gesellschaft, Entwicklung, Defizite, Potentiale, 1997, S. 133-153 (S. 134f.)

${ }^{225}$ Kenneth F. Dyson, Die Ideen des Staates und der Demokratie, Ein Vergleich ,staatlich verfaßter" und ,nicht staatlich verfaßter“ Gesellschaften, in: Der Staat 1980, S. 485-515 (S. 510).

${ }^{226}$ Hierzu beispielsweise Streeck (Fn. 62), S. 474 ff. Rudzio (Fn. 131), S. 87 ff.

227 Diese vermeintlich bessere Moral vermag freilich, wie sich am Beispiel der Partei Bündnis90/Die Grünen zeigt, dank publizistischer Unterstützung diskursiv aufgebläht zu werden und auf diese Weise übergewichteten Rechtfertigungsdruck auf die Politik der parlamentarischen Mehrheit oder des regelmäßig größeren Koalitionspartners auszuüben.

228 Wichtige Hinweise zu dieser Frage bei Stephan Ruß-Mohl, Konjunkturen und Zyklizität in der Politik: Themenkarrieren, Medienaufmerksamkeits-Zyklen und ,lange Wellen“, in: Adrienne Héritier (Hrsg.), Policy-Analyse, Kritik und Neuorientierung (PVS-Sonderheft 24/1993), 1993, S. 356-368.

${ }^{229}$ Ein Beispiel hierfür waren die sogenannten Hartz-Reformen, die die rot-grüne Bundesregierung gegen den erbitterten Widerstand von gewerkschaftlich mitorganisierten „Montagsdemonstrationen“ durchsetzte. Erst kontinuierliche Wahlerfolge der Partei „Die Linke“, hervorgegangen aus der durch die Hartz-Reformen initiierten ,Wahlalternative Soziale Gerechtigkeit" (WASG) - ein Zusammenschluß enttäuschter Sozialdemokraten und von Gewerkschaftsfunktionären - und der zuletzt als „Partei des Demokratischen Sozialismus“ (PDS) firmierenden „Sozialistischen Einheitspartei Deutschlands" (SED) haben zu teilweisen Rücknahmen dieser Reformen geführt. Die neuerlangte Mächtigkeit eines Akteurs bewirkt einen Politikwechsel trotz fortbestehender demokratischer Legitimation der $\mathrm{Re}-$ gierung, weil ein gefühlter Legitimationsverlust eingetreten ist. 
esse der Öffentlichkeit ist sprunghaft, oft nicht nachvollziehbar in seiner Themenauswahl und unkalkulierbar in seiner Beständigkeit. Das, worüber Massenmedien intensiv berichten, wird in der Öffentlichkeit als bedeutsam wahrgenommen. Die Auswahl durch die Medien kann vom Thema selbst abhängen, aber auch davon, ob ein ,,attraktiver“, gut medial vermittelbarer - manchmal auch nur ein lärmender Akteur dieses Thema formuliert. Themen brauchen überdies ihre Zeit, wie sich an so wichtigen Beispielen wie Alterung der Gesellschaft und Klimawandel zeigen läßt, die beide trotz hoher sachlicher Relevanz und Dringlichkeit für lange Zeit nicht aufgegriffen wurden, ${ }^{230}$ und in der Folge möglicherweise übertrieben und alarmistisch behandelt wurden.

Die medial behandelten Themen und das zu ihnen existierende öffentliche Meinungsklima wirken sich stark auf die individuelle Meinungs- und Einstellungsbildung aus. ${ }^{231}$ Soll Öffentlichkeit als Gestaltungselement in ein Verfahren einbezogen werden, so verlangt es das Prinzip der Gleichbehandlung (Art. 3 Abs. 1 GG), dass das Verfahren so ausgestaltet wird, dass auch vergleichsweise wenig öffentlichkeitswirksame Minderheitenpositionen Berücksichtigung finden. Öffentlichkeit darf nicht neue strukturelle Asymmetrien begründen. ${ }^{232}$

Ist Öffentlichkeit für den Rechtsstaat gleichermaßen kennzeichnend wie unverzichtbar, so muss sie ihre Funktionen notwendigerweise auch in rechtsstaatlich strukturierten Bahnen wahrnehmen. Doch dies ist nicht die einzige Schwierigkeit, die es zu erkennen und zu lösen gilt: vor allem aus der Perspektive des demokratischen Rechtsstaats (Art. 20 Abs. 1 und 3 GG) werden kritische Fragen mit Blick auf die Rolle von Öffentlichkeit und Zivilgesellschaft gestellt. ${ }^{233}$ Gerade in Verhandlungssystemen zwischen Staat und Gesellschaft sind aber nicht nur unorganisierte Interessen ausgeschlossen, sondern es verlieren auch die in Interessenverbänden organisierten Bürger gegenüber den miteinander kooperierenden staatlichen und gesellschaftlichen Eliten an Einflußmöglichkeiten. Außerdem entziehen sich politische Prozesse in Politiknetzwerken, die mittels nichtöffentlicher Kontakte zwischen Funktionären und Experten stattfinden, einer demokratischen Kontrolle. ${ }^{234}$ Obwohl ihre demokratischen Rechte hierdurch nicht angetastet werden, werden die Einflußmöglichkeiten der Bürger auf diese Weise faktisch gleich mehrfach eingeschränkt.

${ }^{230} \mathrm{Zu}$ Interessen und Zwängen in den Medien vgl. den Überblick bei Rudzio (Fn. 131), S. 395 ff. Ferner Barbara Pfetsch, Politik und Fernsehen: Strukturen und Bedingungen politischer Kommunikation, in: ZPol 1996, S. 331-347.

231 Zu diesem Fragenkomplex vgl. Michael Schenk/Uwe Pfennning, Individuelle Einstellungen, soziale Netzwerke, Massenkommunikation und öffentliches Meinungsklima: Ein analytisches Interdependenzmodell, in: Stefan Müller-Doohm/Klaus Neumann-Braun (Hrsg.), Öffentlichkeit, Kultur, Massenkommunikation, Beiträge zur Medien- und Kommunikationssoziologie, 1991, S. 165-184; Uwe Krähnke, Selbstbestimmung, 2007, S. $108 \mathrm{ff}$.

${ }^{232}$ Eberhard Schmidt-Aßmann, Grundrechte als Organisations- und Verfahrensgarantien, in: Detlef Merten/Hans-Jürgen Papier (Hrsg.), Handbuch der Grundrechte in Deutschland und Europa, Bd. II: Grundrechte in Deutschland, Allgemeine Lehren 1, 2006, \$45, Rn. 83. Ähnlich bereits Ernst Fraenkel, Strukturanalyse der modernen Demokratie (1969), in: ders., Deutschland und die westlichen Demokratien, 1991, S. 326-359 (S. 358), mit der Forderung nach „Waffengleichheit der Interessengruppen“. Zu den Stärken und Schwächen von Fraenkels pluralistischer Demokratietheorie siehe Schmidt (Fn. 209), S. $235 \mathrm{ff}$.

233 Beispielsweise von Zacher (Fn. 191), S. $174 \mathrm{f}$.

234 Benz (Fn. 134), S. 107. 
Hier setzen Überlegungen an, die Leistungsschwächen des modernen Interventionsstaates $^{235}$ zum Anlaß nehmen, ein neues Gesamtmodell von Politik zu entwerfen, das zunächst politische Teilhaberechte erweitern will. Sodann soll die Verbesserung von effektiven Partizipationschancen in einzelnen Politikbereichen wirksamer als bisher zusammengefaßt werden. Dieser reflexive Ansatz ${ }^{236}$ strebt einerseits eine Demokratisierung der internen Strukturen bestehender staatlicher Institutionen an. Andererseits wird vorgeschlagen, die Meinungsbildung in pluralen gesellschaftlichen Öffentlichkeiten selbst stringenter zu gestalten und gleichzeitig wirksamer mit bestehenden Formen institutionalisierter politischer Willensbildung und Entscheidungsfindung zu verbinden.

\section{d) Offene Fragen}

Zu klären bleibt weiterhin, wie Art und Umfang des Einflusses der verschiedenen zivilgesellschaftlichen Akteure einerseits als Teil der Öffentlichkeit und andererseits als Kooperationspartner des Staates bestimmt werden können und welche Rolle der Staat tatsächlich spielt: Gibt er Steuerungskompetenzen ab und macht sich vom Informationsinput der Interessenvertretungen abhängig? Gelingt es ihm umgekehrt, die Vielfalt der Interessen und Durchsetzungsstrategien durch Einbindung in formalisierte Diskurs- und Verhandlungsprozesse zu kanalisieren und beherrschbar, zumindest kalkulierbarer zu machen? ${ }^{237}$

Föderalismus vervielfacht die Zahl der staatlichen Akteure und sorgt für Koordinationsnotwendigkeiten zwischen ihnen, die sich mitunter schwierig gestalten. Dies ist Ausdruck der ,paralysierenden Binnenkomplexität hochentwickelter Staatsapparate“ ${ }^{238}$ Die seit den 1950er Jahren gewachsene internationale, vor allem europäische Verflechtung hat diese Komplexität zusätzlich erhöht und den Kooperationsbedarf weiter steigen lassen. ${ }^{239}$ Diese Entwicklung hin zu immer komplexeren Systemen läßt es gleichzeitig zu, dass auch andere, nichtstaatliche Akteure ihren Platz finden und als Kooperationspartner akzeptiert werden.

Hinsichtlich einer wichtigen zivilgesellschaftlichen Akteursgruppe, der neuen sozialen Bewegungen, ergeben sich Besonderheiten, vor allem aus der Sozialstruktur

235 Zum Hintergrund vgl. Bob Jessop, Veränderte Staatlichkeit, Veränderungen von Staatlichkeit und Staatsprojekten, in: Dieter Grimm (Hrsg.), Staatsaufgaben, 1994, S. 43-73; s. a. Ulrich (Fn. 196), S. 13ff. sowie die in Fn. 17 genannte Literatur.

236 Etwa bei Ulrich Beck, Die Erfindung des Politischen, Zur Theorie einer reflexiven Modernisierung, 1993; Rainer Schmalz-Bruns, Perspektiven demokratischer Gestaltung - die neuere Diskussion um Demokratie und politische Institutionen, in: Christoph Görg (Hrsg.), Gesellschaft im Übergang, Perspektiven kritischer Soziologie, 1994, S. 157-176 (S. 168ff.).

237 Vgl. von Winter (Fn. 132), S. 42 m.w.Nw.

238 Claus Offe, Die Staatstheorie auf der Suche nach ihrem Gegenstand, in: Jahrbuch für Staats- und Verwaltungswissenschaft, Bd. 1 (1987), S. 301-321 (S. 311).

239 Die Diskussion wird in mehreren Disziplinen unter dem Stichwort Mehrebenensystem geführt; vgl. beispielsweise Thomas König (Hrsg.), Das europäische Mehrebenensystem (Mannheimer Jahrbuch für europäische Sozialforschung, Bd. 1), 1996; Gabriele Bauschke u. a. (Hrsg.), Pluralität des Rechts Regulierung im Spannungsfeld der Rechtsebenen, 2003; Hubert Heinelt/Michèle Knodt (Hrsg.), Politikfelder im EU-Mehrebenensystem, Instrumente und Strategien europäischen Regierens, 2008. 
ihrer primären Trägergruppen und ihrer Resonanzgruppen. ${ }^{240} \mathrm{Im}$ Unterschied zu älteren sozialen Bewegungen - Arbeiterbewegung: wirtschaftsbezogene, Bürgertum: staatsbezogene Problemkomplexe - thematisieren neue soziale Bewegungen Probleme im Zusammenhang mit der soziokulturellen Identität, die allerdings starke Rückwirkungen in den wirtschaftspolitischen und staatlichen Raum haben. Über die Paradigmata von Lebensweise und Lebensstil, welche mittels der soziokulturellen Identität ins Spiel gebracht werden, entfaltet sich ein hohes Mobilisierungs- und Resonanzpotential, das mit einer Integrationskrise des überkommenen politischen Vermittlungssystems durch Parteien und Verbände einhergeht. Deshalb werden soziale Bewegungen als ,demokratische Produktivkraft“ verstanden, die , den Modus repräsentativer Demokratie in fruchtbarer Weise ergänzen“ und „,ein wichtiges Potential für ein demokratisches Gemeinwesen“ bilden. ${ }^{241}$ Auch neue soziale Bewegungen integrieren allerdings nur Teile der Bevölkerung, bei eng gesteckten Themen oftmals nur zeitweilig, sozusagen für die Lebensdauer des Projekts.

Ein Überblick über die sich in sozialen Bewegungen manifestierende Protestaktivität in der Bundesrepublik Deutschland als Verhaltensform der Bürgerschaft zeigt nicht nur inhaltliche Veränderungen zwischen 1950 (v. a. Arbeitskonflikte) und 2000 (ab 1980er: Menschen- und Bürgerrechte, Frieden und Abrüstung), sondern auch geänderte, offensivere Protestformen. Jüngstes Beispiel ist die in vielen Ländern aktive „Occupy-Bewegung“, die für sich in Anspruch nimmt, 99\% der Gesellschaft zu vertreten (siehe unten III).

Man sollte freilich der Versuchung widerstehen, nur emanzipatorische oder sonst „,inhaltlich korrekte“ soziale Bewegungen zu erfassen. ${ }^{242}$ Entscheidend dafür, dass es sich um eine soziale Bewegung handelt, sind die Vorstellung, die Gesellschaft sei gestaltbar, und der darauf aufbauende Versuch, auf ihre Grundstrukturen einzuwirken. Folglich sind auch Neonazis als neue soziale Bewegung zu bezeichnen. Demokratische Produktivkraft können solche repressiven Bewegungen freilich nicht entfalten; allerdings in Form von Gegenbewegungen anstoßen.

Die fortschreitende Kooperation von Staat und Gesellschaft droht die Unterschiede einzuebnen, die trotz schon immer bestehender Verflechtungen zwischen beiden nach wie vor zu beobachten sind. Die gegenseitige Entgrenzung wird aus beiden Perspektiven als Bedrohung der jeweiligen Autonomie empfunden, ist aber neben einem defensiven Entscheidungsstil der Preis für die Sicherheit vor Überraschungen, die ja das Ziel der Verflechtung darstellt. „Wandel durch Annäherung“"243 läßt sich auch hier beobachten und stärkt das Verlangen nach unkonventionellen, wenig institutionalisierten intermediären Organisationen, die sich später, um sich dauerhaften

\footnotetext{
${ }^{240}$ Hierzu und zum folgenden Joachim Raschke, Soziale Bewegungen, Ein historisch-systematischer Grundriß, 1985 , S. $413 \mathrm{ff}$.

241 Dieter Rucht, Soziale Bewegungen als demokratische Produktivkraft, in: Ansgar Klein/Rainer Schmalz-Bruns (Hrsg.), Politische Beteiligung und Bürgerengagement in Deutschland, Möglichkeiten und Grenzen, 1997, S. 382-403 (S. 384).

242 Zutreffend Rucht (Fn. 241), S. 391.

${ }^{243}$ Egon Bahr, Wandel durch Anregung, in: Deutschland Archiv, Zeitschrift für Fragen der DDR und der Deutschlandpolitik, Heft 8/1973, S. 862-865 (= „Tutzinger Rede“ vom 15. Juli 1963). Auch abrufbar unter: http://www.fes.de/archiv/adsd_neu/inhalt/stichwort/tutzinger_rede.pdf (zuletzt besucht am 20. März 2009).
} 
Einfluß zu sichern, ihrerseits institutionalisieren und professionalisieren sowie mit dem Staat und anderen Organisationen verflechten. ${ }^{244}$

\section{Aktuelle Praxis zivilgesellschaftlicher Akteure und neue Forschungsfragen}

Nachstehend kann es nur um einzelne exemplarische Beispiele gehen, wobei versucht werden soll, neben der innerstaatlichen, deutschen Ebene auch die zwischenstaatliche Ebene hinreichend zur Geltung zu bringen, denn „nicht nur die Staaten, sondern auch die Individuen und gesellschaftlichen Gruppen [stehen] in einem komplexen multinationalen Beziehungsgeflecht". ${ }^{245}$ So beteiligen sich zivilgesellschaftliche Akteure seit geraumer Zeit aktiv an dem, was Global Governance genannt wird. ${ }^{246}$ Für Politikfelder wie Umweltschutz oder Abrüstung (etwa Landminenverbot $^{247}$ ) ist ihre Rolle genauso wichtig wie für den Menschenrechtsschutz. Insgesamt wird ihnen eine hohe legitimitätsstiftende Funktion zugeschrieben, auf der internationalen Ebene wird gar erwartet, sie könnten diagnostizierte Demokratiedefizite abmildern.

\section{Praxisbeispiele}

\section{a) Nationale Ebene}

Inwieweit zivilgesellschaftlicher Druck politische Entscheidungen zu beeinflussen vermag, ist im Einzelfall schwer zu ermitteln. Die jahrzehntelang aktive Anti-Atomkraft-Bewegung hat sicherlich dazu beigetragen, dass nach dem Machtwechsel 1998 die sich ihr personell und sachlich verbunden fühlende rot-grüne Bundesregierung mit den Energiekonzernen den Atomausstieg vereinbarte. ${ }^{248}$ Der Wählerwille bei der Bundestagswahl im Jahr 2009 legitimierte die schwarz-gelbe Bundesregierung aus ihrer Sicht dazu, diesen Ausstieg teilweise rückgängig zu machen und die Laufzeiten der Kraftwerke zu verlängern. Hieran konnte auch der neumobilisierte Protest der

244 Siehe hierzu auch Streeck (Fn. 62), S. 488 ff. Guter Überblick bei Bauer (Fn. 224), S. 137.

245 Kotzur (Fn. 17), S. 212.

246 Jan Aart Scholte, Civil Society and Democracy in Global Governance, in: Global Governance 8 (2002), S. 281-304; Klaus Dingwerth, Effektivität und Legitimität globaler Politiknetzwerke, in: Tanja Brühl u.a. (Hrsg.), Unternehmen in der Weltpolitik, Politiknetzwerke, Unternehmensregeln und die Zukunft des Multilateralismus, 2004, S. 74-95; Paul Wapner, Civil Society, in: Thomas G. Weiss/Sam Daws (Hrsg.), The Oxford Handbook on the United Nations, 2007, S. 254-263.

247 Die „International Campaign to Ban Landmines“ (ICBL), deutsch „Internationale Kampagne für das Verbot von Landminen" hatte seit 1991 auf den Abschluß eines entsprechenden Vertrages hingewirkt. Die sogenannte Ottawa-Konvention (,The 1997 Convention on the Prohibition of the Use, Stockpiling, Production and Transfer of Anti-Personnel Mines and on Their Destruction") wurde 1997 vereinbart und trat 1999 in Kraft. Die ICBL wurde im Jahr 1997 mit dem Friedensnobelpreis ausgezeichnet. Siehe auch http://www.icbl.org/index.php (besucht am 10. April 2012).

248 Siehe Alexander $W$. Schneehain, Der Atomausstieg: eine Analyse aus verfassungs- und verwaltungsrechtlicher Sicht, 2005. 
Anti-Atomkraft-Bewegung, der eine gesellschaftliche Mehrheit hinter sich wähnte, nichts ändern. Erst der durch ein Erdbeben mit anschließender Flutwelle ausgelöste Reaktorunfall in Japan im März 2011 führte zu einer Kehrtwende der Bundesregierung, die nun eine Neubewertung der Risiken vornahm und eine neuerliche Verkürzung der Restlaufzeiten verkündete. Dies verprellte freilich einen Teil der eigenen Anhängerschaft und stieß bei der Anti-Atomkraft-Bewegung auf tiefe Skepsis.

Im Falle des Bahnhofsneubaus in Stuttgart (S 21) schien zunächst alles den bei Großprojekten üblichen Gang zu gehen. Das Projekt wurde im Jahr 1994 der Öffentlichkeit vorgestellt, nach einer Machbarkeitsstudie aus dem Folgejahr wurde das Raumordnungsverfahren Ende 1996 eingeleitet. Nachdem Finanzierungsschwierigkeiten aufgetreten und im Jahr 2001 endgültig gelöst worden waren, wurde das Planfeststellungsverfahren ab 2001 abschnittsweise eingeleitet. Teilabschnitte wurden in den Jahren 2005 und 2006 genehmigt. In Baden-Württemberg und auf Bundesebene wurde das Projekt politisch breit unterstützt, lediglich Bündnis90/Die Grünen sprachen sich im Land dagegen aus. Ein im Jahre 2007 beantragter Bürgerentscheid wurde von der Stadt Stuttgart zurückgewiesen. Ab 2007 kam es zu Kundgebungen gegen S 21, an denen jeweils mehrere tausend Menschen teilnahmen, regelmäßiger Protest formierte sich ab November 2009, nachdem die Gerichte den Antrag auf Bürgerentscheid endgültig verworfen hatten. Als bei der Kommunalwahl im Juni 2009 die Parteien, die das Projekt unterstützten, deutliche Stimmenverluste erfuhren, erlangte die hartnäckige, aber bis dahin nicht überwältigende Ablehnung eines überregionalen Verkehrsprojekts schließlich Aufmerksamkeit über Stuttgart hinaus, was ihre Resonanz enorm verstärkte. Freilich wurden die Bewegung(steilnehmer), ihre Haltungen und Ziele durchaus zwiespältig gesehen, was die Wortschöpfung „Wutbürger" belegt. ${ }^{249}$ Nach dem Baubeginn im Februar 2010 nahmen die Proteste weiter zu; im September 2010 erfolgte ein massiver Polizeieinsatz, bei dem mehrere hundert Menschen verletzt wurden.

Von Oktober bis November 2010 fanden daraufhin sogenannte Schlichtungsgespräche unter der Leitung des ehemaligen Politikers Heiner Geißler statt. ${ }^{250}$ Diese sollten eine aktuelle und umfassende Information ermöglichen und anschließend eine Neubewertung der Situation vornehmen, was angesichts einer gerichtlich bestätigten Verwaltungsentscheidung, die von einem breiten, parteiübergreifenden politischen Konsens getragen worden war, eine Unsicherheit von Behörden und Landesregierung belegte, wie mit der Situation umzugehen sei. ${ }^{251}$ Die Schlichtung wurde stundenlang im Fernsehen übertragen und bescherte dem Sender Phoenix ungeahnte Einschaltquoten für ein Programm, das von ermüdender Detailfülle geprägt war und jeglichen Spannungsbogen vermissen ließ; das Interesse dürfte allerdings auch dem zuvor erreichten Grad der Eskalation geschuldet gewesen sein. ${ }^{252}$

249 Dirk Kurbjuweit, Der Wutbürger, in: Der Spiegel 41/2010 vom 11. Oktober 2010, S. $26 \mathrm{f}$.

250 Hierzu beispielsweise Dennis Eger, Stuttgart 21: Schlichtung, Mediation, Theater? Eine neue Form der Legitimation politischer Prozesse?, 2011.

251 Wenn man annimmt, Öffentlichkeit trage zur "Spannungsbalance“ (Arnold Gehlen) des Staates bei, so ließe sich die Schlichtung als institutionalisierte Stabilisierung dieser Spannungsbalance begreifen.

252 So auch Frank Brettschneider, Kommunikation und Meinungsbildung bei Großprojekten, in: Aus Politik und Zeitgeschichte, 2011, 44/45, S. 40-47 (S. 42f.). 
Bei der Landtagswahl im März 2011 verlor erstmals seit 48 Jahren die CDU ihre Mehrheit; es kam zur Bildung einer grün-roten Landesregierung. Zwar hatte die Schlichtung zu einer Versachlichung der Diskussion um S 21 geführt, aber die widerstreitenden Positionen in der Sache nicht versöhnt. Bei der landesweiten Volksabstimmung am 27. November 2011 sprachen sich 58,9 Prozent der Abstimmenden gegen den Ausstieg des Landes aus der Projektfinanzierung von S 21 aus - bei einer Beteiligung von $48,3 \%$ der Stimmberechtigten. ${ }^{253}$

Bürgerbeteiligung in vergleichbarer Form müsste zukünftig allerdings, um tatsächlich befriedend zu wirken und Akzeptanz für Großprojekte herzustellen, früher ansetzen. Ob die Beteiligungsmöglichkeiten des Verwaltungsverfahrens - etwa in

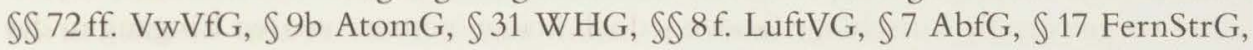
\$ $10 \mathrm{BImSchG}$ - hierfür geeignet und ausreichend sind, wird kontrovers diskutiert.

Ein unverbundenes (bloß) deliberatives Anhörungsverfahren ohne rechtliche Folgen erscheint im Rahmen der Verwaltungsentscheidung wenig sinnvoll. Als Ergänzung zu Parlamentsentscheidungen mag es sinnvoll sein, wird eine zu berücksichtigende Position dadurch doch explizit gemacht, die ansonsten durch die Eigengesetzlichkeiten der innerparteilichen Meinungsbildung und im parlamentarischen Prozess gegebenenfalls nicht hinreichend berücksichtigt werden würde.

\section{b) Internationale Ebene}

Nichtregierungsorganisationen spielen als generelle Akteure innerhalb des Systems der Vereinten Nationen eine immer stärkere Rolle und bearbeiten vor allem die Politikfelder Menschenrechtsschutz, Umweltschutz, Entwicklungszusammenarbeit, humanitäre Hilfe und Konfliktprävention. ${ }^{254}$ Sie sind in den letzten Jahrzehnten zum auch völkerrechtlich anerkannten ${ }^{255}$ Akteur auf der internationalen Ebene geworden $;{ }^{256}$ Bild und Arbeitsweise der NRO sind vielgestaltig.

Ihre Stellung im System der Vereinten Nationen ist jenseits der Akkreditierung beim Wirtschafts- und Sozialrat (ECOSOC) ${ }^{257}$ allerdings noch weitgehend von Un-

253 Zahlen (und weitere Informationen zur Volksabstimmung sowie zu S 21 insgesamt) etwa unter http://www.lpb-bw.de/volksabstimmung_stuttgart21.html (besucht am 12. April 2012).

$254 \mathrm{Vgl}$. Thomas Fitschen, Vereinte Nationen und nichtstaatliche Organisationen, in: Helmut Volger (Hrsg.), Grundlagen und Strukturen der Vereinten Nationen, 2007, S. 309-329 (S.309ff.); Sergey Ripinsky/Peter van den Bossche, NGO Involvement in International Organizations, A Legal Analysis, 2007.

255 Vgl. nur: Stephan Hobe, Der Rechtsstatus von Nichtregierungsorganisationen nach gegenwärtigem Völkerrecht, in: AVR 1999, S. 152-176.

256 Etwa Peter Willetts (Hrsg.), ,The Conscience of the World“, The Influence of Non-Governmental Organisations in the U.N. System, 1996; Thomas Risse/Anja Jetschke/Hans-Peter Schmitz, Die Macht der Menschenrechte, Internationale Normen, kommunikative Prozesse und politischer Wandel in den Ländern des Südens, 2002; Nils Geißler, Einfluss und Rolle der Nichtregierungsorganisationen beim Schutz der Menschenrechte, in: Erwin Müller/Patricia Schneider/Kristina Thony (Hrsg.), Menschenrechtsschutz, Politische Maßnahmen, zivilgesellschaftliche Strategien, humanitäre Intervention, 2002, S. $62-78$.

257 Einführend zum ECOSOC Wolfgang Spröte, Wirtschafts- und Sozialrat (ECOSOC), in: Helmut Volger (Hrsg.), Lexikon der Vereinten Nationen, 2000, S. 662-665; Frederic L. Kirgis Jr., United Nations Economic and Social Council, in: EPIL IV (2000), S. 1089-1093. 
verbindlichkeit geprägt. Zwar eröffnen die Vereinten Nationen den NRO eine förmliche Beteiligung an den Sitzungen des ECOSOC nach einem in Art. 71 SVN festgelegten Modus. ${ }^{258}$ Doch entspricht diese Beteiligungsmöglichkeit nicht mehr den heutigen Anforderungen. Um die Organisation der Vereinten Nationen zu stärken, ihre Arbeit wirksamer zu machen und die Rolle der für das Funktionieren der Organisation in vielen Bereichen inzwischen unverzichtbaren Nichtregierungsorganisationen aufzuwerten, hatte der Generalsekretär die „Gruppe namhafter Persönlichkeiten für die Beziehungen zwischen den Vereinten Nationen und der Zivilgesellschaft" unter dem Vorsitz des damaligen brasilianischen Präsidenten Fernando Henrique Cardoso einberufen. Deren Bericht „We the Peoples ..."259 wurde im Juni 2004 vorgelegt; die Vorschläge fanden jedoch keinen nennenswerten Eingang in das Ergebnisdokument des Weltgipfels von 2005. Dort wird lediglich ihr Beitrag zur Arbeit der Vereinten Nationen gewürdigt ${ }^{260}$ die empfohlene institutionalisierte Beteiligung von NRO ist bislang nicht verwirklicht worden. ${ }^{261}$

Das soll freilich nicht heißen, dass es keine tatsächlichen Fortschritte gegeben hätte. So koordiniert eine Arbeitsgruppe die Kooperation und Information von Nichtregierungsorganisationen mit Blick auf den Sicherheitsrat bereits seit 1995, der seine Arbeitsmethoden überdies weitgehend unbeachtet von Öffentlichkeit und Wissenschaft angepasst und offener gestaltet hat. ${ }^{262}$

Die Aktivitäten der NRO in den Vereinten Nationen und anderen internationalen Organisationen reichen vom sogenannten Agenda-setting bis zu Formulierungsvorschlägen für einzelne Artikel oder ganze Verträge und geschehen beispielsweise durch Lobby- und Kampagnenarbeit in den internationalen Organisationen aber auch direkt bei den Regierungen. Auf diese Weise wurde unter anderem auf die Beratungen über das Übereinkommen gegen Folter und über die Kinderrechtskonvention Einfluß genommen. ${ }^{263}$

Wichtig war und ist auch das gemeinsame Auftreten in sogenannten NRO-Foren, die die Weltkonferenzen vorbereitet oder begleitet haben. So haben sich zur Welt-

258 Einzelheiten hierzu bei Rainer Lagoni/Eleni Chaitidou, Art. 71, in: Bruno Simma (Hrsg.), The Charter of the United Nations, A Commentary, Bd. 2, 2. Aufl. 2002, S. 1068-1082; Anna-Karin Lindblom, Non-Governmental Organizations in International Law, 2005, S. $374 \mathrm{ff}$.

259 „We the Peoples: Civil Society, the United Nations and Global Governance“ (UN-Dok. A/58/817) vom 11. Juni 2004.

260 UN-Dok A/RES/60/1 vom 16. September 2005, Nr. 169. Einzelheiten bei Helmut Volger, Die Reform der Vereinten Nationen, in ders. (Hrsg.), Grundlagen und Strukturen der Vereinten Nationen, 2007, S. 487-571 (S. 533 ff.).

261 Siehe Jens Martens, Zukunftsperspektiven der Mitwirkung von Nichtregierungsorganisationen in den Vereinten Nationen nach dem Weltgipfel 2005, in: Sabine von Schorlemer (Hrsg.), ,Wir, die Völker (...)" - Strukturwandel in der Weltorganisation, 2006, S. 53-67.

262 Hierzu James A. Paul, A Short History of the NGO Working Group on the Security Council, 2001; online verfügbar unter: http://www.globalpolicy.org/component/content/article/185/40407. html (zuletzt besucht am 2. März 2012). Ferner Helmut Volger, Mehr Transparenz und mehr Beteiligung, Die informelle Reform der Arbeitsmethoden des UN-Sicherheitsrats, in: Vereinte Nationen 2010, S. 195-203.

${ }^{263}$ Hierzu und zu weiteren Beispielen Wolfgang S. Heinz, Der Einfluss von Nichtregierungsorganisationen auf das Berichtsprüfungs- und Individualbeschwerdeverfahren im Menschenrechtsschutz der Vereinten Nationen, in: Sabine von Schorlemer (Hrsg.), ,Wir, die Völker (...)“- Strukturwandel in der Weltorganisation, 2006, S. 27-44 (S. $31 \mathrm{ff}$.). 
menschenrechtskonferenz in Wien (1993) mehr als 1.000 NRO, zur Weltfrauenkonferenz in Peking (1995) mehr als 30.000 Menschen zum NRO-Forum getroffen. ${ }^{264}$ Dies signalisiert den Staaten die Mächtigkeit der nichtstaatlichen Organisationen, belegt gleichzeitig aber auch ihre Vielfalt (mit der möglichen Folge der Zersplitterung). Die NRO-Foren dienen der Netzwerkarbeit und dem Informationsaustausch. Die NRO verabreden dort auch Strategien für ihr Vorgehen auf der jeweiligen Weltkonferenz selbst. Im Umfeld der Weltkonferenzen entfalten die NRO eine vielfältige Lobby- und Kampagnenarbeit. Das Generalsekretariat der Vereinten Nationen unterstützt diese Organisationen dabei in einem gewissen Umfang auch logistisch.

Die Hochzeit der Weltkonferenzen ist allerdings vorbei und die Debatten über wirtschaftliche und soziale Themen finden zunehmend wieder in den Organen und Gremien der Vereinten Nationen statt. ${ }^{265}$ Dementsprechend wird es zukünftig vor allem darauf ankommen, die Beteiligungs- und Mitwirkungsrechte der NRO dort auszubauen. ${ }^{266}$ Daran wird abzulesen sein, wie weit die Bemühungen der Vereinten Nationen reichen, die internationale Demokratie im Ansatz zu unterstützen, indem sie den NRO auf unterschiedliche Weise Foren bieten, um die von den Regierungen dominierte internationale Politik aktiv zu begleiten und so „Global deliberations“ ermöglichen. Überdies ergänzen sich die Vereinten Nationen und die NRO in ihrem Bestreben, Einfluß auf die Staaten und Regierungen zu nehmen, und arbeiten auch aus diesem Grund zusammen. ${ }^{267} \mathrm{Nach}$ dem Scheitern des Weltklimagipfels von Kopenhagen im Dezember 2009 wird allerdings darüber diskutiert, wie sinnvoll bisherige Strategiemodelle der weltweiten Mobilisierung noch sind. ${ }^{268}$

\section{Forschungsfragen und Ausblick}

Es kann hier nur darum gehen, Forschungsfragen zu umreißen und mögliche Diskussionsrichtungen aufzuzeigen. Blickt man zunächst auf die Akteure, so ist die Grundfrage, wer für wen spricht.

Der informelle Charakter zivilgesellschaftlicher Zusammenschlüsse steht formellen Zugehörigkeits- und Zurechnungskriterien oft entgegen. Die Piratenpartei steht

264 Einzelheiten bei Manfred Nowak (Hrsg.), World Conference on Human Rights, Vienna June 1993, The Contribution of NGOs, Reports and Documents, S. 71; vgl. auch Michael G. Schechter, United Nations Global Conferences, 2005.

265 Allerdings haben die sogenannten G20 seit 2008 regelmäßig Treffen auf Ebene der Staats- und Regierungschefs eingerichtet, um die globalen Themen zu beraten und koordiniertes Vorgehen zu erreichen. Diese Form des „Weltregierens" durch einen exklusiven Staatenclub gefährdet einerseits die Bedeutung der Vereinten Nationen und schließt andererseits zivilgesellschaftliche Akteure grundsätzlich von der Mitwirkung aus.

266 Hierzu Fitschen (Fn. 254), S. 319 ff.

267 So auch Wapner (Fn. 246), S. $261 \mathrm{f}$.

268 Hierzu Malte Kreutzfeldt/Nadine Michel, Strategiestreit nach der „, historischen Chance“, in: Die Tageszeitung vom 6./7. Februar 2010, S. 7. Das dort in Bezug genommene Papier von Jürgen Maier, Klimagipfel gescheitert: Nach der COP ist vor der COP??, Diskussionsanstoss vom 7. Januar 2010, wurde dem Verfasser freundlicherweise von Malte Kreutzfeldt überlassen. Maier spricht sich darin für einen Bottom-up-Ansatz aus, der dafür sorgen soll, dass zu Hause die Weichenstellungen vorgenommen werden, die es ermöglichen sollen, anschließend auf der UN-Ebene weitergehende Verpflichtungen zu übernehmen. 
derzeit für den Versuch, das an sich unvereinbare zusammenzuführen und macht mit „Liquid Democracy“ den ständigen Prozesscharakter von Debatte und Entscheidungsfindung nebst nachheriger Infragestellung deutlich. Der Verweis auf das vergleichbare Experimentieren mit Entscheidungsfindungen während bestimmter Phasen der Französischen Revolution und dessen zeitweiliges Abgleiten in Terror und Diktatur mag irritieren, darf aber nicht unterbleiben. Denn die Versachlichung von Debatten in der repräsentativen Demokratie westeuropäischen Zuschnitts nach dem Kriege darf durchaus als Gewinn gelten, für den der Preis gelegentlicher Blässe nicht $\mathrm{zu}$ hoch ist.

Repräsentativität zivilgesellschaftlicher Akteure ist mithin schwer zu messen, was sich auch auf die Legitimität der vertretenen Positionen auswirkt. Sicherlich kann die Mächtigkeit einer Position nicht von der Lautstärke der Sprecher abhängen. Ganz banal ist dann auch zu fragen, wann eine Streitfrage beendet ist. Die Diskussionen um Stuttgart 21 oder Endlager für Atommüll zeigen die damit verbundenen Implikationen. Welche Art von Partizipation ist geeignet, wirklich eine hinreichende Zahl von Interessen und Positionen zu berücksichtigen? Wann beugt sich eine Minderheit der Einsicht, keine Mehrheit errungen zu haben? Wie können hohe Beteiligungsraten erreicht werden? ${ }^{269}$ Bei der Volksabstimmung über S 21 waren rund 7,6 Millionen Menschen stimmberechtigt, 3,68 Millionen haben sich an der Abstimmung beteiligt. 2.160.411 davon haben den Weiterbau befürwortet. Einer solchen Mehrheit fehlt gelegentlich die Überzeugungskraft, wenn auch Ministerpräsident Kretschmann nach der Abstimmung klarstellte, die Entscheidung der Bürgerinnen und Bürger sei in der Demokratie das Maß aller Dinge.

Diese Fragen lassen sich, wenn man nicht am offenbar für einige Teile der Gesellschaft schwer erträglichen Modell der repräsentativen Demokratie als Regelfall, ergänzt durch gelegentliche Ergänzung durch Abstimmungen in Sachfragen, festhalten will, kaum in allgemein gültiger Weise entscheiden.

Ein sinnvoller Schritt scheint es zu sein, Elemente direkter Demokratie zu verstärken, wie dies in den Bundesländern zunehmend der Fall ist. Die berechtigte Warnung vor der Irrationalität von Volkes Stimme mit Blick auf Themen wie Wiedereinführung der Todesstrafe oder dem Umgang mit Kinderschändern darf nicht als bequeme Ausflucht dienen, eine stärkere Entscheidungsbefugnis insgesamt zu blockieren. Sachfragen wie der Nichtraucherschutz (Bayern 2010) oder der obligatorische Religionsunterricht (Berlin 2009) sind selbstverständlich einem Bürgerentscheid zugänglich. Allerdings wäre eine höhere Beteiligung wünschenswert. ${ }^{270}$ Fraglich ist hingegen auch bei Sachthemen, inwieweit es ein grenzüberschreitendes Interesse von Bürgern - aber auch von Politikern - gibt, das entsprechende Entscheidungen sinnvoll einordnet. Ob tatsächlich ein „kosmopolitisches Moment ${ }^{\text {"271 }}$ erfahren und handlungsleitend wird, lässt sich nicht mit Sicherheit sagen. Manche Aspekte

269 Hierzu Wolfgang Merkel/Alexander Petring, Partizipation und Inklusion, in: Friedrich-Ebert-Stiftung (Hrsg.), Demokratie in Deutschland 2011. Abrufbar unter http://www.demokratie-deutschland2011.de/common/pdf/Partizipation_und_Inklusion.pdf (besucht am 12. April 2012).

${ }^{270}$ Vgl. Patrizia Nanz/Miriam Fritsche, Handbuch Bürgerbeteiligung. Verfahren und Akteure, Chancen und Grenzen, 2012.

271 Ulrich Beck, Weltrisikogesellschaft, Auf der Suche nach der verlorenen Sicherheit, 2007, S. 94 ff. 
der Diskussionen über die Schuldenkrise im Euroraum lassen hieran Zweifel aufkommen.

Zivilgesellschaftlichen Akteuren hat sich nicht nur mit Blick auf den Menschenrechtsschutz in den letzten zwanzig Jahren ein erweitertes Betätigungsfeld eröffnet. Der Nationalstaat ist trotz Globalisierung und Verflechtung weder obsolet ${ }^{272}$ noch machtlos ${ }^{273}$ und gerade für den Schutz der Menschenrechte unverzichtbar, ${ }^{274}$ doch es gibt eine Reihe teils ergänzender, teils kontrollierender Funktionen, die zivilgesellschaftliche Akteure wahrnehmen können und müssen. Diese Akteure treten dem Staat hierbei als neue Figurationen des ,globalen Zeitalters“ zur Seite. ${ }^{275}$ Formalisierte und verstetigte internationale Kontrollmechanismen und -prozesse verlangen nach Teilnehmern, die wie Staaten und internationale Organisationen über Dauerhaftigkeit und einen gewissen Organisationsgrad verfügen. So sind es vor allem größere, international aufgestellte NRO, die sich auf der völkerrechtlichen Ebene an diesen Verfahren beteiligen.

Wiener Erklärung und Aktionsprogramm anerkennen die wichtige Rolle von NRO und fordern ihre stärkere Beteiligung in allen Phasen des Menschenrechtsschutzes (Nr. I.38). Fast zwanzig Jahre später ist ihre Beteiligung erkennbar größer geworden, ohne dass die Hauptverantwortung der Staaten geschmälert oder gar ersetzt worden wäre. Gleichzeitig sind weitere zivilgesellschaftliche Akteure als bedeutsam identifiziert worden und werden in den aktuellen Dokumenten der Vereinten Nationen mittlerweile auch unmittelbar angesprochen: So setzen die Vereinten Nationen beispielsweise im Kampf gegen Korruption und Bestechung auf eine verstärkte Einbeziehung von und Zusammenarbeit mit NRO, der Zivilgesellschaft und dem privaten Sektor. ${ }^{276}$ Sie fordern ferner eine aktive Einbeziehung von NRO und Zivilgesellschaft in den Entwicklungsprozess ${ }^{277}$ und plädieren für deren verstärkte Einbindung in die Schaffung einer Friedenskultur ${ }^{278}$. Diese sinnvollen Tätigkeiten müssen und können im Rahmen der Anforderungen von Rechtsstaatlichkeit und Demokratie wahrgenommen werden.

${ }^{272}$ Vgl. Michael Gehler, Zeitgeschichte im dynamischen Mehrebenensystem, Zwischen Regionalisierung, Nationalstaat, Europäisierung, internationaler Arena und Globalisierung, 2001, S. $118 \mathrm{ff}$.; Alfred van Staden/Hans Vollaard, The Erosion of State Sovereignty: Towards a Post-territorial World?, in: Gerard Kreijen (Hrsg.), State, Sovereignty and International Governance, 2002, S. 165-184.

${ }^{273}$ Hierzu Linda Weiss, Is the State being Transformed by Globalization?, in: dies. (Hrsg.), States in the Global Economy: Bringing Domestic Institutions Back In, 2003, S. 293-317; Michael Zürn, Regieren jenseits des Nationalstaats, Globalisierung und Denationalisierung als Chance, 1998, S. $392 \mathrm{ff}$. Ein Versagen der Staaten konstatiert hingegen Thilo Bode, Globalisierung und Demokratie, in: Stefan Brink/Heinrich Amadeus Wolff (Hrsg.), Gemeinwohl und Verantwortung, FS für Hans Herbert von Arnim, 2004, S. 31-42.

${ }^{274}$ Hierzu Norman Weiß, Die Verantwortung des Staates für den Schutz der Menschenrechte, in: Eckart Klein/Christoph Menke (Hrsg.) Universalität - Schutzmechanismen - Diskriminierungsverbote. 15 Jahre nach der Weltmenschenrechtskonferenz 1993 in Wien, 2008, S. 517-540.

${ }^{275}$ Martin Albrow, Abschied vom Nationalstaat, Staat und Gesellschaft im Globalen Zeitalter, 1996, dt. 1998 , S. 189 ff., 220 ff.

${ }^{276}$ United Nations Declaration Against Corruption and Bribery in International Commercial Transactions vom 16. Dezember 1996, UN-Dok. A/RES/51/191; United Nations Convention against Corruption vom 31. Oktober 2003 , UN-Dok. A/RES/58/4.

277 Agenda for Development vom 20. Juni 1997, UN-Dok. A/RES/51/240.

278 Declaration and Programme of Action on a Culture of Peace, vom 13. September 1999, UNDok. A/RES/53/243. 